\title{
Living Systematic Review on Cannabis and Other Plant- Based Treatments for Chronic Pain
}




\section{Living Systematic Review on Cannabis and Other Plant-Based Treatments for Chronic Pain}

Prepared for:

Agency for Healthcare Research and Quality

U.S. Department of Health and Human Services

5600 Fishers Lane

Rockville, MD 20857

www.ahrq.gov

Contract No. 75Q80120D00006

Prepared by:

Pacific Northwest Evidence-based Practice Center

Portland, OR

Investigators:

Marian S. McDonagh, Pharm.D.

Jesse Wagner, M.A.

Azrah Y. Ahmed, B.A.

Rongwei Fu, Ph.D.

Benjamin Morasco, Ph.D.

Devan Kansagara, M.D., M.C.R.

Roger Chou, M.D., FACP

AHRQ Publication No. 21(22)-EHC036

October 2021 
This report is based on research conducted by the Pacific Northwest Evidence-based Practice Center (EPC) under contract to the Agency for Healthcare Research and Quality (AHRQ), Rockville, MD (Contract No. 75Q80120D00006). The findings and conclusions in this document are those of the authors, who are responsible for its contents; the findings and conclusions do not necessarily represent the views of AHRQ. Therefore, no statement in this report should be construed as an official position of AHRQ or of the U.S. Department of Health and Human Services.

\section{None of the investigators have any affiliations or financial involvement that conflicts with the material presented in this report.}

The information in this report is intended to help healthcare decision makers - patients and clinicians, health system leaders, and policymakers, among others-make well-informed decisions and thereby improve the quality of healthcare services. This report is not intended to be a substitute for the application of clinical judgment. Anyone who makes decisions concerning the provision of clinical care should consider this report in the same way as any medical reference and in conjunction with all other pertinent information, i.e., in the context of available resources and circumstances presented by individual patients.

This report is made available to the public under the terms of a licensing agreement between the author and the Agency for Healthcare Research and Quality. This report may be used and reprinted without permission except those copyrighted materials that are clearly noted in the report. Further reproduction of those copyrighted materials is prohibited without the express permission of copyright holders.

AHRQ or U.S. Department of Health and Human Services endorsement of any derivative products that may be developed from this report, such as clinical practice guidelines, other quality enhancement tools, or reimbursement or coverage policies, may not be stated or implied.

AHRQ appreciates appropriate acknowledgment and citation of its work. Suggested language for acknowledgment: This work was based on an evidence report, Living Systematic Review on Cannabis and Other Plant-Based Treatments for Chronic Pain, by the Evidence-based Practice Center Program at the Agency for Healthcare Research and Quality (AHRQ).

Suggested citation: McDonagh MS, Wagner J, Ahmed AY, Fu R, Morasco B, Kansagara D, Chou R. Living Systematic Review on Cannabis and Other Plant-Based Treatments for Chronic Pain. Comparative Effectiveness Review No. 250. (Prepared by Pacific Northwest Evidencebased Practice Center under Contract No. 75Q80120D00006.) AHRQ Publication No. 21(22)EHC036. Rockville, MD: Agency for Healthcare Research and Quality; October 2021. DOI: https://doi.org/10.23970/AHRQEPCCER250. Posted final reports are located on the Effective Health Care Program search page. 


\section{Preface}

The Agency for Healthcare Research and Quality (AHRQ), through its Evidence-based Practice Centers (EPCs), sponsors the development of systematic reviews to assist public- and private-sector organizations in their efforts to improve the quality of healthcare in the United States. These reviews provide comprehensive, science-based information on common, costly medical conditions, and new healthcare technologies and strategies.

Systematic reviews are the building blocks underlying evidence-based practice; they focus attention on the strength and limits of evidence from research studies about the effectiveness and safety of a clinical intervention. In the context of developing recommendations for practice, systematic reviews can help clarify whether assertions about the value of the intervention are based on strong evidence from clinical studies. For more information about AHRQ EPC systematic reviews, see https://effectivehealthcare.ahrq.gov/about/epc/evidence-synthesis.

AHRQ expects that these systematic reviews will be helpful to health plans, providers, purchasers, government programs, and the healthcare system as a whole. Transparency and stakeholder input are essential to the Effective Health Care Program. Please visit the website (www.effectivehealthcare.ahrq.gov) to see draft research questions and reports or to join an email list to learn about new program products and opportunities for input.

If you have comments on this systematic review, they may be sent by mail to the Task Order Officer named below at: Agency for Healthcare Research and Quality, 5600 Fishers Lane, Rockville, MD 20857, or by email to epc@ahrq.hhs.gov.

David Meyers, M.D. Acting Director Agency for Healthcare Research and Quality

Craig A. Umscheid, M.D., M.S.

Director

Evidence-based Practice Center Program

Center for Evidence and Practice Improvement

Agency for Healthcare Research and Quality
Arlene S. Bierman, M.D., M.S.

Director

Center for Evidence and Practice Improvement

Agency for Healthcare Research and Quality

Suchitra Iyer, Ph.D.

Task Order Officer

Evidence-based Practice Center Program

Center for Evidence and Practice

Improvement

Agency for Healthcare Research and Quality 


\section{Acknowledgments}

The authors gratefully acknowledge the following individuals for their contributions to this project: research associate and librarian Tracy Dana, M.L.S., from Oregon Health \& Science University, and Meghan Wagner, Pharm.D., M.B.A., and Task Order Officer Suchitra Iyer, Ph.D., at the Agency for Healthcare Research and Quality.

\section{Technical Expert Panel}

In designing the study questions and methodology at the outset of this report, the EPC consulted several technical and content experts. Broad expertise and perspectives were sought. Divergent and conflicted opinions are common and perceived as healthy scientific discourse that results in a thoughtful, relevant systematic review. Therefore, in the end, study questions, design, methodologic approaches, and/or conclusions do not necessarily represent the views of individual technical and content experts.

Technical Experts must disclose any financial conflicts of interest greater than $\$ 5,000$ and any other relevant business or professional conflicts of interest. Because of their unique clinical or content expertise, individuals with potential conflicts may be retained. The TOO and the EPC work to balance, manage, or mitigate any potential conflicts of interest identified.

The list of Technical Experts who provided input to the report follows:

Inna Belfer, M.D., Ph.D.*

Program Officer/Program Director, National Center for Complementary and Integrative Health

National Institutes of Health

Bethesda, MD

Kevin Boehnke, Ph.D.*

Research Investigator, Chronic Pain and

Fatigue Research Center, Anesthesiology

Department, University of Michigan

Ann Arbor, MI

Wilson M. Compton, M.D., M.P.E.* Deputy Director, National Institute on Drug Abuse, National Institutes of Health Bethesda, MD

Emily Deng, M.D., M.P.H., M.S.*

Medical Officer, Controlled Substance Staff

Office of Center Director, Center for Drug

Evaluation and Research

Food and Drug Administration

Silver Spring, MD
Erin E. Krebs, M.D., M.P.H., FACP*

Chief of General Internal Medicine, Minneapolis Veterans Affairs Health Care System

Professor of Medicine, Department of

Medicine, University of Minnesota

Minneapolis, MN

Mallory Loflin, Ph.D.

Principal Investigator/Clinical Scientist, Center of Excellence in Stress and Mental Health, Veterans Affairs, San Diego Healthcare System Assistant Professor, University of California San Diego School of Medicine, Department of Psychiatry

San Diego, CA 
Mark Sullivan, M.D., Ph.D.*

Professor of Psychiatry and Behavioral

Sciences, Adjunct Professor of

Anesthesiology and Pain Medicine, Adjunct

Professor of Bioethics and Humanities

University of Washington

Seattle, WA
C. Michael White, Pharm.D., FCCP, FCP* Department Head of Pharmacy Practice, University of Connecticut, School of Pharmacy

Co-Director, Health Outcomes, Policy, and Evidence Synthesis Research Group Hartford, CT

*Provided input on Draft Report.

\section{Peer Reviewers}

Prior to publication of the final evidence report, EPCs sought input from independent Peer Reviewers without financial conflicts of interest. However, the conclusions and synthesis of the scientific literature presented in this report do not necessarily represent the views of individual reviewers.

Peer Reviewers must disclose any financial conflicts of interest greater than $\$ 5,000$ and any other relevant business or professional conflicts of interest. Because of their unique clinical or content expertise, individuals with potential nonfinancial conflicts may be retained. The TOO and the EPC work to balance, manage, or mitigate any potential nonfinancial conflicts of interest identified.

The list of Peer Reviewers follows:

Matthew Bair, M.D., M.S.

Core Investigator, Veterans Affairs Health

Services Research and Development

Service, Center for Health Information and Communication

Research Scientist, William M. Tierney

Center for Health Services Research, Regenstrief Institute

Professor of Medicine, Indiana University

School of Medicine, Indiana University Indianapolis, IN
Tianjing Li, M.D., M.H.S., Ph.D.

Associate Professor, Department of Ophthalmology, University of Colorado Anschutz Medical Campus Associate Professor, Department of Epidemiology, University of Colorado School of Public Health Aurora, CO

Kerri Schoedel, Ph.D.

Principal and Director, Altreos Research

Partners, Inc.

Toronto, ON, Canada

Heather Tick, M.D., M.A.

Clinical Professor, Department of Family

Medicine and Department of Anesthesiology and Pain Medicine, University of

Washington

Seattle, WA 


\section{Living Systematic Review on Cannabis and Other Plant-Based Treatments for Chronic Pain}

\section{Structured Abstract}

Objectives. To evaluate the evidence on benefits and harms of cannabinoids and similar plantbased compounds to treat chronic pain.

Data sources. Ovid ${ }^{\circledR}$ MEDLINE $^{\circledR}$, PsycINFO $^{\circledR}$, Embase $^{\circledR}$, the Cochrane Library, and SCOPUS ${ }^{\circledR}$ databases, reference lists of included studies, submissions received after Federal Register request were searched to July 2021.

Review methods. Using dual review, we screened search results for randomized controlled trials (RCTs) and observational studies of patients with chronic pain evaluating cannabis, kratom, and similar compounds with any comparison group and at least 1 month of treatment or followup. Dual review was used to abstract study data, assess study-level risk of bias, and rate the strength of evidence. Prioritized outcomes included pain, overall function, and adverse events. We grouped studies that assessed tetrahydrocannabinol (THC) and/or cannabidiol (CBD) based on their THC to CBD ratio and categorized them as high-THC to CBD ratio, comparable THC to CBD ratio, and low-THC to CBD ratio. We also grouped studies by whether the product was a whole-plant product (cannabis), cannabinoids extracted or purified from a whole plant, or synthetic. We conducted meta-analyses using the profile likelihood random effects model and assessed between-study heterogeneity using Cochran's Q statistic chi square and the $\mathrm{I}^{2}$ test for inconsistency. Magnitude of benefit was categorized into no effect or small, moderate, and large effects.

Results. From 2,850 abstracts, 20 RCTs $(\mathrm{N}=1,776)$ and 7 observational studies $(\mathrm{N}=13,095)$ assessing different cannabinoids were included; none of kratom. Studies were primarily short term, and 75 percent enrolled patients with a variety of neuropathic pain. Comparators were primarily placebo or usual care. The strength of evidence (SOE) was low, unless otherwise noted. Compared with placebo, comparable THC to CBD ratio oral spray was associated with a small benefit in change in pain severity ( $7 \mathrm{RCTs}, \mathrm{N}=632,0$ to 10 scale, mean difference [MD] $-0.54,95 \%$ confidence interval $[\mathrm{CI}]-0.95$ to $-0.19, \mathrm{I}^{2}=28 \%$; SOE: moderate) and overall function (6 RCTs, $\mathrm{N}=616,0$ to 10 scale, $\mathrm{MD}-0.42,95 \% \mathrm{CI}-0.73$ to $-0.16, \mathrm{I}^{2}=24 \%$ ). There was no effect on study withdrawals due to adverse events. There was a large increased risk of dizziness and sedation and moderate increased risk of nausea (dizziness: 6 RCTs, N=866, 30\% vs. $8 \%$, relative risk [RR] 3.57, 95\% CI 2.42 to $5.60, \mathrm{I}^{2}=0 \%$; sedation: 6 RCTs, $\mathrm{N}=866,22 \%$ vs. $16 \%$, RR 5.04, 95\% CI 2.10 to $11.89, \mathrm{I}^{2}=0 \%$; and nausea: 6 RCTs, $\mathrm{N}=866,13 \%$ vs. $7.5 \%$, RR $1.79,95 \%$ CI 1.20 to $2.78, \mathrm{I}^{2}=0 \%$ ). Synthetic products with high-THC to CBD ratios were associated with a moderate improvement in pain severity, a moderate increase in sedation, and a large increase in nausea (pain: $6 \mathrm{RCTs}, \mathrm{N}=390$ to 10 scale, $\mathrm{MD}-1.15,95 \% \mathrm{CI}-1.99$ to -0.54 , $\mathrm{I}^{2}=39 \%$; sedation: 3 RCTs, $\mathrm{N}=335,19 \%$ vs. $10 \%$, RR $1.73,95 \%$ CI 1.03 to $4.63, \mathrm{I}^{2}=0 \%$; nausea: 2 RCTs, $\mathrm{N}=302,12 \%$ vs. $6 \%$, RR $2.19,95 \%$ CI 0.77 to $5.39 ; \mathrm{I}^{2}=0 \%$ ). We found moderate SOE for a large increased risk of dizziness (2 RCTs, 32\% vs. 11\%, RR 2.74, 95\% CI 1.47 to 6.86 , $\mathrm{I}^{2}=0 \%$ ). Extracted whole-plant products with high-THC to CBD ratios (oral) were associated 
with a large increased risk of study withdrawal due to adverse events (1 RCT, 13.9\% vs. 5.7\%, RR 3.12, 95\% CI 1.54 to 6.33 ) and dizziness (1 RCT, 62.2\% vs. 7.5\%, RR 8.34, 95\% CI 4.53 to 15.34). We observed a moderate improvement in pain severity when combining all studies of high-THC to CBD ratio ( $8 \mathrm{RCTs}, \mathrm{N}=684, \mathrm{MD}-1.25,95 \% \mathrm{CI}-2.09$ to $-0.71, \mathrm{I}^{2}=50 \%$; $\mathrm{SOE}$ : moderate). Evidence on whole-plant cannabis, topical CBD, low-THC to CBD, other cannabinoids, comparisons with active products, and impact on use of opioids was insufficient to draw conclusions. Other important harms (psychosis, cannabis use disorder, and cognitive effects) were not reported.

Conclusions. Low to moderate strength evidence suggests small to moderate improvements in pain (mostly neuropathic), and moderate to large increases in common adverse events (dizziness, sedation, nausea) and study withdrawal due to adverse events with high- and comparable THC to CBD ratio extracted cannabinoids and synthetic products in short-term treatment (1 to 6 months). Evidence for whole-plant cannabis, and other comparisons, outcomes, and PBCs were unavailable or insufficient to draw conclusions. Small sample sizes, lack of evidence for moderate and long-term use and other key outcomes, such as other adverse events and impact on use of opioids during treatment, indicate that more research is needed. 


\section{Contents}

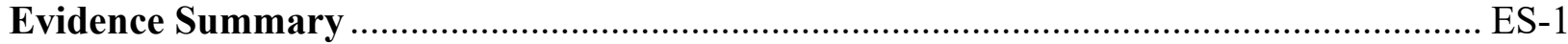

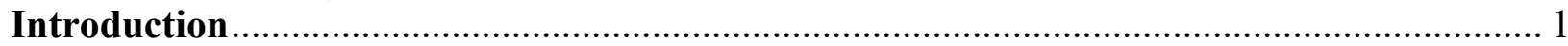

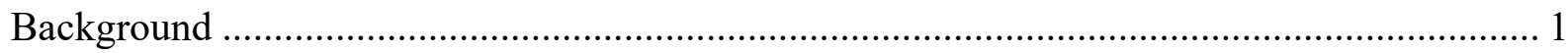

Purpose and Scope of the Systematic Review................................................................... 2

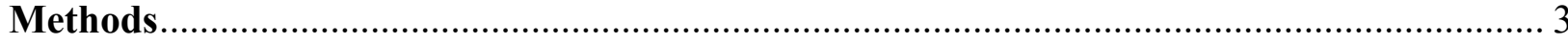

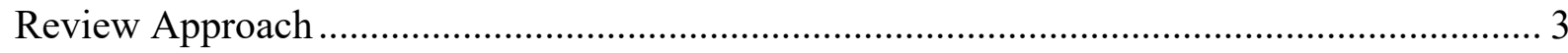

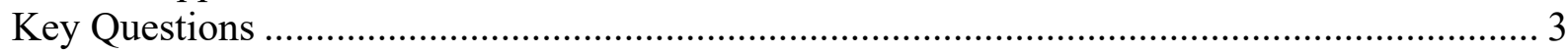

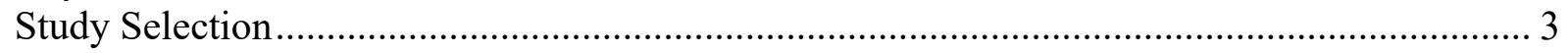

Data Extraction and Risk of Bias Assessment ………..................................................... 4

Data Synthesis and Analysis ....................................................................................... 5

Grading the Strength of the Body of Evidence ................................................................... 7

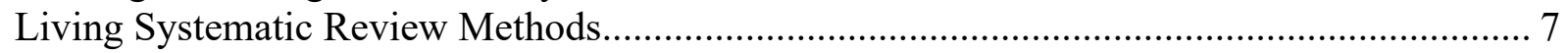

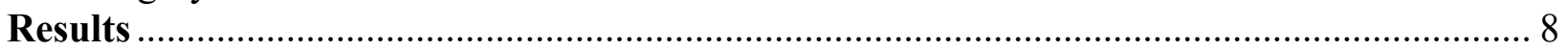

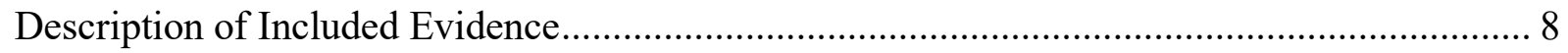

KQ 1 and KQ 2. In adults with chronic pain, what are the benefits (KQ 1) and harms (KQ 2)

of cannabinoids for treatment of chronic pain? .............................................................. 10

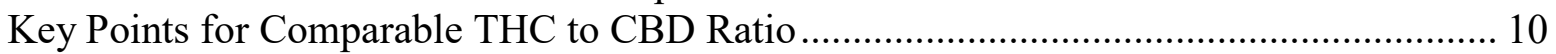

Summary of Findings for Comparable THC to CBD Ratio ............................................... 10

Key Points for High-THC to CBD Ratio ........................................................................ 12

Summary of Findings for High-THC to CBD Ratio.......................................................... 13

Key Points for Low-THC to CBD Ratio and Other Cannabinoids....................................... 17

Summary of Findings for Low-THC to CBD Ratio ......................................................... 18

Key Points for Whole-Plant Cannabis and Mixed (Patient-Choice) Cannabis Products...... 18

Summary of Findings for Whole-Plant Cannabis and Mixed (Patient-Choice) Cannabis

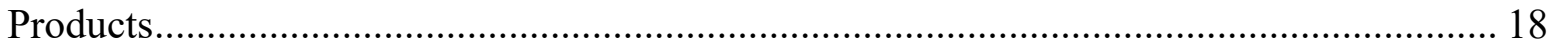

KQ 3 and KQ 4. In adults with chronic pain, what are the benefits (KQ 3) and harms (KQ 4) of kratom or other plant-based substances for treatment of chronic pain?.............................. 20

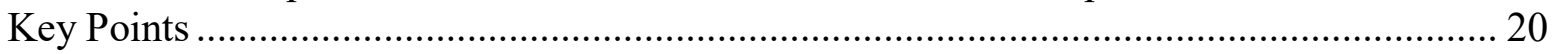

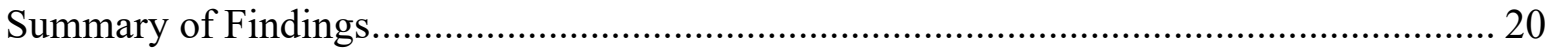

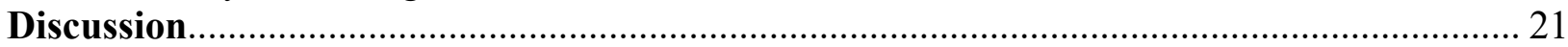

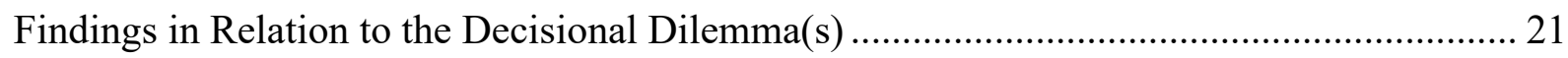

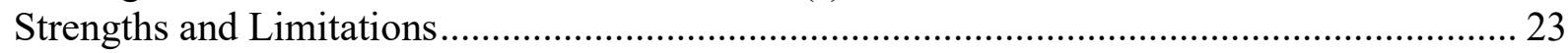

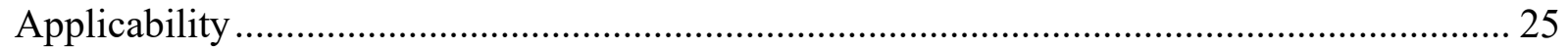

Implications for Clinical Practice, Education, Research, or Health Policy............................... 26

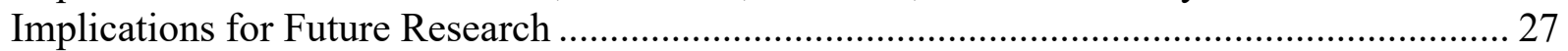

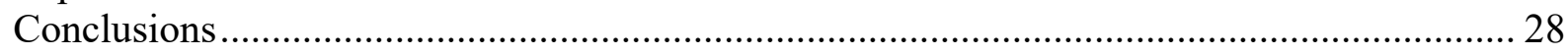

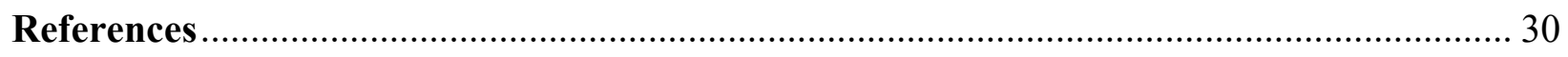

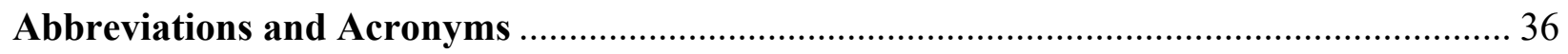

\section{Tables}

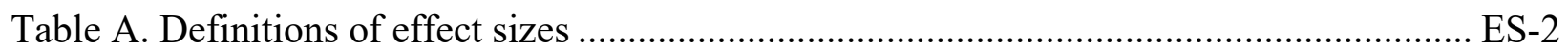

Table B. Characteristics of included randomized controlled trials of cannabinoids ................ ES-2

Table C. Characteristics of included observational studies ....................................................... ES-3

Table D. Key Question 1: Benefits of cannabinoids for chronic pain compared with placebo in the short term (4 weeks to $<6$ months)................................................................................ ES-3 
Table E. Key Question 2: Harms of cannabinoids for chronic pain compared with placebo in the

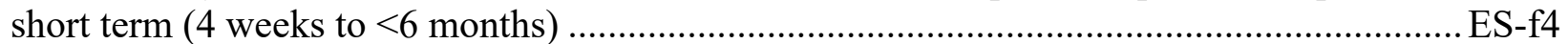

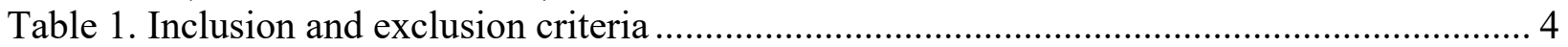

Table 2. Organizing principle of cannabis-related studies based on ratios of THC to CBD .......... 5

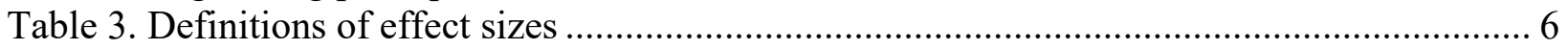

Table 4. Characteristics of included randomized controlled trials of cannabinoids ....................... 9

Table 5. Characteristics of included observational studies .......................................................... 9

Table 6. Key Question 1: Benefits of cannabinoids for chronic pain compared with placebo in the

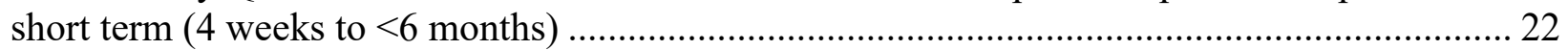

Table 7. Key Question 2: Harms of cannabinoids for chronic pain compared with placebo in the short term (4 weeks to $<6$ months) ……………………....................................................... 23

Table 8. Future research needs for cannabis and other plant-based treatments for chronic pain . 27

\section{Figures}

Figure 1. Literature flow diagram ....................................................................................... 8

Figure 2. Change in pain severity with comparable THC to CBD ratio versus placebo (short term, 4 weeks to 6 months followup)................................................................................... 11

Figure 3. Overall function: comparable THC to CBD ratio versus placebo (short term, 4 weeks to 6 months followup)

Figure 4. Change in pain severity with high-THC ratio versus placebo (short term, 4 weeks to 6 months followup)

\section{Appendixes}

Appendix A. Literature Search Strategies

Appendix B. Methods

Appendix C. Included Studies List

Appendix D. Results

Appendix E. Evidence Tables

Appendix F. Risk of Bias Assessment

Appendix G. Details on Strength of Evidence

Appendix H. Excluded Studies List

Appendix I. Funnel Plot of High-THC Ratio Studies Included in Meta-Analysis for Pain Severity 


\section{Evidence Summary}

\section{Main Points}

In RCTs (mostly placebo controlled) of patients with chronic (mainly neuropathic) pain with short-term treatment ( 4 weeks to $<6$ months):

- Studies of cannabis-related products were grouped based on their tetrahydrocannabinol (THC) to cannabidiol (CBD) ratio using the following categories: high-THC to CBD, comparable THC to CBD, and low-THC to CBD.

- Comparable THC to CBD ratio oral spray is probably associated with small improvements in pain severity and overall function. There was no effect on serious adverse events. There may be a large increased risk of dizziness and sedation and a moderate increased risk of nausea.

- Synthetic THC (high-THC to CBD) may be associated with moderate improvement in pain severity, no effect on overall function and increased risk of sedation, and large increased risk of nausea. Synthetic THC is probably associated with a large increased risk of dizziness.

- Extracted whole-plant high-THC to CBD ratio products may be associated with large increases in risk of study withdrawal due to adverse events and dizziness.

- Evidence on whole-plant cannabis (including patient's choice of products), low-THC to CBD ratio products (topical CBD), other cannabinoids (cannabidivarin), and comparisons with other active interventions was insufficient to draw conclusions.

- Other key adverse event outcomes (psychosis, cannabis use disorder, cognitive deficits) and outcomes on the impact on opioid use were not reported.

- No evidence on other plant-based compounds such as kratom met criteria for this review.

\section{Background and Purpose}

Chronic pain is defined as pain lasting longer than 3 to 6 months or past normal time for tissue healing ${ }^{1,2}$ and affects approximately 100 million people in the United States. ${ }^{3}$ Chronic pain adversely affects physical and mental functioning, productivity, and quality of life, and is often refractory to treatment and associated with substantial costs. ${ }^{4-6}$ While opioids are often prescribed for chronic pain, they have small to moderate effects on pain and overall function, with frequent adverse effects, ${ }^{7}$ and the 2016 Centers for Disease Control and Prevention Guideline for Prescribing Opioids for Chronic Pain recommends nonopioid therapy as the preferred treatment of chronic pain. ${ }^{1,2}$ However, recent systematic reviews found that several nonopioid drugs, ${ }^{8}$ and some nonpharmacologic treatments ${ }^{9}$ also have small to moderate effects on chronic pain and overall function. Some nonopioid treatments had frequent overall adverse events and some less frequent yet serious adverse effects, while nonpharmacological treatments typically reported few adverse events. ${ }^{8}$

Cannabinoids are a group of closely related compounds that are active in cannabis, with the two main cannabinoid compounds being THC and CBD. THC has demonstrated analgesic properties, ${ }^{10,11}$ although its psychoactive effects and abuse potential may limit its suitability as an analgesic. Based on preclinical studies, CBD and related cannabinoids may also have some analgesic or anti-inflammatory properties and are not thought to be psychoactive or addictive. ${ }^{12,13}$ While not derived from plants, two synthetic cannabinoid products, dronabinol 
(synthetic THC) and nabilone (a THC analog), have also been studied for treating chronic pain. Other plant-based compounds with effects similar to opioids or cannabis, such as kratom, have been considered to treat chronic pain. These may also have serious harms including dependence, addiction, and physiological withdrawal potential. ${ }^{14}$

The ongoing opioid crisis and the limited efficacy of opioids drive a search for alternative pain treatments, including cannabis and related compounds to better treat chronic pain. ${ }^{7,15}$ The purpose of this systematic review was to evaluate the evidence on benefits and harms of cannabinoids and similar plant-based substances (e.g., kratom) to treat chronic pain.

\section{Methods}

We employed methods consistent with those outlined in the Agency for Healthcare Research and Quality Effective Healthcare Program Methods Guidance (https://effectivehealthcare.ahrq.gov/topics/cer-methods-guide/overview), and we describe these in the full report. Our searches covered publication dates from database inception to July 2021. Cannabinoid interventions were categorized according to their THC to CBD ratio (comparable, high, low) and according to the source of the compound (whole-plant, extracted from whole-plant, or synthetic). Strength of evidence was assessed as low, moderate, high, or insufficient, and magnitude of effect was assessed according to Table A. Additionally, results that were below the threshold for a small effect were considered to reflect "no effect." Results with a small, medium, or large effect that were not statistically significant were considered to have "potential effects" if the 95 percent confidence interval included meaningful benefit or harm, but were not so wide that they included the potential for both meaningful benefits and harms. ${ }^{16,17}$

Table A. Definitions of effect sizes

\begin{tabular}{|c|c|}
\hline Effect Size & Definition \\
\hline Small effect & $\begin{array}{l}\text { - MD } 0.5 \text { to } 1.0 \text { points on a } 0 \text { to } 10 \text {-point scale, } 5 \text { to } 10 \text { points on a } 0 \text { to } 100 \text {-point scale } \\
\text { - SMD } 0.2 \text { to } 0.5 \\
\text { - } \mathrm{RR} / \mathrm{OR} 1.2 \text { to } 1.4\end{array}$ \\
\hline Moderate effect & $\begin{array}{l}\text { - } \mathrm{MD}>1 \text { to } 2 \text { points on a } 0 \text { to } 10 \text {-point scale, }>10 \text { to } 20 \text { points on a } 0 \text { to } 100 \text {-point scale } \\
\text { - } \mathrm{SMD}>0.5 \text { to } 0.8 \\
\text { - } \mathrm{RR} / \mathrm{OR} 1.5 \text { to } 1.9\end{array}$ \\
\hline Large effect & $\begin{array}{l}\text { - } \mathrm{MD}>2 \text { points on a } 0 \text { to } 10 \text {-point scale, }>20 \text { points on a } 0 \text { to } 100 \text {-point scale } \\
\text { - } \mathrm{SMD}>0.8 \\
\text { - } \mathrm{RR} / \mathrm{OR} \geq 2.0\end{array}$ \\
\hline
\end{tabular}

Abbreviations: $\mathrm{MD}=$ mean difference; $\mathrm{OR}=$ odds ratio; $\mathrm{RR}=$ relative risk; $\mathrm{SMD}=$ standardized mean difference.

\section{Results}

The included randomized controlled trials (RCTs) are described in Table B. Seven observational studies were also included and are described in Table C.

Table B. Characteristics of included randomized controlled trials of cannabinoids

\begin{tabular}{|l|l|l|l|l|l|}
\hline Characteristic & THC/CBD & THC & Synthetic THC & CBD & CBDV \\
\hline THC to CBD Ratio & Comparable & High & High & Low & $\begin{array}{l}\text { NA - other } \\
\text { cannabinoids }\end{array}$ \\
\hline Source & Plant-extracted & $\begin{array}{l}\text { Plant- } \\
\text { extracted }\end{array}$ & Synthetic & Plant-extracted & Plant-extracted \\
\hline N Studies & 7 & 2 & 9 & 1 & 1 \\
\hline $\begin{array}{l}\text { Comparator } \\
\text { (Study Count) }\end{array}$ & Placebo (7) & Placebo (2) & $\begin{array}{l}\text { Placebo (6); } \\
\text { Ibuprofen (1); } \\
\text { Diphenhydramine (1); } \\
\text { Dihydrocodeine (1) }\end{array}$ & Placebo (1) & Placebo (1) \\
\hline
\end{tabular}




\begin{tabular}{|c|c|c|c|c|c|}
\hline Characteristic & THC/CBD & THC & Synthetic THC & CBD & CBDV \\
\hline $\begin{array}{l}\text { Risk of Bias } \\
\% \text { High, } \% \\
\text { Moderate, \% Low }\end{array}$ & $\begin{array}{l}29 \%, 57 \% \\
14 \%\end{array}$ & $\begin{array}{l}0 \%, 50 \%, \\
50 \%\end{array}$ & $22 \%, 44 \%, 33 \%$ & $100 \%$ high & $100 \%$ moderate \\
\hline Total Randomized & 882 & 297 & 534 & 29 & 34 \\
\hline Age, Mean Years & 53 & 52 & 50 & 68 & 50 \\
\hline Female, \% & $66 \%$ & $89 \%$ & $61 \%$ & $38 \%$ & $3 \%$ \\
\hline $\begin{array}{l}\text { \% Non-White } \\
\text { (Study Count) }\end{array}$ & $1.6 \%(2)$ & $1 \%(1)$ & $5.4 \%(3)$ & NA & NA \\
\hline $\begin{array}{l}\text { Primary Pain } \\
\text { Type (Study } \\
\text { Count) }\end{array}$ & $\begin{array}{l}\text { NPP (6); } \\
\text { inflammatory } \\
\text { arthritis (1) }\end{array}$ & $\begin{array}{l}\text { NPP (1); } \\
\text { fibromyalgia } \\
\text { (1) }\end{array}$ & $\begin{array}{l}\text { NPP (6); } \\
\text { fibromyalgia (1); } \\
\text { headache (1); } \\
\text { visceral pain (1) }\end{array}$ & NPP (1) & NPP (1) \\
\hline $\begin{array}{l}\text { Baseline Pain } \\
\text { Score, Mean } \\
\text { (Range) }^{b}\end{array}$ & $\begin{array}{l}6.59 \text { (5.3 to } \\
7.3)\end{array}$ & $\begin{array}{l}8.47(8.25 \text { to } \\
8.67)\end{array}$ & $6.46(4 \text { to } 8.1)^{\mathrm{c}}$ & $\begin{array}{l}5.38 \text { (4.67 to } \\
6.14)\end{array}$ & $\begin{array}{l}6.28(6.12 \text { to } \\
6.44)\end{array}$ \\
\hline Study Duration & 4 to 15 weeks & 8 to 12 weeks & 4 to 47 weeks & 4 weeks & 4 weeks \\
\hline
\end{tabular}

Abbreviations: $\mathrm{CBD}=$ cannabidiol; $\mathrm{CBDV}=$ cannabidivarin; $\mathrm{NA}=$ not applicable; $\mathrm{NPP}=$ neuropathic pain; $\mathrm{THC}=$

tetrahydrocannabinol.

a $($ Study count $)=$ number of studies reporting this characteristic at baseline.

${ }^{\mathrm{b}}$ Scores were standardized to a 0 to 10 scale.

${ }^{\mathrm{c}}$ Weighted mean includes median scores for one study (6 vs. 6).

Table C. Characteristics of included observational studies

\begin{tabular}{|l|l|l|l|}
\hline Characteristic & THC/CBD & THC & Synthetic THC \\
\hline THC to CBD Ratio & Unclear & High & High \\
\hline Source & $\begin{array}{l}\text { Any cannabis product } \\
\text { (patient's choice) }\end{array}$ & Plant-based & $\begin{array}{l}\text { Synthetic } \\
\text { (nabilone) }\end{array}$ \\
\hline N Studies & 5 & 1 & 1 \\
\hline Comparator (Study Count) & $\begin{array}{l}\text { No cannabis use (3); } \\
\text { usual care (1); no } \\
\text { medical cannabis } \\
\text { authorization (1) }\end{array}$ & Usual care (1) & $\begin{array}{l}\text { Gabapentin only; } \\
\text { gabapentin }+ \\
\text { nabilone (1) }\end{array}$ \\
\hline $\begin{array}{l}\text { ROB } \\
\% \text { High, \% Moderate, \% Low }\end{array}$ & $\begin{array}{l}60 \% \text { high, 40\% } \\
\text { moderate }\end{array}$ & $100 \%$ high & $100 \%$ moderate \\
\hline N Total & 12,508 & 431 & 156 \\
\hline Age, Mean Years & 53 & 49 & 61 \\
\hline Female, \% & $55 \%$ & $57 \%$ & $59 \%$ \\
\hline$\%$ Non-white (study count) & $54 \%(1) ;$ NR (4) & NR & NPP \\
\hline Primary Pain Type(s) & $\begin{array}{l}\text { Mixed musculoskeletal, } \\
\text { chronic non-cancer pain }\end{array}$ & Chronic non-cancer pain & $4.98(4.58$ to 5.31) \\
\hline Baseline Pain Score, Mean (Range) & $5.35(4.56$ to 8.00) & $6.35(6.1$ to 6.6) & 26 \\
\hline Study Duration, Weeks (Range) & 12 to 208 & 52 & N \\
\hline
\end{tabular}

Abbreviations: $\mathrm{CBD}=$ cannabidiol; $\mathrm{NPP}=$ neuropathic pain; $\mathrm{NR}=$ not reported; $\mathrm{ROB}=$ risk of bias; $\mathrm{THC}=$ tetrahydrocannabinol.

${ }^{\text {a }}$ Scores were standardized to a 0 to 10 scale.

Tables D and E summarize the findings of the review. Other prioritized adverse events (cannabis use disorder [CUD], psychosis, cognitive deficits) and the impact on the use of opioids for chronic pain, were not reported in the RCTs.

Table D. Key Question 1: Benefits of cannabinoids for chronic pain compared with placebo in the short term ( 4 weeks to $<6$ months)

\begin{tabular}{|l|c|c|c|}
\hline & $\begin{array}{l}\text { Pain Response } \\
\text { Effect Size (N Studies) }^{\text {[SOE] }}\end{array}$ & $\begin{array}{l}\text { Pain Severity } \\
\text { Effect Size (N Studies) } \\
\text { [SOE] }^{\text {a }}\end{array}$ & $\begin{array}{l}\text { Overall Function } \\
\text { Effect Size (N } \\
\text { Studies) } \\
\text { [SOE] }^{\mathrm{a}}\end{array}$ \\
\hline $\begin{array}{l}\text { Comparable RHC/CBD } \\
\text { Oromucosal Spray }\end{array}$ & $\begin{array}{c}\text { Potential effect }(4)^{\mathrm{b}} \\
{[+]}\end{array}$ & $\begin{array}{c}\text { Small effect (7) } \\
{[++]}\end{array}$ & $\begin{array}{c}\text { Small effect (6) } \\
{[++]}\end{array}$ \\
\hline
\end{tabular}




\begin{tabular}{|c|c|c|c|}
\hline THC to CBD Ratio & $\begin{array}{l}\text { Pain Response } \\
\text { Effect Size (N Studies) } \\
\text { [SOE] }^{\mathrm{a}}\end{array}$ & $\begin{array}{l}\text { Pain Severity } \\
\text { Effect Size (N Studies) } \\
\text { [SOE] }^{\mathrm{a}}\end{array}$ & $\begin{array}{l}\text { Overall Function } \\
\text { Effect Size (N } \\
\text { Studies) } \\
\text { [SOE] }^{\mathrm{a}}\end{array}$ \\
\hline High-THC - Synthetic, Oral & Insufficient (1) & $\begin{array}{c}\text { Moderate effect (5) } \\
{[+]}\end{array}$ & $\begin{array}{c}\text { No effect (3) } \\
{[+]}\end{array}$ \\
\hline $\begin{array}{l}\text { High-THC - Extracted From } \\
\text { Whole-plant, Oral }\end{array}$ & No evidence & Insufficient (2) & Insufficient (1) \\
\hline Low-THC - Topical CBD & No evidence & Insufficient (1) & No evidence \\
\hline $\begin{array}{l}\text { Other Cannabinoids - CBDV, } \\
\text { Oral }\end{array}$ & Insufficient (1) & Insufficient (1) & No evidence \\
\hline $\begin{array}{l}\text { Whole-Plant Cannabis (12\% } \\
\text { THC, Smoked) }\end{array}$ & No evidence & Insufficient (1) & No evidence \\
\hline
\end{tabular}

Abbreviations: $\mathrm{CBD}=$ cannabidiol; $\mathrm{CBDV}=$ cannabidivarin; $\mathrm{SOE}=$ strength of evidence; $\mathrm{THC}=$ tetrahydrocannabinol.

${ }^{a}$ Effect size: none (i.e., no effect/no statistically significant effect), small, moderate, or large increased risk; SOE: $+=$ low, $++=$ moderate, $+++=$ high.

${ }^{\mathrm{b}}$ Findings with small or larger magnitude of effect, not statistically significant; but with SOE rating of Low or higher (downgraded mainly for imprecision).

Table E. Key Question 2: Harms of cannabinoids for chronic pain compared with placebo in the short term (4 weeks to $<6$ months)

\begin{tabular}{|c|c|c|c|c|c|}
\hline THC to CBD Ratio & $\begin{array}{l}\text { WAE } \\
\text { Effect Size (N } \\
\text { Studies) } \\
\text { [SOE] }^{a}\end{array}$ & $\begin{array}{l}\text { SAE } \\
\text { Effect Size (N } \\
\text { Studies) } \\
\text { [SOE] }^{\mathrm{a}}\end{array}$ & $\begin{array}{l}\text { Dizziness } \\
\text { Effect Size (N } \\
\text { Studies) } \\
\text { [SOE] }^{\mathrm{a}}\end{array}$ & $\begin{array}{l}\text { Nausea } \\
\text { Effect Size (N } \\
\text { Studies) } \\
\text { [SOE] }^{\mathrm{a}}\end{array}$ & $\begin{array}{l}\text { Sedation } \\
\text { Effect Size (N } \\
\text { Studies) } \\
\text { [SOE] }^{\mathrm{a}}\end{array}$ \\
\hline $\begin{array}{l}\text { Comparable } \\
\text { THC/CBD } \\
\text { Oromucosal Spray }\end{array}$ & Insufficient (5) & $\begin{array}{c}\text { No effect (2) } \\
{[+]}\end{array}$ & $\begin{array}{c}\text { Large effect (6) } \\
{\left[{ }^{+}\right]}\end{array}$ & $\begin{array}{c}\text { Moderate effect } \\
(6) \\
{[+]}\end{array}$ & $\begin{array}{c}\text { Large effect } \\
(6) \\
{[+]}\end{array}$ \\
\hline $\begin{array}{l}\text { High-THC - } \\
\text { Synthetic, Oral }\end{array}$ & $\begin{array}{c}\text { Potential effect } \\
(4) \\
{[+]} \\
\end{array}$ & Insufficient (1) & $\begin{array}{c}\text { Large effect (2) } \\
\qquad[++]\end{array}$ & $\begin{array}{c}\text { Potential effect } \\
(2) \\
{[+]} \\
\end{array}$ & $\begin{array}{c}\text { Moderate } \\
\text { effect }(3) \\
{[+]}\end{array}$ \\
\hline $\begin{array}{l}\text { High-THC - } \\
\text { Extracted From } \\
\text { Whole-plant, Oral }\end{array}$ & $\begin{array}{c}\text { Large effect (1) } \\
{[+]}\end{array}$ & Insufficient (1) & $\begin{array}{c}\text { Large effect (1) } \\
{[+]}\end{array}$ & No evidence & No evidence \\
\hline $\begin{array}{l}\text { Low-THC - Topical } \\
\text { CBD }\end{array}$ & No evidence & No evidence & No evidence & No evidence & No evidence \\
\hline $\begin{array}{l}\text { Other Cannabinoids } \\
\text { - CBDV, oral }\end{array}$ & Insufficient (1) & Insufficient (1) & No evidence & No evidence & No evidence \\
\hline $\begin{array}{l}\text { Whole-Plant } \\
\text { Cannabis }(12 \% \\
\text { THC, smoked) }\end{array}$ & Insufficient (1) & Insufficient (1) & Insufficient (1) & Insufficient (1) & Insufficient (1) \\
\hline
\end{tabular}

Abbreviations: $\mathrm{CBD}=$ cannabidiol; $\mathrm{CBDV}=$ cannabidivarin; $\mathrm{SAE}=$ serious adverse event; $\mathrm{SOE}=$ strength of evidence; $\mathrm{THC}=$ tetrahydrocannabinol; WAE = withdrawal due to adverse event.

${ }^{\text {a }}$ Effect size: none (i.e., no effect/no statistically significant effect), small, moderate, or large increased risk; SOE: $+=$ low, $++=$ moderate, $+++=$ high.

${ }^{\mathrm{b}}$ Findings with small or larger magnitude of effect, not statistically significant; but with SOE rating of Low or higher (downgraded mainly for imprecision).

\section{Limitations}

Key limitations of the evidence base relate to the limited ability to provide strong, reliable, estimates of effect due to: 1) inadequate sample sizes or numbers of studies, 2) narrowness of enrolled populations (see Tables B and C), 3) lack of evidence or adequate evidence on highTHC to CBD products extracted from whole-plant cannabis, whole-plant cannabis products, lowTHC to CBD products (e.g., topical CBD), and other plant-based compounds including kratom, and 4) inconsistent reporting of important outcomes such as pain response, overall function or disability, effect on opioid use, and longer-term adverse events, such as CUD, psychosis, and cognitive deficits. These limitations affect both the stability and applicability of the findings. 


\section{Implications and Conclusions}

The implications of the present findings for clinical practice are mixed. Select individuals with chronic neuropathic pain may experience small to moderate short-term improvements in pain with some cannabis products, but the impact on moderate or long-term outcomes is unknown. The evidence on adverse events with cannabis-related products is much less robust than the evidence on similar outcomes with opioids or nonopioid medications. Comparing the results with recent systematic reviews that used the same methodology, suggests that the risk of sedation and dizziness appear similar between cannabis-related products, opioids, and the anticonvulsants pregabalin and gabapentin, while the risk for nausea appears to be larger with opioids and the antidepressant duloxetine than with cannabis-related products. 7,8 These qualitative and indirect comparisons with very limited evidence on cannabis products relative to the other drugs however need confirmation. The comparisons of effects on serious and long-term harms are however not possible, even indirectly. Understanding how the adverse event profiles of cannabis products compare with other available treatments for chronic pain, particularly opioid and non-opioid medications, is essential to determining the benefit to harm ratio.

However, the strength of this evidence is mostly low, and more data are needed to confidently recommend this as a treatment for various chronic pain-related conditions or for patients with diverse demographic or clinical characteristics.

In the short term ( 4 weeks to $<6$ months), small magnitude improvements in pain severity and overall functioning or disability were found with comparable THC to CBD ratio oral sprays, with large increased risk of dizziness and sedation, and moderate increased risk of nausea compared with placebo. In the short term, moderate improvements in pain severity and no effect on overall function were found with high-THC to CBD synthetic oral products, with moderate increased risk of withdrawal from studies due to adverse events, serious adverse events, and sedation, and a large increased risk of dizziness compared with placebo. In the short-term, moderate improvements in pain severity were found with whole-plant extracted, high-THC to CBD oral products, with large increased risk of study withdrawal due to adverse events and dizziness, and moderate increased risk of serious adverse events. The strength of these findings are low to moderate. Evidence on whole-plant cannabis, topical CBD, and other cannabinoids was insufficient to draw conclusions. There was no evidence on other plant-based compounds such as kratom. Important limitations include small sample sizes, lack of evidence for moderate and long-term use, and few data for key outcomes, such as other serious adverse events (e.g., psychosis, CUD) and impact on use of opioids during treatment. In order to better understand the small to moderate improvements in pain, and the complete adverse event profile of cannabinoids used to treat chronic pain, future studies that resolve these limitations are needed. Specific recommendations for future research are included in the full report.

\section{References}

1. Dowell D, Haegerich TM, Chou R. CDC

Guideline for Prescribing Opioids for

Chronic Pain- United States, 2016. Jama.

2016 Apr 19;315(15):1624-45. doi:

10.1001/jama.2016.1464. PMID: 26977696.
2. Dowell D, Haegerich TM, Chou R. CDC Guideline for Prescribing Opioids for Chronic Pain - United States, 2016. MMWR Recomm Rep. 2016 Mar 18;65(1):1-49. doi: 10.15585/mmwr.rr6501e1. PMID: 26987082 . 
3. Dahlhamer J LJ, Zelaya, C, et al. Prevalence of chronic pain and high-impact chronic pain among adults - United States, 2016. MMWR Morb Mortal Wkly Rep 2018. doi: 10.15585/mmwr.mm6736a2.

4. Institute of Medicine Committee on Advancing Pain Research. Relieving Pain in America: A Blueprint for Transforming Prevention, Care, Education, and Research. Washington, DC: National Academies Press; National Academy of Sciences; 2011.

5. Ballantyne JC, Shin NS. Efficacy of opioids for chronic pain: a review of the evidence. Clin J Pain. 2008 Jul-Aug;24(6):469-78. doi: 10.1097/AJP.0b013e31816b2f26. PMID: 18574357.

6. Eriksen J, Sjogren P, Bruera E, et al. Critical issues on opioids in chronic non-cancer pain: an epidemiological study. Pain. 2006 Nov;125(1-2):172-9. doi: 10.1016/j.pain.2006.06.009. PMID: 16842922 .

7. Chou R, Hartung D, Turner J, et al. Opioid Treatments for Chronic Pain. Comparative Effectiveness Review No. 229. (Prepared by the Pacific Northwest Evidence-based Practice Center under Contract No. 2902015-00009-I.) AHRQ Publication No. 20EHC011. Rockville, MD: Agency for Healthcare Research and Quality; April 2020. PMID: 32338848.

8. McDonagh MS, Selph SS, Buckley DI, et al. Nonopioid Pharmacologic Treatments for Chronic Pain. Comparative Effectiveness Review No. 228. (Prepared by the Pacific Northwest Evidence-based Practice Center under Contract No. 290-2015-00009-I.) AHRQ Publication No. 20-EHC010. Rockville, MD: Agency for Healthcare Research and Quality; April 2020. PMID: 32338847.

9. Skelly AC, Chou R, Dettori JR, et al. Noninvasive Nonpharmacological Treatment for Chronic Pain: A Systematic Review Update. Comparative Effectiveness Review No. 227. (Prepared by the Pacific Northwest Evidence-based Practice Center under Contract No. 290-2015-00009-I.) AHRQ Publication No. 20-EHC009. Rockville, MD: Agency for Healthcare Research and Quality; April 2020. PMID: 32338846 .
10. Elikkottil J, Gupta P, Gupta K. The analgesic potential of cannabinoids. J Opioid Manag. 2009 Nov-Dec;5(6):341-57. PMID: 20073408.

11. Whiting PF, Wolff RF, Deshpande S, et al. Cannabinoids for Medical Use: A Systematic Review and Meta-analysis. Jama. 2015 Jun 23-30;313(24):2456-73. doi: https://dx.doi.org/10.1001/jama.2015.6358. PMID: 26103030.

12. Vučković S, Srebro D, Vujović KS, et al. Cannabinoids and Pain: New Insights From Old Molecules. Front Pharmacol. 2018;9:1259-. doi: 10.3389/fphar.2018.01259. PMID: 30542280 .

13. Morales P, Hurst DP, Reggio PH. Molecular Targets of the Phytocannabinoids: A Complex Picture. Prog Chem Org Nat Prod. 2017;103:103-31. doi: 10.1007/978-3-31945541-9_4. PMID: 28120232.

14. White CM. Pharmacologic and clinical assessment of kratom: An update. Am J Health-Syst Pharm. 201911 13;76(23):1915-25. doi: https://dx.doi.org/10.1093/ajhp/zxz221. PMID: 31626272.

15. Stockings E, Campbell G, Hall WD, et al. Cannabis and cannabinoids for the treatment of people with chronic noncancer pain conditions: a systematic review and metaanalysis of controlled and observational studies. Pain. 2018 Oct;159(10):1932-54. doi:

https://dx.doi.org/10.1097/j.pain.000000000 0001293. PMID: 29847469.

16. Guyatt GH, Oxman AD, Kunz R, et al. GRADE guidelines 6. Rating the quality of evidence--imprecision. J Clin Epidemiol. 2011 Dec;64(12):1283-93. doi: 10.1016/j.jclinepi.2011.01.012. PMID: 21839614.

17. Guyatt GH, Norris SL, Schulman S, et al. Methodology for the development of antithrombotic therapy and prevention of thrombosis guidelines: Antithrombotic Therapy and Prevention of Thrombosis, 9th ed: American College of Chest Physicians Evidence-Based Clinical Practice Guidelines. Chest. 2012 Feb;141(2 Suppl):53s-70s. doi: 10.1378/chest.11-2288. PMID: 22315256. 


\section{Introduction}

\section{Background}

Chronic pain, defined as pain lasting longer than 3 to 6 months or past normal time for tissue healing, ${ }^{1,2}$ is a serious public health issue in the United States, affecting approximately 100 million people ${ }^{3}$ and resulting in over $\$ 560$ billion annually in costs. ${ }^{4}$ Chronic pain substantially impacts physical and mental functioning, reducing productivity and quality of life. It is the leading cause of disability and is often refractory to treatment. ${ }^{5,6}$ Opioids are often prescribed for chronic pain. In the United States, prescription of opioid medications for chronic pain more than tripled from 1999 to $2015 .^{7}$ This increase was accompanied by marked increases in rates of opioid use disorder and drug overdose mortality ${ }^{7-9}$ involving prescription opioids. From 1999 to 2014 , over 165,000 people died from overdoses related to prescription opioids in the United States, ${ }^{1}$ with an estimated 17,087 prescription opioid overdose deaths in $2016 .{ }^{7}$ In October 2017 , the U.S. Department of Health and Human Services declared a nationwide public health emergency regarding the opioid crisis. ${ }^{10}$

While opioids are often prescribed for chronic pain, they have small to moderate effects on pain and overall function with frequent adverse effects, ${ }^{11}$ and the 2016 Centers for Disease Control and Prevention Guideline for Prescribing Opioids for Chronic Pain recommends nonopioid therapy as the preferred treatment of chronic pain. ${ }^{1,2}$ However, recent systematic reviews found that several nonopioid drugs, ${ }^{12}$ and some nonpharmacologic treatments ${ }^{13}$ also have small to moderate effects on chronic pain and overall function. Some nonopioid treatments had frequent overall adverse events and some less frequent but serious adverse effects, while nonpharmacological treatments typically reported few adverse events. ${ }^{12}$

The challenges of treating chronic pain in light of the lackluster evidence on commonly prescribed prescription medications and the ongoing opioid crisis drive a search for alternative pain treatments, including cannabis. The goals of current research are to identify alternative treatments with equal or better benefits for pain while avoiding potential unintended consequences that could result in harms. Plants have historically been evaluated for medicinal properties, with some being developed into drug therapies (i.e., the field of pharmacognosy). Some preclinical data suggest that cannabinoids may have analgesic properties, though research in this area is mixed. ${ }^{14}$ Tetrahydrocannabinol (THC), one of many cannabinoids in cannabis, has demonstrated analgesic properties, ${ }^{15,16}$ though its psychoactive effects and abuse potential increase its risk and suitability as an analgesic. Other cannabinoids (e.g., cannabidiol [CBD], cannabigerol $[\mathrm{CBG}]$, and cannabichromene $[\mathrm{CBC}]$ ) may also have some analgesic or antiinflammatory properties and are not thought to be psychoactive or addictive, ${ }^{17,18}$ but may not be as potent as THC. Observational studies indicate that some patients use cannabis and related compounds as a substitute for opioids. ${ }^{19-22}$

Other plant-based compounds (PBCs) such as kratom, though pharmacologically distinct from cannabis, may be considered as analgesics, in part due to their community-use as substitutes for opioids. ${ }^{23,24}$ They may also have serious harms, such as dependence, addiction, and physiological withdrawal potential. ${ }^{25}$ Although some PBCs thought to reduce pain are currently classified as Schedule I by the Drug Enforcement Administration, there is disagreement on scheduling others, such as kratom. ${ }^{26}$ Recent legalization of cannabis by several states ${ }^{27}$ may lead to more, and higher quality research on PBCs with potential for treating chronic pain. ${ }^{28}$ Initiatives to develop and study alternative interventions for chronic pain are expected to 
contribute to this increase in research on PBCs, specifically for pain. This living review was initiated in response to a request from Congress. ${ }^{28,29}$

The key decisional dilemmas for treating chronic pain with cannabis and other PBCs include the effectiveness in treating chronic pain and the effect of specific formulations, doses or potencies, routes of administration, types of pain, and other patient characteristics on outcomes. Similarly, it is important to identify harms and adverse effects of these interventions which may include risks of frequent or daily use, risk of developing dependence or addiction (e.g., cannabis use disorder), mental health effects, and impacts on harms of co-prescribed opioids. It is also unclear what the impact of using cannabis or other PBCs for pain has on opioid use, and, how their effectiveness compares to other interventions.

\section{Purpose and Scope of the Systematic Review}

This is a "living systematic review," which assesses the effectiveness and harms of plantbased treatments for chronic pain conditions. The review is living in the sense that it uses methods to identify and synthesize recently published literature on an ongoing basis. For the purposes of this review, PBCs included are those that are similar to opioids in effect and that have the potential for addiction, misuse, and serious adverse effects; other PBCs, such as herbal treatments are not included. The intended audience includes policy and decision makers, funders and researchers of treatments for chronic pain, and clinicians who treat chronic pain. 


\section{Methods}

\section{Review Approach}

This Systematic Review follows the methods suggested in the Agency for Healthcare Research and Quality (AHRQ) Methods Guide for Effectiveness and Comparative Effectiveness Reviews (hereafter "AHRQ Methods Guide"). ${ }^{30}$ All methods were determined a priori, and a protocol was published on the AHRQ website (https://effectivehealthcare.ahrq.gov/topics/nonopioid-chronic-pain/protocol) and on the PROSPERO systematic reviews registry (registration no. CRD42021229579). Below is a summary of the specific methods used in this review. Search strategies appear in Appendix A, and a complete description of methods are presented in Appendix B.

\section{Key Questions}

This review will address the following Key Questions (KQs):

1. In adults with chronic pain, what are the benefits of cannabinoids for treatment of chronic pain?

2. In adults with chronic pain, what are the harms of cannabinoids for treatment of chronic pain?

3. In adults with chronic pain, what are the benefits of kratom or other plant-based substances for treatment of chronic pain?

4. In adults with chronic pain, what are the harms of kratom or other plant-based substances for treatment of chronic pain?

\section{Study Selection}

Electronic searches for evidence were conducted in $\mathrm{Ovid}^{\circledR}$ MEDLINE $^{\circledR}$, PsycINFO $^{\circledR}$, Embase $^{\circledR}$, the Cochrane Library, and SCOPUS ${ }^{\circledR}$ databases through July 5, 2021. Searches were initially run in September 2020 with ongoing, automated monthly searches to identify newly published studies. Search strategies are available in Appendix A. Electronic searches were supplemented with review of reference lists of relevant studies and reviewing the two prior AHRQ pain reports ${ }^{11,12}$ for studies that met our inclusion criteria. A Federal Register Notice was posted, and a Supplemental Evidence And Data for Systematic review (SEADS) portal was available for submission of unpublished studies. Pre-established criteria were used to determine eligibility for inclusion and exclusion of abstracts in accordance with the AHRQ Methods Guide, based on the KQs and populations, interventions, comparators, outcomes, timing, and settings (PICOTS; Table 1) ${ }^{30}$ See Appendix B for more details on eligibility criteria and methods for study selection, including dual review of studies screened. 
Table 1. Inclusion and exclusion criteria

\begin{tabular}{|c|c|c|}
\hline PICOTS Element & Inclusion Criteria & Exclusion Criteria \\
\hline Population & $\begin{array}{l}\text { All KQs: Adults (including pregnant or } \\
\text { breastfeeding women) } 18 \text { years and older with } \\
\text { chronic pain (>12 weeks or pain persisting past the } \\
\text { time for normal tissue healing). See categorization } \\
\text { of specifically included pain populations below. }\end{array}$ & $\begin{array}{l}\text { All KQs: Children and adolescents }<18 \text { years old; } \\
\text { adults with acute or subacute pain; } \\
\text { patients at end of life or in palliative care (e.g., } \\
\text { with late stage cancer-related pain) }\end{array}$ \\
\hline Interventions & $\begin{array}{l}\text { KQs } 1 \text { and 2: Cannabinoids (including synthetics) } \\
\text { using different delivery mechanisms such as oral, } \\
\text { buccal, inhalational, topical, or other administration } \\
\text { routes } \\
\text { KQs } 3 \text { and } 4 \text { : Kratom or other plant-based } \\
\text { substances; co-use of kratom or other plant-based } \\
\text { substances and opioids } \\
\text { All KQs: Co-use of other drugs for pain }\end{array}$ & $\begin{array}{l}\text { All KQs: Non-plant-based interventions, } \\
\text { capsaicin, herbal supplements }\end{array}$ \\
\hline Comparators & All KQs: Any comparator, or usual care & All KQs: No comparison \\
\hline Outcomes & $\begin{array}{l}\text { All KQs: Primary efficacy outcomes (i.e., pain, } \\
\text { overall function or disability, including pain } \\
\text { interference }^{a} \text { ); harms and adverse effects (e.g., } \\
\text { dizziness, nausea, sedation, development of } \\
\text { cannabis use disorder, serious adverse events as } \\
\text { defined by study); secondary outcomes (i.e., } \\
\text { psychological distress including depression and } \\
\text { anxiety, quality of life, opioid use, sleep quality, } \\
\text { sleep disturbance, healthcare utilization) }\end{array}$ & All KQs: Other outcomes \\
\hline Time of followup & $\begin{array}{l}\text { All KQs: short term ( } 4 \text { weeks to }<6 \text { months), } \\
\text { intermediate term ( } 6 \text { to }<12 \text { months), long term }(\geq 1 \\
\text { year) }\end{array}$ & $\begin{array}{l}\text { All KQs: studies with <1-month ( } 4 \text { weeks) of } \\
\text { treatment or followup after treatment }\end{array}$ \\
\hline Setting & $\begin{array}{l}\text { All KQs: Any nonhospital setting or setting of self- } \\
\text { directed care }\end{array}$ & $\begin{array}{l}\text { All KQs: Hospital care, hospice care, emergency } \\
\text { department care }\end{array}$ \\
\hline Study design & $\begin{array}{l}\text { All KQs: RCTs; observational studies with a } \\
\text { concurrent control group for harms, and to fill gaps } \\
\text { in the evidence for benefits }\end{array}$ & All KQs: Other study designs \\
\hline
\end{tabular}

Abbreviations: KQ = Key Question; PICOTS = populations, interventions, comparators, outcomes, timing, and settings; RCT = randomized controlled trial.

a The degree to which pain directly interferes with patients' ability to participate in their daily activities.

\section{Data Extraction and Risk of Bias Assessment}

After studies were selected for inclusion, data were abstracted into evidence tables in categories that included but not limited to: study design, year, setting, country, sample size, eligibility criteria, population and clinical characteristics, intervention characteristics, and results. Information relevant for assessing applicability included the number of patients randomized relative to the number of patients enrolled, use of run-in or wash-out periods, and characteristics of the population, intervention, and care settings. All study data were verified for accuracy and completeness by a second team member. Quarterly Progress reports describing recently published studies as they were newly identified are available at: https://effectivehealthcare.ahrq.gov/products/plant-based-chronic-pain-treatment/living-review

The risk of bias of individual studies was assessed using methods consistent with the AHRQ Methods Guide. ${ }^{30}$ Separate criteria were used for randomized controlled trials and observational studies. Two reviewers independently assessed risk of bias, resulting in final ratings of low, moderate, or high, with any disagreements resolved by consensus. For full details about data extraction, risk of bias assessment, and other methods, please see Appendix B. 


\section{Data Synthesis and Analysis}

To assist with narrative synthesis, we constructed summary tables of the abstracted study characteristics, results, and risk of bias ratings for all included studies. Data were additionally summarized in in-text tables, using ranges and descriptive analysis and interpretation of the results. We assessed the persistence of benefits or harms by evaluating the three periods consistent with prior AHRQ pain reports ( 1 to 6 months, 6 to 12 months, and $\geq 12$ months). ${ }^{11-}$ $13,31,32$

We organized cannabis interventions into three categories based on their ratios of tetrahydrocannabinol (THC) to cannabidiol (CBD) (Table 2). The first category, high-THC, includes products with a ratio of THC to CBD of at least 2 to 1 . This category was further stratified based on whether interventions consisted of synthetic THC or were derived from whole-plant cannabis. We categorized nabilone, which is a synthetic cannabinoid product similar to synthetic THC (such as dronabinol), as a synthetic high-THC product. Whole plant-based products can be either extracted or purified, depending on the process used to isolate higher concentrations of THC or CBD. Extracted products may contain additional cannabinoids and other compounds (e.g., terpenes) present in whole-plant cannabis that may or may not affect the impact of the intervention. Purified products are pharmaceutical grade and considered free of contaminants (i.e., consist of only THC or THC and CBD combinations).

The second category, low-THC, contains a ratio of THC to CBD of less than one (i.e., higher CBD than THC, at least 1 to 2 ratio). These may similarly be extracted or purified products.

The third category, comparable THC to CBD ratios, consists of products with ratios that fall between the other two groups (generally, close to 1 to 1 ), and these may also be extracted or purified products.

Interventions consisting of whole-plant cannabis products (not extracted, purified, or synthetic) were categorized according to any information provided about the THC to CBD ratio. Interventions using cannabinoids other than THC and CBD were categorized separately.

Table 2. Organizing principle of cannabis-related studies based on ratios of THC to CBD

\begin{tabular}{|l|l|l|l|}
\hline Intervention Category & Definition & Possible Derivatives & Example Products \\
\hline High-THC & $\begin{array}{l}\text { THC to CBD ratio equals } \geq 2: 1 \\
\text { ratio }\end{array}$ & $\begin{array}{l}\text { Synthetic, extracted or } \\
\text { purified from whole-plant, } \\
\text { whole-plant }\end{array}$ & $\begin{array}{l}\text { Synthetic: } \\
\text { dronabinol/Marinol } \\
\text { nabilone/Cesamet } \\
\text { Extracted: THC oil } \\
\text { (oral) }\end{array}$ \\
\hline Low-THC & $\begin{array}{l}\text { THC to CBD ratio equals 1: } \geq 2 \\
\text { ratio }\end{array}$ & $\begin{array}{l}\text { Extracted or purified from } \\
\text { whole-plant, whole-plant }\end{array}$ & $\begin{array}{l}\text { CBD topical cream } \\
\text { or ointment; } \\
\text { cannabis flowers, } \\
\text { buds, leaves }\end{array}$ \\
\hline $\begin{array}{l}\text { Comparable THC to } \\
\text { CBD }\end{array}$ & $\begin{array}{l}\text { THC to CBD ratio is between } \\
\text { threshold for high-THC and } \\
\text { low-THC categories }\end{array}$ & $\begin{array}{l}\text { Extracted or purified from } \\
\text { whole-plant, whole-plant }\end{array}$ & $\begin{array}{l}\text { Nabiximols } \\
\text { (Sativex }\end{array}$ \\
\hline $\begin{array}{l}\text { Whole-Plant Cannabis } \\
\text { Products }\end{array}$ & $\begin{array}{l}\text { Potentially unknown THC to } \\
\text { CBD ratio; categorized based } \\
\text { on information provided }\end{array}$ & $\begin{array}{l}\text { Whole-plant or } \\
\text { parts/materials from the } \\
\text { plant, not extracted, purified, } \\
\text { or synthetic }\end{array}$ & $\begin{array}{l}\text { Cannabis flowers, } \\
\text { resins, buds, } \\
\text { leaves, hashish }\end{array}$ \\
\hline Other Cannabinoids & $\begin{array}{l}\text { Interventions testing } \\
\text { cannabinoids other than THC } \\
\text { and/or CBD }\end{array}$ & $\begin{array}{l}\text { Extracted or purified from } \\
\text { whole-plant }\end{array}$ & Extracted oils (oral) \\
\hline
\end{tabular}

Abbreviations: CBD = cannabidiol; THC $=$ tetrahydrocannabinol.

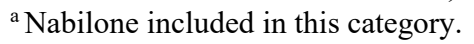


Meta-analyses were conducted to summarize data and obtain more precise estimates on outcomes for which studies were similar enough to provide a meaningful combined estimate. ${ }^{33}$ The decision to conduct quantitative synthesis depended on the presence of at least two studies with similar methodology, completeness of reported outcomes, and a lack of statistical heterogeneity among the reported results. Statistical heterogeneity among the studies was assessed using Cochran's $\chi^{2}$ test and the $I^{2}$ statistic. ${ }^{34}$ Mean difference was used as the effect measure for change in pain, and pain scales were converted to a standardized 0 to 10 scale. A similar approach was used for other primary continuous outcomes (e.g. overall function). For primary binary outcomes (pain response and adverse events), relative risk was used as the effect measure. See Appendix B for more details.

We used a random effects model based on the profile likelihood method ${ }^{35}$ to combine interventions with comparable THC to CBD ratios and high-THC trials. The primary analysis of high-THC trials was stratified by the type of derivative used in the intervention (synthetic vs. whole-plant extracts). Sensitivity analysis was conducted by excluding studies rated as high risk of bias. All meta-analyses were conducted using Stata/SE 16.1 (StataCorp, College Station, TX). Publication bias (small sample size bias) was assessed using both funnel plots and the Egger test when there were eight or more studies included in a meta-analysis.

The magnitude of effects for primary outcomes were classified using the same system used in other recent AHRQ reviews conducted on chronic pain ${ }^{11-13,31,32}$ to provide a consistent benchmark for comparing results of pain interventions across reviews. The findings were categorized as small, moderate, and large magnitudes of effect based on the ranges of effect shown in Table 3. Additionally, results that were below the threshold for a small effect were considered to reflect "no effect." Results with a small, medium, or large effect that were not statistically significant were considered to have "potential effects" if the 95 percent confidence interval included meaningful benefit or harm, but were not so wide that they included the potential for both meaningful benefits and harms.

Table 3. Definitions of effect sizes

\begin{tabular}{|l|l|}
\hline Effect Size & Definition \\
\hline Small effect & $\begin{array}{l}\text { - MD } 0.5 \text { to } 1.0 \text { points on a } 0 \text { to 10-point scale, } 5 \text { to } 10 \text { points on a } 0 \text { to 100-point scale } \\
\text { - SMD } 0.2 \text { to } 0.5 \\
\text { - RR/OR } 1.2 \text { to } 1.4\end{array}$ \\
\hline Moderate effect & $\begin{array}{l}\text { - MD }>1 \text { to } 2 \text { points on a } 0 \text { to10-point scale, }>10 \text { to } 20 \text { points on a } 0 \text { to 100-point scale } \\
\text { - SMD }>0.5 \text { to } 0.8\end{array}$ \\
\hline Large effect & $\begin{array}{l}\text { - } \mathrm{RR} / \mathrm{OR} 1.5 \text { to } 1.9 \\
\text { - SMD }>0.8\end{array}$ \\
& - RR/OR $\geq 2.0$
\end{tabular}

Abbreviations: $\mathrm{MD}=$ mean difference; $\mathrm{OR}=$ odds ratio; $\mathrm{RR}=$ relative risk; $\mathrm{SMD}=$ standardized mean difference.

Small effects using this system may be below published thresholds for clinically meaningful effects; however, there is variability across individual patients regarding what constitutes a clinically meaningful effect, which is influenced by a number of factors such as preferences, duration and type of chronic pain, baseline symptom severity, harms, and costs. For some patients a small improvement in pain or overall function using a treatment with low cost or no serious harms may be important.

When data were available, we conducted subgroup analysis based on type of product (synthetic vs. extracted from whole-plant), duration (short-, medium-, long-term followup), and type of pain (e.g. neuropathic, visceral, joint). 


\section{Grading the Strength of the Body of Evidence}

We assessed the strength of evidence for all primary comparisons and outcomes listed above. Regardless of whether evidence was synthesized quantitatively or qualitatively, the strength of evidence for each KQ/body of evidence is initially assessed by one researcher for each clinical outcome (see PICOTS) by using the approach described in the AHRQ Methods Guide. ${ }^{30,36}$ To ensure consistency and validity of the evaluation, the strength of evidence is reviewed by the entire team of investigators prior to assigning a final grade on the following factors:

- Study limitations (low, medium, or high level of study limitations)

- Consistency (consistent, inconsistent, or unknown/not applicable)

- Directness (direct or indirect)

- Precision (precise or imprecise)

- Reporting/publication bias (suspected or undetected)

For description of overall grade, please see Appendix B.

In narratively describing the findings on the strength of the evidence, we followed the principles outlined in recent guidance to improve clarity. ${ }^{37-39}$ Using these principles, evidence that is low-strength is described as "may" have an effect, moderate strength evidence is described as "probably" has an effect, and high-strength evidence is simply described as having an effect.

\section{Living Systematic Review Methods}

This report is a part of a living systematic review, with regular updating of the evidence on a quarterly basis. Methods for the updates are consistent with those described here, and more details can be found in Appendixes A and B. Previous quarterly progress reports, describing new evidence as it became available, can be found at:

https://effectivehealthcare.ahrq.gov/products/plant-based-chronic-pain-treatment/living-review

Future updates will be posted at this location. 


\section{Results}

\section{Description of Included Evidence}

The results of this systematic review are organized first by Key Questions (KQs), with evidence on KQs 1 and 2 (benefits and harms of cannabinoids) reported together. The evidence is then organized according to the categories described in the Methods, comparable tetrahydrocannabinol (THC) to cannabidiol (CDB) ratio interventions, high-THC to CBD ratio interventions (stratified into synthetic, extracted from whole-plant, and whole-plant cannabis products), low-THC to CBD ratio interventions (topical CBD), and other cannabinoids. There was no evidence included for KQs 3 and 4.

After screening 2,850 abstracts, 214 full-text publications of studies were dually reviewed, resulting in 20 randomized controlled trials (RCTs) and 7 observational studies being included in this review. All included studies assessed cannabinoid interventions; no studies of kratom or other plant-based compounds met inclusion criteria.

The search results and selection of studies are summarized in the literature flow diagram (Figure 1). Appendix C provides a list of all included studies. In total, seven RCTs evaluated products that contain a combination of THC and CBD (comparable THC to CBD ratio), ${ }^{40-46}$ Two RCTs evaluated the effects of high-THC to CBD ratio, whole-plant derived extracts. ${ }^{47,48}$ Nine RCTs evaluated synthetic forms of THC (high-THC to CBD ratio). ${ }^{49-57}$ One trial assessed the effect of topical CBD (low-THC to CBD ratio), ${ }^{58}$ and another evaluated the phytocannabinoid, cannabidivarin (CBDV). ${ }^{59}$

Appendix D contains individual study-level data and additional results for pooled data from studies where data were available. Detailed evidence tables for included studies and risk of bias assessments are available in Appendixes E and F. Appendix G contains details on the strength of evidence, and Appendix $\mathrm{H}$ lists excluded studies at the full-text level and their reasons for exclusion.

\section{Figure 1. Literature flow diagram}

Abstracts of potentially relevant articles identified through Ovid ${ }^{\circledR}$ MEDLINE ${ }^{\circledR}$, PsycINFO $^{\circledR}$, Embase $^{\circledR}$, the Cochrane Central Register of Controlled Trials, the Cochrane Database of Systematic Reviews databases, and prior chronic pain reports $(n=2,850)$

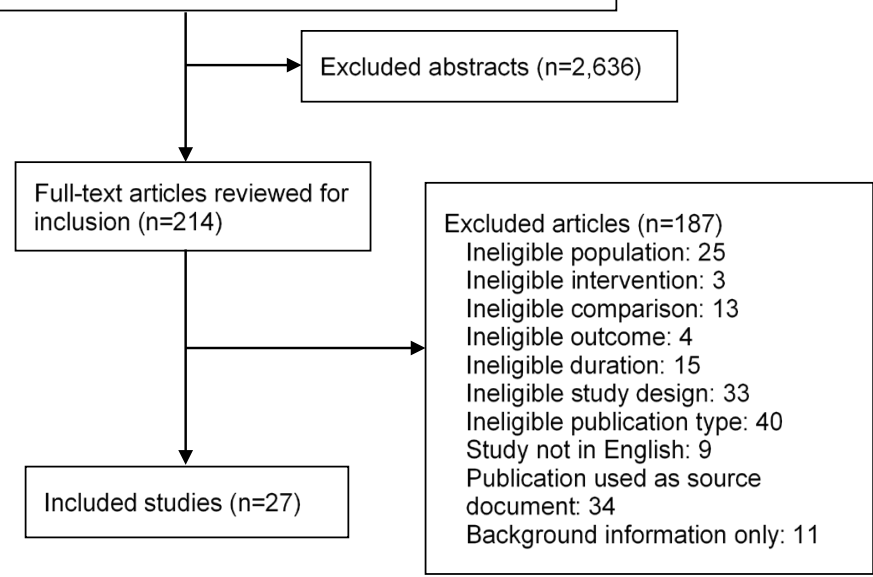


Table 4 summarizes the characteristics of the included trials, and Table 5 provides details on included observational studies.

Table 4. Characteristics of included randomized controlled trials of cannabinoids

\begin{tabular}{|c|c|c|c|c|c|}
\hline Characteristic & THC/CBD & THC & Synthetic THC & CBD & CBDV \\
\hline THC to CBD Ratio & Comparable & High & High & Low & $\begin{array}{l}\text { NA - other } \\
\text { cannabinoids }\end{array}$ \\
\hline Source & Plant-extracted & $\begin{array}{l}\text { Plant- } \\
\text { extracted }\end{array}$ & Synthetic & Plant-extracted & Plant-extracted \\
\hline N Studies & 7 & 2 & 9 & 1 & 1 \\
\hline $\begin{array}{l}\text { Comparator } \\
\text { (Study Count) }\end{array}$ & Placebo (7) & Placebo (2) & $\begin{array}{l}\text { Placebo (6); } \\
\text { Ibuprofen (1); } \\
\text { Diphenhydramine (1); } \\
\text { Dihydrocodeine (1) }\end{array}$ & Placebo (1) & Placebo (1) \\
\hline $\begin{array}{l}\text { Risk of Bias } \\
\% \text { High, } \% \\
\text { Moderate, \% Low }\end{array}$ & $\begin{array}{l}29 \%, 57 \% \\
14 \%\end{array}$ & $\begin{array}{l}0 \%, 50 \%, \\
50 \%\end{array}$ & $22 \%, 44 \%, 33 \%$ & $100 \%$ high & $100 \%$ moderate \\
\hline Total Randomized & 882 & 297 & 534 & 29 & 34 \\
\hline Age, Mean Years & 53 & 52 & 50 & 68 & 50 \\
\hline Female, \% & $66 \%$ & $89 \%$ & $61 \%$ & $38 \%$ & $3 \%$ \\
\hline $\begin{array}{l}\text { \% Non-white } \\
\text { (Study Count) }\end{array}$ & $1.6 \%(2)$ & $1 \%(1)$ & $5.4 \%(3)$ & NA & NA \\
\hline $\begin{array}{l}\text { Primary Pain } \\
\text { Type (Study } \\
\text { Count) }\end{array}$ & $\begin{array}{l}\text { NPP (6); } \\
\text { inflammatory } \\
\text { arthritis (1) }\end{array}$ & $\begin{array}{l}\text { NPP (1); } \\
\text { fibromyalgia } \\
\text { (1) }\end{array}$ & $\begin{array}{l}\text { NPP (6); } \\
\text { fibromyalgia (1); } \\
\text { headache (1); } \\
\text { visceral pain (1) }\end{array}$ & NPP (1) & NPP (1) \\
\hline $\begin{array}{l}\text { Baseline Pain } \\
\text { Score, Mean } \\
(\text { Range })^{b}\end{array}$ & $\begin{array}{l}6.59 \text { (5.3 to } \\
7.3)\end{array}$ & $\begin{array}{l}8.47(8.25 \text { to } \\
8.67)\end{array}$ & $6.46(4 \text { to } 8.1)^{\mathrm{c}}$ & $\begin{array}{l}5.38(4.67 \text { to } \\
6.14)\end{array}$ & $\begin{array}{l}6.28(6.12 \text { to } \\
6.44)\end{array}$ \\
\hline Study Duration & 4 to 15 weeks & 8 to 12 weeks & 4 to 47 weeks & 4 weeks & 4 weeks \\
\hline
\end{tabular}

Abbreviations: $\mathrm{CBD}=$ cannabidiol; $\mathrm{CBDV}=$ cannabidivarin; $\mathrm{NA}=$ not applicable; $\mathrm{NPP}=$ neuropathic pain; $\mathrm{THC}=$

tetrahydrocannabinol.

${ }^{\text {a }}(\mathrm{N})=$ number of studies reporting this characteristic at baseline.

b Scores were standardized to a 0 to 10 scale.

${ }^{c}$ Weighted mean includes median scores for one study (6 vs. 6).

Table 5. Characteristics of included observational studies

\begin{tabular}{|c|c|c|c|}
\hline Characteristic & THC/CBD & THC & Synthetic THC \\
\hline THC to CBD Ratio & Unclear & High & High \\
\hline Source & $\begin{array}{l}\text { Any cannabis product } \\
\text { (patient's choice) }\end{array}$ & Plant-based & $\begin{array}{l}\text { Synthetic } \\
\text { (nabilone) }\end{array}$ \\
\hline N Studies & 5 & 1 & 1 \\
\hline Comparator (Study Count) & $\begin{array}{l}\text { No cannabis use (3); } \\
\text { usual care (1); no } \\
\text { medical cannabis } \\
\text { authorization (1) }\end{array}$ & Usual care (1) & $\begin{array}{l}\text { Gabapentin only; } \\
\text { gabapentin + } \\
\text { nabilone (1) }\end{array}$ \\
\hline $\begin{array}{l}\text { ROB } \\
\% \text { High, \% Moderate, \% Low }\end{array}$ & $\begin{array}{l}60 \% \text { high, } 40 \% \\
\text { moderate }\end{array}$ & $100 \%$ high & $100 \%$ moderate \\
\hline N Total & 12,508 & 431 & 156 \\
\hline Age, Mean Years & 53 & 49 & 61 \\
\hline Female, $\%$ & $55 \%$ & $57 \%$ & $59 \%$ \\
\hline$\%$ Non-white (study count) & $54 \%(1) ;$ NR (4) & NR & NR \\
\hline Primary Pain Type(s) & $\begin{array}{l}\text { Mixed musculoskeletal, } \\
\text { chronic non-cancer pain }\end{array}$ & Chronic non-cancer pain & NPP \\
\hline Baseline Pain Score, Mean (Range) ${ }^{a}$ & 5.35 (4.56 to 8.00$)$ & $6.35(6.1$ to 6.6$)$ & $4.98(4.58$ to 5.31$)$ \\
\hline Study Duration, Weeks (Range) & 12 to 208 & 52 & 26 \\
\hline
\end{tabular}

Abbreviations: $\mathrm{CBD}=$ cannabidiol; $\mathrm{NPP}=$ neuropathic pain; $\mathrm{NR}=$ not reported; $\mathrm{ROB}=$ risk of bias; $\mathrm{THC}=$ tetrahydrocannabinol.

${ }^{\text {a }}$ Scores were standardized to a 0 to 10 scale. 


\section{$\mathrm{KQ} 1$ and KQ 2. In adults with chronic pain, what are the benefits (KQ 1) and harms (KQ 2) of cannabinoids for treatment of chronic pain?}

\section{Key Points for Comparable THC to CBD Ratio}

- All results are short-term (4 weeks to $<6$ months) in duration.

- Comparable THC to CBD ratio products were associated with small improvements in pain severity ( $7 \mathrm{RCTs}, \mathrm{N}=702,0$ to 10 scale, mean difference [MD] $-0.54,95 \%$ confidence interval $[\mathrm{CI}],-0.95$ to $-0.19, \mathrm{I}^{2}=28 \%$ ) and overall function $(6 \mathrm{RCTs}, \mathrm{N}=616$, 0 to 10 scale, $\mathrm{MD}-0.42,95 \% \mathrm{CI}-0.73$ to -0.16 ) (strength of evidence [SOE]: moderate). While more patients had a response ( $\geq 30 \%$ improvement from baseline), the difference was small and did not reach statistical significance (4 RCTs, N=733, 38\% vs. $31 \%$, relative risk [RR] $1.18,95 \%$ CI 0.93 to $1.71, \mathrm{I}^{2}=0 \%$ ) (SOE: low).

- Compared with placebo, comparable THC to CBD was associated with a large increase in risk of dizziness ( $6 \mathrm{RCTs}, \mathrm{N}=866,30 \%$ vs. $8 \%$, RR 3.57, 95\% CI 2.42 to $5.60, \mathrm{I}^{2}=0 \%$ ) and sedation ( 6 RCTs, $\mathrm{N}=866,22 \%$ vs. $16 \%$, RR 5.04, 95\% CI 2.10 to $11.89, \mathrm{I}^{2}=0 \%$ ), and a moderate increased risk of nausea (6 RCTs, N=866, 13\% vs. 7.5\%, RR 1.79, 95\% CI 1.20 to $2.78, \mathrm{I}^{2}=0 \%$ ). There was no effect on study withdrawal due to adverse events (SOE: low).

\section{Summary of Findings for Comparable THC to CBD Ratio}

Seven RCTs $(\mathrm{N}=882 \text {, range } 18 \text { to } 339)^{40-46}$ compared products containing a combination of extracted THC and CBD (THC/CBD; comparable THC to CBD ratio) with placebo in patients experiencing chronic pain. All used nabiximols, extracted from whole-plant cannabis with 2.7 $\mathrm{mg}$ of THC and $2.5 \mathrm{mg}$ of CBD per $100 \mathrm{mcl}$ oromucosal spray (specified as the product Sativex ${ }^{\circledR}$ in 6 studies). Six trials enrolled patients with neuropathic pain, ${ }^{40-44,46}$ while the other study included patients with rheumatoid arthritis. Studies ranged from 4 to 16 weeks in duration of active treatment; all were short-term followup ( 1 to $<6$ months). Across trials, the weighted mean daily dose was 8.4 sprays ( $21 \mathrm{mg}$ THC/23 mg CBD) for patients assigned to THC/CBD and 12.7 sprays for those assigned to placebo. One study did not specify the product name, strength or dosing in milligrams, but the number of sprays per day ( 8 vs. 11 for intervention vs. placebo), were similar to other trials. ${ }^{42}$ Two trials were high risk of bias: one a small $(n=16), 4$-week, crossover trial, and the other a small $(n=29), 12$-week, parallel design trial. ${ }^{42,45}$ The rest were parallel design trials, four moderate risk of bias, ${ }^{40,43,44,46}$ and one low risk of bias. ${ }^{41}$ The mean age of participants was 53 years, and 66 percent were female. Race was poorly reported, with two trials reporting 1.2 percent of participants being non-white, and the others not reporting it at all. Four trials allowed patients using opioids and other analgesics to enroll and to continue using them during the study period. ${ }^{41-43,46}$ The proportion of patients taking opioids was low in two studies $(11 \% \text { to } 24 \%)^{41,46}$ and much greater in the third study (63\% in the cannabis group vs. $74 \%$ in the placebo group). ${ }^{43}$ The other three trials did not report opioid use. All of the RCTs of comparable THC to CBD ratio products allowed prior cannabis use, with a range of 5 percent to 64 percent of enrolled patients having used cannabis previously. None of the studies analyzed results according to prior cannabis use.

Study details and results can be found in Appendix E, Tables E-1 to E-5 and risk of bias assessments in Appendix F, Tables F-1 and F-2. 
For pain response ( $\geq 30 \%$ reduction in pain) pooled analysis of four $\mathrm{RCTs}^{41,43,45,46}$ found a statistically nonsignificant increase with combination THC/CBD treatment (4 RCTs, 38\% vs. $31 \%$, RR 1.18, 95\% CI 0.93 to 1.71, $\mathrm{I}^{2}=0 \%$; Appendix D, Figure D-1). Based on pooled analysis of all seven RCTs, pain severity showed a small, statistically significant improvement with combination THC/CBD treatment (7 RCTs, 0 to 10 scale, MD $-0.54,95 \% \mathrm{CI}-0.95$ to -0.19 , $\mathrm{I}^{2}=28 \%$; Figure 2). ${ }^{40-46}$ Figure 2 shows that, except for the small, high risk of bias, crossover study, the size of effect was larger and statistically significant in the shorter studies (4 to 5 weeks) compared with the longer studies (12 to 15 weeks). Subgroup analysis was not conducted because all of the studies are of short duration ( 1 to $<6$ months). Sensitivity analysis excluding two high risk of bias studies ${ }^{42,45}$ did not alter the findings ( 0 to 10 scale, MD $-0.64,95 \%$ CI -1.15 to $\left.-0.24, \mathrm{I}^{2}=43 \%\right)^{41,46}$

Six studies $(\mathrm{N}=616)$ with 5 to 15 weeks followup reported on overall function or disability (including measures of pain interference). ${ }^{40,41,43-46}$ Pooled analysis showed a small benefit for nabiximols versus placebo (6 RCTs, 0 to 10 scale, $\mathrm{MD}-0.42,95 \% \mathrm{CI}-0.73$ to $-0.16, \mathrm{I}^{2}=24 \%$; Figure 3).

For secondary outcomes, all of the trials reported quality of life. Overall, there were not statistically significant differences in quality of life between groups. Three used the EQ-5D scale ( 0 to 100), with none finding a significant difference between groups. ${ }^{41,45,46}$ One used the Short General Health Questionnaire (GHQ-12; 0 to 36 scale), and found a small, but not statistically significant, difference between groups. ${ }^{43}$ Three of the studies reported on the Short Form-36 (SF36) Physical and Mental scales (0 to 100). ${ }^{41,42,45}$ Two did not find statistically significant between-group differences. The third study, a high risk of bias crossover trial $(\mathrm{N}=16)$, reported that the SF-36 Physical scale scores improved with placebo, with little change in the THC/CBD group, while the SF-36 Mental scale scores stayed similar in the THC/CBD group and decreased (worsened) in the placebo group. ${ }^{42}$ Five studies assessed sleep quality or sleep disturbance using a 0 to 10 scale; four reported statistically significantly better sleep outcomes in the THC/CBD groups versus placebo groups. ${ }^{40,41,43,44,46}$ The studies did not report on other secondary outcomes (e.g., depression or anxiety).

The four RCTs that allowed opioid use during the study period did not report on changes in opioid used during the study period. ${ }^{41,43,46}$

Figure 2. Change in pain severity with comparable THC to CBD ratio versus placebo (short term, 4 weeks to 6 months followup)

\begin{tabular}{|c|c|c|c|c|c|c|c|}
\hline Author, Year & $\begin{array}{l}\text { Pain } \\
\text { Population }\end{array}$ & $\begin{array}{l}\text { Treatment } \\
\text { Duration } \\
\text { (weeks) }\end{array}$ & Intervention Dose & $\begin{array}{l}\text { Risk of } \\
\text { Bias }\end{array}$ & $\begin{array}{l}\mathrm{N}, \text { Mean (SD), } \\
\text { Intervention }\end{array}$ & $\begin{array}{l}\mathrm{N} \text {, Mean (SD), } \\
\text { Control }\end{array}$ & $\begin{array}{l}\text { Mean difference } \\
(95 \% \mathrm{Cl})\end{array}$ \\
\hline Lynch, 2014 & NPP & 4 & 8 sprays & High & $8,6.31(0.87)$ & $8,6.38(0.85)$ & $-0.07(-0.91,0.77)$ \\
\hline Rog, 2005 & NPP & 5 & 9.6 sprays/day & Moderate & $33,3.85(2.04)$ & $32,4.96(2.12)$ & $-1.25(-2.11,-0.39)$ \\
\hline Blake, 2006 & IA & 5 & 5.4 sprays/day & Moderate & $31,3.10(\mathrm{NR})$ & $27,4.10$ (NR) & $-1.04(-1.90,-0.18)$ \\
\hline Nurmikko, 2007 & NPP & 5 & 10.9 sprays/day & Moderate & $63,5.82(N R)$ & 62, 6.68 (NR) & $-0.96(-1.59,-0.33)$ \\
\hline Selvarajah, 2010 & NPP & 12 & 7 sprays/day $^{\mathrm{a}}$ & High & $15,5.16(2.19)$ & $14,5.19(2.41)$ & $-0.03(-1.78,1.72)$ \\
\hline Langford, 2013 & NPP & 15 & 8.8 sprays/day & Low & $167,4.54(2.24)$ & $172,4.73(2.26)$ & $-0.19(-0.67,0.29)$ \\
\hline Serpell, 2014 & NPP & 15 & 8.9 sprays/day & Moderate & NR & NR & $-0.34(-0.79,0.11)$ \\
\hline \multicolumn{7}{|c|}{ Overall $\left(I^{2}=27.9 \%, p=0.133\right)$} & $-0.54(-0.95,-0.19)$ \\
\hline
\end{tabular}

Abbreviations: $\mathrm{CBD}=$ cannabidiol; $\mathrm{CI}=$ confidence interval; $\mathrm{IA}=$ inflammatory arthritis; $\mathrm{NPP}=$ neuropathic pain; $\mathrm{NR}=$ not reported; $\mathrm{SD}=$ standard deviation; $\mathrm{THC}=$ tetrahydrocannabinol.

${ }^{\text {a }}$ Calculated by review team. 
Figure 3. Overall function: comparable THC to CBD ratio versus placebo (short term, 4 weeks to 6 months followup)

\begin{tabular}{|c|c|c|c|c|c|c|c|}
\hline Author, Year & Scale & $\begin{array}{l}\text { Treatment } \\
\text { Duration } \\
\text { (weeks) }\end{array}$ & Intervention Dose & $\begin{array}{l}\text { Risk of } \\
\text { Bias }\end{array}$ & $\begin{array}{l}\mathrm{N}, \text { Mean }(\mathrm{SD}) \text {, } \\
\text { Intervention }\end{array}$ & $\begin{array}{l}\mathrm{N} \text {, Mean (SD), } \\
\text { Control }\end{array}$ & $\begin{array}{l}\text { Mean difference } \\
(95 \% \mathrm{Cl})\end{array}$ \\
\hline Rog, 2005 & GNDS & 5 & 9.6 sprays/day & Moderate & $33,-0.27(0.75)$ & $32,-0.08(0.73)$ & $-0.26(-0.62,0.10)$ \\
\hline Blake, 2006 & DAS28 & 5 & 5.4 sprays/day & Moderate & $31,5.00$ (NR) & $27,5.90$ (NR) & $-0.76(-1.23,-0.29)$ \\
\hline Nurmikko, 2007 & PDI & 5 & 10.9 sprays/day & Moderate & $63,-0.80(N R)$ & $62,0.03(\mathrm{NR})$ & $-0.84(-1.37,-0.31)$ \\
\hline Selvarajah, 2010 & SF-36 PF & 12 & 7 sprays/day & High & $15,6.95(1.66)$ & $14,6.35(2.79)$ & $-0.60(-2.33,1.13)$ \\
\hline Langford, 2013 & BPI-SF & 15 & 8.8 sprays/day & Low & $167,-1.47$ (NR) & $172,-1.35$ (NR) & $-0.12(-0.52,0.28)$ \\
\hline Serpell, 2014 & BPI-SF & 15 & 8.9 sprays/day & Moderate & NR & NR & $-0.32(-0.79,0.15)$ \\
\hline \multicolumn{7}{|c|}{ Overall $\left(I^{2}=24.4 \%, p=0.193\right)$} & $-0.42(-0.73,-0.16)$ \\
\hline
\end{tabular}

Abbreviations: BPI-SF = Brief Pain Inventory- Short Form; CBD = cannabidiol; CI = confidence interval; DAS28 = 28-Joint Disease Activity Scale; GNDS = Guy's Neurological Disability Scale; IA = inflammatory arthritis; NPP = neuropathic pain; NR = not reported; PDI = Pain Disability Index; SD = standard deviation; SF-36 = 36 Item Short Form Survey; SF-36 PF = 36 Item Short Form Survey Physical Functioning; THC = tetrahydrocannabinol.

Adverse events were reported in all the trials. Based on two RCTs, rates of any adverse event were significantly higher in the THC/CBD groups than placebo (2 RCTs, 75\% vs. 63\%, RR 1.19, $95 \%$ CI 1.02 to $1.44, \mathrm{I}^{2}=0 \%$, Appendix D, Figure D-2). ${ }^{41,44}$

Serious adverse events (SAEs) were reported in four studies, with two reporting that none occurred. ${ }^{42,44}$ Pooling results from the other two studies found no effect on SAEs with comparable THC/CBD products (2 RCTs, $1.1 \%$ vs. $2.2 \%$, RR $0.68,95 \%$ CI 0.04 to 10.85 , $\mathrm{I}^{2}=38 \%$, Appendix D, Figure D- 3$) .^{40,43}$

Five RCTs reported on withdrawals from study due to adverse events (WAEs). Pooled analysis of these results found a statistically nonsignificant difference ( 5 RCTs, $12.5 \%$ vs. $10.2 \%$, RR 1.14, 95\% CI 0.65 to $3.02, \mathrm{I}^{2}=0 \%$, Appendix D, Figure D-4). ${ }^{40,41,43,44,46}$

Statistically significant differences in specific adverse events of interest occurred more often in the THC/CBD groups than placebo across six RCTs (one did not report specific adverse events). ${ }^{45}$ Dizziness occurred significantly more in the THC/CBD groups than placebo groups (6 RCTs, $30 \%$ vs. $8 \%$, RR 3.57, 95\% CI 2.42 to $5.60, \mathrm{I}^{2}=0 \%$, Appendix D, Figure D-5). ${ }^{40-44,46}$ Nausea was reported in 13 percent of THC/CBD patients compared with 7.5 percent of placebo patients (6 RCTs, RR 1.79, 95\% CI 1.20 to $2.78, \mathrm{I}^{2}=0 \%$, Appendix D, Figure D-6). ${ }^{40-44,46}$ Sedation was reported in 8 percent of THC/CBD patients compared with 1.2 percent of placebo patients (6 RCTS, RR 5.04, 95\% CI 2.10 to $11.89, \mathrm{I}^{2}=0 \%$, Appendix D, Figure D-7). ${ }^{40-44,46}$

\section{Key Points for High-THC to CBD Ratio}

- All RCT results are short-term (4 weeks to $<6$ months) in duration

- Synthetic high-THC to CBD ratio (100\% THC) was associated with a moderate improvement in pain severity (6 RCTs, $\mathrm{N}=390,0$ to 10 scale, $\mathrm{MD}-1.15,95 \% \mathrm{CI}-1.99$ to $-0.54, \mathrm{I}^{2}=39 \%$ ) and no effect on overall function or disability (2 RCTs, N=unclear, 0 to 10 scale, $\mathrm{MD}-0.35,95 \% \mathrm{CI}-1.9$ to $0.94, \mathrm{I}^{2}=40 \%$ ) (SOE: low).

- Synthetic high-THC to CBD ratio (100\% THC) was associated with a moderate increase in risk of sedation ( 3 RCTs, $\mathrm{N}=335,19 \%$ vs. $10 \%$, RR $1.73,95 \%$ CI 1.03 to $4.63, \mathrm{I}^{2}=0 \%$ ) (SOE: low), and dizziness (2 RCTs, $\mathrm{N}=132,32 \%$ vs. 11\%, RR 2.74, 95\% CI 1.47 to 6.86 , $\mathrm{I}^{2}=0 \%$ ) (SOE: moderate). 
- Synthetic high-THC to CBD ratio (100\% THC) was associated with a moderate increased risk of study withdrawal due to adverse events (4 RCTs, N=357, 13\% vs. 9\%, RR 1.72 , $95 \%$ CI 0.90 to $4.13, \mathrm{I}^{2}=0 \%$ ) and a large increased risk of nausea ( 2 RCTs, $\mathrm{N}=302,12 \%$ vs. $6 \%$, RR $2.19,95 \%$ CI 0.77 to $5.39 ; \mathrm{I}^{2}=0 \%$ ), but the differences did not reach statistical significance.

- Plant-based, extracted high-THC to CBD ratio products were associated with a large increased risk of study withdrawal due to adverse events ( $1 \mathrm{RCT}, \mathrm{N}=277,13.9 \%$ vs. $5.7 \%$, RR 3.12, 95\% CI 1.54 to 6.33), and dizziness ( 1 RCT, N=277, 62.2\% vs. $7.5 \%$, RR $8.34,95 \%$ CI 4.53 to 15.34 ) (SOE: low). Outcomes of benefit were not reported or insufficient.

- The combined evidence for extracted and synthetic high-THC to CBD ratio products found a moderate improvement in pain severity ( 8 RCTs, $\mathrm{N}=684,-1.25,95 \% \mathrm{CI}-2.09$ to $-0.71, \mathrm{I}^{2}=50 \%$ ) (SOE: moderate).

\section{Summary of Findings for High-THC to CBD Ratio}

Eleven RCTs studied products with a high-THC to CBD ratio, ${ }^{47-57}$ with nine RCTs of synthetic THC (100\% THC: 3 dronabinol, 100\% THC analog: 6 nabilone), ${ }^{49-57}$ and two products extracted from whole-plant cannabis (one with a 48:1 and the other with a 2:1 THC to CBD ratio). ${ }^{47,48}$ Six of the synthetic THC RCTs were placebo-controlled, ${ }^{49,53-57}$ and three were activecontrolled crossover trials. ${ }^{50-52}$ Both studies of THC extracted from whole-plant were placebocontrolled. All of the RCTs were short duration (4 weeks to 6 months followup). Additionally, one short duration observational study was included. ${ }^{60}$ The evidence for synthetic and plantderived products are presented below separately. Where meta-analyses could be conducted for placebo-controlled trials, the data for both types of products are presented on one plot, stratified by type, with subgroup analyses conducted when possible.

\section{Synthetic THC}

Nine RCTs ( $\mathrm{N}=467 ; 3$ dronabinol, and 6 nabilone $)^{49-57}$ studied synthetic THC for treating chronic pain. Six of the trials enrolled patients with neuropathic pain (3 multiple sclerosis [MS], 1 each painful diabetic neuropathy, spinal cord injury, and mixed neuropathic pain conditions), ${ }^{50,52,53,55-57}$ and one each in patients with chronic abdominal pain, ${ }^{49}$ medication overuse headache, ${ }^{51}$ and fibromyalgia. ${ }^{54}$ All studies were of short-duration followup, ranging from 4 to 14 weeks of active treatment. Both medications were titrated upward, with a maximum dose of 15 to $20 \mathrm{mg}$ per day of dronabinol and 0.5 to $2 \mathrm{mg}$ per day of nabilone (mean dose received at endpoint was inconsistently reported).

One trial of nabilone used an enriched enrollment randomized withdrawal design, with a 4week, single-blind, flexible dose run-in period prior to randomization. ${ }^{55}$ Only patients who achieved a 30 percent improvement in pain severity, completed 75 percent of diary entries, and did not withdraw from the study due to adverse events were randomized to treatment or placebo. Thirty percent of patients (11/37) were withdrawn from the study during the run-in period.

Six trials were parallel design placebo-controlled, with one adding nabilone or placebo to gabapentin treatment in patients who had not achieved pain relief (visual analog scale [VAS] score for pain $>50) .{ }^{56}$ The other three RCTs were crossover trials with an active control arm; one using diphenhydramine as an active control (47 weeks), ${ }^{52}$ another using ibuprofen ( 8 weeks) ${ }^{51}$ and the third using dihydrocodeine ( 6 weeks).${ }^{50}$ Risk of bias was high in two trials, ${ }^{52,57}$ moderate in four, ${ }^{49,50,54,56}$ and low in three. ${ }^{51,53,55}$ The mean age of participants was 50 years, and 61 
percent were female. Race was poorly reported, with only three trials reporting 5.4 percent of participants being non-White. Three studies allowed patients to continue taking their current medication for pain, not specifically excluding opioids or requiring their discontinuation, ${ }^{49,53,54}$ with one specifically allowing tramadol as rescue medication for acute pain during the trial. ${ }^{53}$ The other studies required patients to discontinue opioid use before the study ${ }^{50,52}$ or did not report baseline opioid use or use during the study period. ${ }^{51,55-57}$ Five parallel design placebocontrolled trials ( 2 dronabinol, 3 nabilone) excluded patients with prior cannabis use. ${ }^{49,53-56}$ One crossover designed trial (nabilone vs. dihydrocodeine) excluded patients with prior cannabis use. $^{50}$

A small ( $\mathrm{n}=156)$, moderate risk of bias cohort study evaluated nabilone and gabapentin in patients with neuropathic pain of various types for six months. ${ }^{60}$ Patients were prospectively allowed to initiate nabilone or gabapentin, or to add one of them to pre-existing treatment with the other. The mean dose at 6 months was $3 \mathrm{mg}$ per day for nabilone and 2,296 $\mathrm{mg}$ per day for gabapentin.

Study details and results can be found in Appendix E, Tables E-1 to E-5, and risk of bias assessments can be found in Appendix F, Tables F-1 and F-2.

\section{Placebo-Controlled Trials of Synthetic THC}

Based on pooled analysis of six RCTs, synthetic high-THC to CBD ratio products were associated with moderate improvements in pain severity (6 RCTs, 0 to 10 scale, MD $-1.15,95 \%$ $\mathrm{CI}-1.99$ to $-0.54, \mathrm{I}^{2}=39 \%$; Figure 4$) .{ }^{49,53-57}$ Stratified analysis showed that the pooled effect estimate for nabilone (MD $-1.59,95 \% \mathrm{CI}-2.49$ to $-0.82, \mathrm{I}^{2}=0 \%$ ) was somewhat larger than with dronabinol (MD $-0.52,95 \% \mathrm{CI}-1.43$ to $0.07, \mathrm{I}^{2}=0 \%$; Appendix D, Figure D-8, Table D-6), but the difference was not statistically significant $(\mathrm{p}=0.077) .{ }^{49,53-57}$ A single, low risk of bias $\operatorname{RCT}(n=26)$ of patients with diabetic neuropathy reported on pain response $(\geq 30 \%$ improvement from baseline), finding a large effect with nabilone ( $85 \%$ vs. 38\%, RR 2.20, 95\% CI 1.06 to 4.55). ${ }^{55}$

Three RCTs reported on overall function (including pain interference) or disability. ${ }^{55-57}$ Pooled analysis of two RCTs $(\mathrm{N}=41)$ did not find a statistically significant difference between synthetic high-THC and placebo ( 0 to 10 scale, $\mathrm{MD}-0.35,95 \% \mathrm{CI}-1.9$ to $0.94, \mathrm{I}^{2}=40 \%$; Appendix D, Figure D-9). The third RCT $(n=13)$ reported that neither group had a change in disability, measured with the Bartell Index (no data reported). ${ }^{57}$

Few synthetic THC studies reported on secondary outcomes. A small $(n=26)$, low risk of bias RCT of patients with diabetic neuropathy reported no difference in depression using the Hospital Anxiety and Depression-D [HADS-D] scale (0 to 10, MD $-0.4,95 \%$ CI -1.26 to 1.46 ), but statistically significantly improved anxiety (HADS-A, 0 to 10 scale, MD $-2.9,95 \% \mathrm{CI}-3.80$ to -2.0) with nabilone after five weeks. ${ }^{55}$ Quality of life findings were mixed, with a statistically nonsignificant difference between groups using the EQ-5D Utility scores (endpoint scores 72.6 vs. 61.4) and a statistically significant difference using the EQ-5D Index scores (endpoint scores 0.74 vs. $0.60, \mathrm{p}<0.05$ using analysis of covariance [ANCOVA]). A small, moderate risk of bias study $(n=40)$ of patients with fibromyalgia evaluated secondary outcomes using the Fibromyalgia Impact Questionnaire (FIQ). The overall FIQ score improved more at four weeks with nabilone than with placebo (MD -12.07, $\mathrm{p}<0.02$ ). Using the anxiety questions on the FIQ, anxiety was significantly improved in the nabilone group after 4 weeks (FIQ anxiety questions, 0 to 10 scale, $\mathrm{MD}-2.2, \mathrm{p}<0.01) .{ }^{54}$ Depression was not significantly improved using the FIQ. The 
three RCTs that allowed opioid use during the study period did not report on the effect of the study medications on opioid use..$^{50,53,54}$

Adverse events were poorly reported. The most commonly reported was WAEs. Pooled analysis of WAEs in four trials showed a statistically nonsignificant increase with synthetic THC ( $13 \%$ vs. 9\%, RR 1.72, 95\% CI 0.90 to $4.13, \mathrm{I}^{2}=0 \%$, Appendix D, Figure D-10). Of these four studies, two were of nabilone and two of dronabinol; there was no apparent difference in the direction or magnitude of effect between the drugs, with no heterogeneity found in the metaanalysis $\left(\mathrm{I}^{2}=0 \%\right)$. Pooled analysis of two RCTs reporting any adverse event ( 1 nabilone, 1 dronabinol) found a nonsignificant increase with synthetic THC (2 RCTs, 86\% vs. 71\%, RR $1.20,95 \%$ CI 0.96 to $1.48, \mathrm{I}^{2}=0 \%$, Appendix D, Figure D-11). ${ }^{53,55}$ A single study reported SAEs and found a non-statistically significant increased risk with dronabinol $(\mathrm{n}=240,10 \% \mathrm{vs} .6 \%$, RR $1.60,95 \%$ CI 0.65 to 3.93$).^{53}$

Specific adverse events of interest were reported more often in the synthetic THC groups, reaching statistically significant differences with dizziness (2 dronabinol RCTs, 32\% vs. 11\%, RR 2.74, 95\% CI 1.47 to $6.86, \mathrm{I}^{2}=0 \%$, Appendix D, Figure D-12) (9,53 $^{4}$ and sedation (3 RCTs, 1 nabilone, 2 dronabinol, $19 \%$ vs. $10 \%$, RR 1.73, 95\% CI 1.03 to 4.63, $\mathrm{I}^{2}=0 \%$, Appendix D, Figure D-13). ${ }^{49,53,54}$ There were too few studies to conduct subgroup analyses, but the study of nabilone $(n=33)$ had a greater magnitude of effect (RR 8.40,95\% CI, 1.16 to 60.84) than either dronabinol study ( $\mathrm{n}=240$, RR $1.87,95 \%$ CI 0.66 to 5.31 ; $n=62$, RR $1.45,95 \%$ CI, 0.80 to 2.64 ). Nausea was also reported more often with synthetic THC (dronabinol), but the difference was not statistically significant ( 2 RCTs, $12 \%$ vs. $6 \%$, RR 2.19 , 95\% CI 0.77 to $5.39, \mathrm{I}^{2}=0 \%$, Appendix D, Figure D14). ${ }^{49,53}$

\section{Active-Control Studies of Synthetic THC}

Three crossover design trials ${ }^{50-52}$ and one observational study, ${ }^{61}$ compared a synthetic cannabinoid with active-controls. One high risk of bias trial used diphenhydramine as the control (47 weeks), ${ }^{52}$ another low risk of bias trial used ibuprofen ( 8 weeks), ${ }^{51}$ and the third moderate risk of bias trial used dihydrocodeine ( 6 weeks). ${ }^{50}$ None of the crossover trials reported pain response ( $\geq 30 \%$ reduction in pain from baseline). In a 6-week RCT of patients with neuropathic pain ( $\mathrm{n}=96$ randomized, 73 analyzed) comparing nabilone versus dihydrocodeine (30 to $240 \mathrm{mg}$ per day), dihydrocodeine resulted in greater reduction in pain severity (VAS 0 to 100 scale; MD $-5.7,95 \% \mathrm{CI}-10.9$ to $-0.5, \mathrm{p}=0.03) .{ }^{50}$ There were no statistically significant differences in secondary outcome measures (depression, anxiety, quality of life, or sleep). While the study indicated patients could continue to use other drugs for pain, it was not clear what those were or if new drugs (including other opioids) were started outside of the protocol.

A low risk of bias RCT of nabilone and ibuprofen ( $400 \mathrm{mg}$ per day) in patients with medication overuse headache $(n=60)$ found that after 8 weeks of treatment, there was not a significant difference in pain severity between treatments. ${ }^{51}$ There were no statistically significant differences in secondary outcomes measured (depression, anxiety, and quality of life). There were no differences in rates of any adverse events or WAEs (SAEs were not reported). Analgesic intake and dependence for headache control were measured at baseline and 2 weeks after the end of study, but the specific medications were not reported, except that the most common form of analgesic consisted of "combination medications." At two weeks post-study, treatment with nabilone resulted in lower daily analgesic intake than after ibuprofen (0.89/d vs. $1.34 / \mathrm{d} ; \mathrm{p}=0.03) .{ }^{51}$ Although overall rates were low, dizziness $(7.7 \%$ vs. $0 \%)$ and cognitive 
deficits $(3.8 \%$ vs. $0 \%)$ occurred more frequently when taking nabilone, while nausea $(3.8 \%$ vs. $7.7 \%$ ) and sedation ( $0 \%$ vs. $3.8 \%$ ) occurred more frequently with ibuprofen.

In the very small $(n=7)$, high risk of bias RCT comparing dronabinol with diphenhydramine in patients with spinal cord injury, pain intensity did not differ between treatments. ${ }^{52}$ No other outcomes were reported for efficacy. More patients withdrew from the study when assigned to nabilone ( 2 of 7 patients), and dry mouth, constipation, fatigue, and drowsiness were reported in similar numbers of patients for both groups.

A moderate risk of bias, prospective observational study of nabilone and gabapentin (or the combination, not reported here) among patients with mixed neuropathic pain found no difference in pain severity between groups at 3 months. At 6 months nabilone was associated with a greater reduction in pain intensity ( 0 to $100 \mathrm{VAS}, \mathrm{MD}-5.8,95 \% \mathrm{CI}-10.18$ to -1.42$)$, and better sleep scores on the Medical Outcomes Study Sleep Scale (scale 0 to 60, MD -3.1, 95\% CI -7.57 to 1.37 vs. gabapentin) than gabapentin. ${ }^{60}$ There were no differences in pain interference, quality of life, depression, or anxiety at 6 months. Overall adverse events were lower in the nabilone group (47\% vs. 35\%), and no SAEs were reported. WAEs were also lower in the nabilone group (10\% vs. $23 \%)$. More patients in the gabapentin group reported sedation $(60 \%)$ than in the nabilone group (35\%). Dizziness was reported in similar proportions of patients in the groups (33\% vs. $39 \%)$.

\section{Plant-Based Extracted THC}

Two placebo-controlled RCTs $(\mathrm{N}=294)$ studied THC extracted from whole-plant cannabis, with different ratios of THC to CBD. ${ }^{47,48}$ A 12-week, moderate risk of bias RCT of 277 patients with pain due to MS studied a product described as an extract from Cannabis sativa L. using an extraction medium of ethanol 96 percent. The product contained $2.5 \mathrm{mg}$ of THC and CBD in the range of 0.8 to $1.8 \mathrm{mg}$ per soft gelatine capsule. ${ }^{48}$ Dosing was THC $2.5 \mathrm{mg}$ twice daily titrated to a maximum daily dose of $25 \mathrm{mg} /$ day or placebo (mean not reported). More than half of patients enrolled were using an analgesic at baseline, but the type or whether they could continue use during the trial was not reported; patients using cannabis within 30 days of study enrollment were excluded. ${ }^{48}$ An 8-week, low risk of bias RCT of 17 patients with fibromyalgia studied lowdose, sublingual THC oil. ${ }^{47}$ The product contained $24.44 \mathrm{mg} / \mathrm{mL}$ of THC and $0.51 \mathrm{mg} / \mathrm{mL}$ of CBD; a 48 to $1 \mathrm{THC}$ to $\mathrm{CBD}$ ratio, and small quantities of other cannabinoids, but the extraction process was not described. Dosing was described as starting with THC $1.2 \mathrm{mg} / \mathrm{CBD} 0.02 \mathrm{mg}$ oil per dropper-full (a 60 to 1 ratio) given as a single daily dose. The mean daily dose was $4.4 \mathrm{mg}$ $\mathrm{THC} / 0.08 \mathrm{mg} \mathrm{CBD}$ in the active treatment group. The dose of CBD in this preparation was described as so low as to not contribute meaningfully to outcomes. Twenty five percent of patients had used an opioid prior to the study, but did not report on opioid use during the trial.

In pooled analysis, pain severity was improved with the extracted THC products, but the difference was not statistically significant (2 RCTs, 0 to 10 scale, MD $-1.97,95 \% \mathrm{CI}-5.91$ to $1.21, \mathrm{I}^{2}=66 \%$; Figure 4 ). There was a high degree of heterogeneity in this combined estimate, likely due to multiple differences between the studies, including sample size, dose, duration, and specific pain condition (fibromyalgia vs. multiple sclerosis), resulting in a large difference in the magnitude of effect across the two studies. Individually, each study found a statistically significant reduction in pain severity. The 8-week, low-dose THC oil study of 17 women with fibromyalgia reported a larger effect (MD $-3.92,95 \% \mathrm{CI}-5.98$ to -1.86$)^{47,48}$ on pain than the larger $(n=277) 12$-week study of a much higher dose of extracted cannabis (MD $-0.90,95 \% \mathrm{CI}$ -1.49 to -0.31$).{ }^{47,48}$ Pain response was not reported. 
In patients with fibromyalgia, physical functioning was not improved (1 RCT, FIQ subscale 0 to $10, \mathrm{MD} 1.75,95 \% \mathrm{CI}-0.46$ to 3.98 ) compared with placebo. ${ }^{47}$ Quality of life was improved with extracted THC (1 RCT, FIQ scale 0 to 100 scale, MD 36.0, $p=0.005$ ). ${ }^{47}$ These analyses did not adjust for potentially important differences in baseline scores between groups. Differences in depression and anxiety were not found between groups.

In patients with MS there was a higher risk of WAEs, (1 RCT, 13.9\% vs. 5.7\%, RR 3.12, 95\% CI 1.54 to 6.33 ), and dizziness (1 RCT, 62.2\% vs. 7.5\%, RR 8.34, 95\% CI 4.53 to 15.34 ) with extracted THC compared with placebo. ${ }^{48}$ An increased risk of SAEs was also found, but the difference did not reach statistical significance (1 RCT, $4.9 \%$ vs. $2.2 \%$, RR $2.19,95 \%$ CI 0.58 to 8.28). In patients with fibromyalgia, there was a large increased risk of somnolence with extracted THC (1 RCT, 88\% vs $11 \%$, RR 7.9, 95\% CI 1.2 to 50.9$).{ }^{47}$ No other adverse events of interest were reported by either study.

\section{Combined Analysis of Synthetic THC and Plant-Based Extracted THC Products}

To evaluate whether there was an effect for any form of high-THC product (synthetic or extracted), we combined results from all studies of high-THC to CBD ratio interventions (Figure 4). The overall combined mean difference is -1.25 (95\% CI -2.09 to $\left.-0.71, \mathrm{I}^{2}=50 \%\right)$. Although there is substantial statistical heterogeneity in the overall pooled estimate, subgroup analysis of synthetic versus plant-extracted forms of high-THC (Appendix D, Table D-7) did not find statistically significant differences in estimates of effect $(p=0.42)$. This analysis allowed evaluation of publication (small-study size) bias ( $\geq 8$ studies). Both the funnel plot and the Egger test indicated potential bias, with smaller studies with small effect sizes missing (Appendix I, Figure I-1).

Figure 4. Change in pain severity with high-THC ratio versus placebo (short term, 4 weeks to 6 months followup)

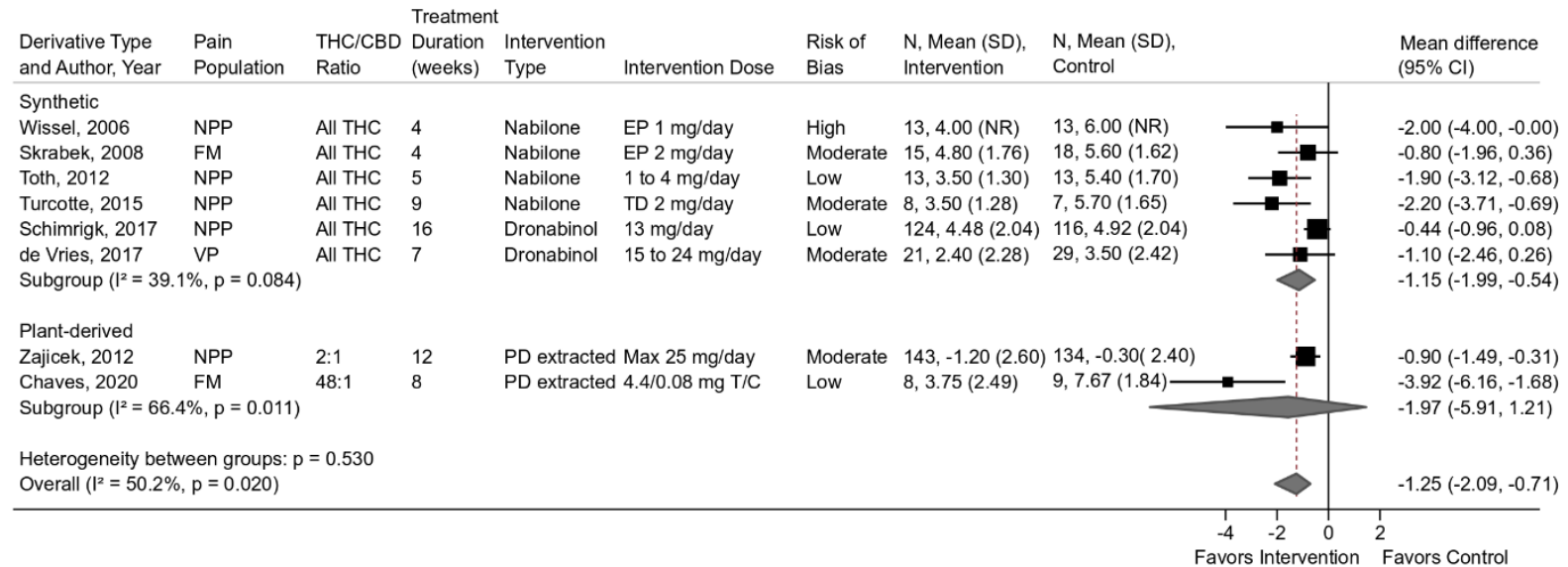

Abbreviations: $\mathrm{CBD}=$ cannabidiol; $\mathrm{CI}=$ confidence interval; $\mathrm{FM}=$ fibromyalgia; $\mathrm{NPP}=$ neuropathic pain; $\mathrm{SD}=\mathrm{standard}$ deviation; $\mathrm{THC}=$ tetrahydrocannabinol; $\mathrm{VP}=$ visceral pain; $\mathrm{WP}=$ whole plant.

\section{Key Points for Low-THC to CBD Ratio and Other Cannabinoids}

- In the short-term, low-THC to CBD ratio (CBD topical cream) had insufficient evidence to draw conclusions ( $1 \mathrm{RCT}, \mathrm{N}=29$ ) 
- In the short-term, evidence on cannabinoids other than THC and CBD was insufficient to draw conclusions ( $1 \mathrm{RCT}, \mathrm{N}=31)$

\section{Summary of Findings for Low-THC to CBD Ratio}

A single, small $(\mathrm{n}=29)$, high risk of bias RCT of topical CBD oil in patients with neuropathic pain (mean age 68 years, 38\% female) was included. ${ }^{58}$ Patients were randomized to four weeks of CBD cream $(250 \mathrm{mg} / 3 \mathrm{oz})$ applied to symptomatic areas up to 4 times daily or placebo; the total daily dose received was not reported.

Improvement in pain intensity was statistically significantly greater in the CBD group versus the placebo group ( -1.34 vs. $-0.59, \mathrm{p}=0.009$ by ANCOVA). It was not clear if the analysis also included a crossover extension phase wherein patients initially randomized to placebo were given CBD. A planned analysis taking baseline score into account was not reported. This study did not report pain response, pain interference, overall function/disability, or secondary outcomes. No adverse events were reported.

\section{Other Cannabinoids}

A small ( $\mathrm{n}=31$ ), moderate risk of bias trial of oral CBDV (described as "a novel phytocannabinoid derived from the Cannabis sativa L. plant") was included ${ }^{59}$ Patients with HIV-related chronic pain (mean age 50 years, $3 \%$ female) were randomized to oral CBDV oil $(50 \mathrm{mg} / \mathrm{ml})$ dosed at $8 \mathrm{ml}$ daily ( $400 \mathrm{mg}$ CBDV) or placebo oil for 4 weeks, then crossed over after a 21-day washout.

Using the numerical rating scale (NRS)

pain scale (10-point scale), statistically significantly fewer patients achieved response $(\geq 30 \%$ pain reduction) with CBDV compared with placebo ( $38 \%$ vs. $81 \%$, RR $0.46,95 \%$ CI 0.24 to $0.91)$. There was no difference between CBDV and placebo in the change in pain severity from baseline (MD $0.62,95 \%$ CI -0.05 to 1.32 ). Secondary outcomes of anxiety, depression, and insomnia also did not differ statistically between the groups. Although more patients reported any adverse event while using CBDV than placebo (91\% vs. 79\%), the difference was not statistically significant $(\mathrm{p}=0.28)$. Other adverse event outcomes occurred slightly more often in the CBDV groups than placebo (WAEs, 1 vs. 0 ; SAEs, 1 vs. 0; diarrhea, 3 vs. 0; dry mouth, 3 vs. $0)$.

\section{Key Points for Whole-Plant Cannabis and Mixed (Patient-Choice) Cannabis Products}

- There was insufficient evidence to draw conclusions about the effectiveness and harms of whole-plant cannabis products or patient-choice cannabis products in treating chronic pain.

\section{Summary of Findings for Whole-Plant Cannabis and Mixed (Patient-Choice) Cannabis Products}

Six observational studies $(\mathrm{N}=12,939)$ reported on the effects of cannabis, with five (3 high, 2 moderate risk of bias) studies evaluating medical cannabis programs, ${ }^{62-64}$ or self-reported use of cannabis, ${ }^{65,66}$ and one moderate risk of bias study evaluating a specific whole-plant cannabis product. ${ }^{61}$ Patient characteristics are summarized across studies in Table 5. The type of pain was 
not well reported. Mean age was 53 years, and 55 percent were female. Baseline pain was 5.35 (95\% CI 4.56 to 8.00$)$ on a 0 to 10 scale. One study evaluated outcomes at 3 months (short duration), ${ }^{64}$ and the other five were long duration (1 to 4 years observation) ${ }^{61-63,65,66}$ The three studies of medical cannabis programs allowed patients to self-select the cannabis products they used and compared them with patients who chose not to enroll in the programs (assumed to be no cannabis use). ${ }^{61-63}$ Two of the studies are retrospective analyses of larger prospective cohort studies of patients with chronic pain taking opioids, ${ }^{65,66}$ based on patient self-report of cannabis use, but specific products used were not reported. In the study of a whole-plant cannabis product, the cannabis group received herbal cannabis containing 12.5 percent $(+/-1.5 \%)$ THC. ${ }^{61}$ Total daily doses received were reported in two studies with one reporting $93 \mathrm{mg}$ of THC per week (mean) in a medical cannabis program, ${ }^{64}$ and the other reporting 2.5 grams per day of a wholepant cannabis product (dose confirmed with study authors). ${ }^{61}$

Two studies reported on primary pain or function outcomes. A high risk of bias study assessing a medical cannabis program study $(n=46)$ found nonstatistically significant differences between groups on measures of pain severity, pain-related disability, quality of life, depression, anxiety, and sleep. ${ }^{64}$ A moderate risk of bias study of opioid users also reported no statistically significant differences on pain or pain interference outcomes between frequent cannabis users (daily or near-daily) ${ }^{65}$ and non-users over 4 years of followup. Because the number of patients enrolled changed from year to year along with their cannabis use status, these analyses were conducted based on use in the prior 12 months.

A high risk of bias cohort study $(n=431)$ of a whole-plant cannabis product with 12.5 percent THC (amount of CBD not reported) with 52 weeks of followup reported on adverse events. ${ }^{61}$ Patients for whom standard treatments were not effective were enrolled, with patients already using cannabis for pain preferentially enrolled in the treatment group. The median dose was 2.5 gm of herbal cannabis per day (confirmed with study authors as amount dispensed). While the overall percentage of patients reporting any adverse event or serious adverse events was greater than in other studies, differences were not statistically different between groups. Dizziness was also not reported more often in the cannabis group. Both nausea $(16.7 \%$ vs. 9.7\%, RR 1.72, 95\% CI 1.04 to 2.85$)$ and sedation ( $13.5 \%$ vs. $4.6 \%$, RR $2.91,95 \%$ CI 1.46 to 5.83$)$ were reported significantly more frequently in the cannabis group. Study withdrawal due to adverse events was poorly reported for the usual care group and occurred in 4.7 percent of those using cannabis.

Four observational studies reported on the association between cannabis use and opioid use for chronic pain. ${ }^{62,63,65,66}$ The studies used different methods and reported outcomes differently, with no consistent direction of effect across the studies. A large, moderate risk of bias, retrospective cohort study $(\mathrm{n}=10,746)$ with propensity matching found a nonstatistically significant decrease in weekly oral morphine equivalent (OME) doses in the cannabis group (-183.2 OME, 95\% CI -449.8 to 83.3). Preplanned subgroup analyses found that patients taking lower initial doses of opioids ( $<50 \mathrm{OME} /$ week) increased opioid use after medical cannabis authorization, while those using higher doses at baseline ( $>100 \mathrm{OME} /$ week) had a decrease $(-435.5,95 \%$ CI -596.8 to -274.2$)$. Discontinuation of prescription opioids was found to be less likely in the cannabis group versus the control group (49.3\% vs. $72.3 \%$, adjusted odds ratio [OR] $0.38,95 \%$ CI 0.34 to 0.41 ).

In a moderate risk of bias study $(n=1,514$ at baseline, 1,217 at year 4$)$ of opioid users with chronic pain, a statistically nonsignificant difference in OME use at one year was found between patients reporting daily or near daily cannabis use (type and dose reported) and those reporting no use. ${ }^{65}$ The analysis used a lagged mixed-effects linear regression model, identifying cannabis 
use in the prior year and opioid use in the current year across four possible years of study enrollment. The adjusted mean daily OMEs were 97.1 in frequent cannabis users and 85.5 in non-users (difference $32.76 \mathrm{mg} /$ day, $95 \% \mathrm{CI},-25.04$ to 90.57 ).

A high risk of bias, 52-week, prospective cohort study of patients with HIV-related chronic pain $(n=433)$ evaluated the effect of cannabis use. ${ }^{66}$ At baseline 47 percent were using an opioid for chronic pain. Among daily or near daily cannabis users also using opioids, the adjusted OR for discontinuing opioids was 1.67 (95\% CI 0.52 to 5.37). Among daily or near daily cannabis users not using opioids at baseline, the adjusted OR for initiating an opioid was 2.29 (95\% CI 0.86 to 6.16$)$. Impact on morphine equivalents were not reported.

In a small $(n=66)$, high risk of bias, retrospective cohort of patients in a medical cannabis program for low back pain, compared with a group who declined to participate, those in the cannabis program were more likely to reduce their daily opioid dose than the control group (83.8\% vs. $44.8 \%$, OR 5.12, 95\% CI 1.56 to 16.88$).{ }^{63}$ The reduction in dose was small, but statistically significant (MD $-0.64 \mathrm{mg}$ intravenous morphine equivalent, $95 \% \mathrm{CI}-1.10$ to -0.18 from starting mean doses in the two groups of $24.4 \mathrm{mg}$ vs. $16.2 \mathrm{mg}$ ).

\section{$\mathrm{KQ} 3$ and KQ 4. In adults with chronic pain, what are the benefits (KQ 3) and harms (KQ 4) of kratom or other plant-based substances for treatment of chronic pain?}

\section{Key Points}

- No studies of kratom or other plant-based substances with properties similar to cannabis were found.

\section{Summary of Findings}

No evidence was found for kratom or other plant-based substances. 


\section{Discussion}

\section{Findings in Relation to the Decisional Dilemma(s)}

The key decisional dilemmas for treating chronic pain with plant-based compounds include their effectiveness and safety in treating chronic pain and the effect of route of administration, formulation, dose or potency of products, types of pain, and other patient characteristics on outcomes, including harms. Important harms include typical adverse effects such as dizziness, sedation and nausea, but may also include more serious risks, such as cannabis use disorder (CUD), psychosis, and cognitive impairment. Potential benefits and harms must be considered in the context of frequent, possibly daily, long-term use.

The findings are applicable to the short-term treatment ( 1 to $<6$ months), in patients with chronic pain (mainly neuropathic pain) compared with placebo. Change in pain severity was reported across all studies, but other pain-related and overall functional outcomes (including pain interference) were reported sporadically.

Comparable tetrahydrocannabinol (THC) to cannabidiol (CBD) ratio oromucosal spray is probably associated with small improvements in pain severity (strength of evidence [SOE]: moderate) and overall functioning (SOE: low) in the short-term. Combined THC/CBD may also be associated with a moderate to large increased risk of dizziness, sedation and nausea, with no effect on serious adverse events. There was a small increase in the proportion of patients with at least 30 percent improvement in pain (pain response); while the SOE was low, the finding was not statistically significant due to inadequate sample size (imprecision). For secondary outcomes, sleep quality was improved in the treatment groups, and quality of life was not different between groups.

Synthetic oral THC (which had high-THC to CBD ratios) may be associated with moderate improvement in pain severity and no effect on overall function (SOE: low). They are probably associated with a large increase in risk of dizziness (SOE: moderate) and may be associated with large increased risk of nausea and moderate increased risk of sedation (SOE: low). There was a moderate increase in the proportion of patients that withdrew from studies due to adverse events; the SOE was low, but the finding was not statistically significant due to inadequate sample size (imprecision). For secondary outcomes, evidence was very limited with no clear effect on quality of life or depression, and inconsistent results for anxiety and global disease improvement for patients with fibromyalgia treated with synthetic high-THC to CBD ratio products.

Extracted whole-plant high-THC to $\mathrm{CBD}$ ratio products may be associated with large increases in risk of study withdrawal due to adverse events and dizziness (SOE: low). For secondary outcomes, a single study found no difference between groups in depression or anxiety. Combining the evidence for all high-THC to $\mathrm{CBD}$ ratio products resulted in a moderate improvement in pain severity, with a low SOE.

Evidence on whole-plant cannabis, mixed forms of cannabis (patient-choice), low-THC to CBD ratio products (topical CBD), other cannabinoids (cannabidivarin [CBDV]), and comparisons with other active interventions were insufficient to draw conclusions. Similarly, evidence for other outcomes reported for comparable THC to CBD and high-THC to CBD ratio products was insufficient. See Appendix G for details.

Other adverse events (psychosis, CUD, cognitive deficits) and secondary outcomes were not reported for any product.

While there are no applicable clinical practice guidelines with which to compare these results, there have been multiple systematic reviews conducted on the use of cannabinoids to 
treat chronic pain, including a 2015 publication in the Journal of the American Medical Association, a 2018 Cochrane review, and a 2017 Veteran's Affairs Evidence Synthesis Program review. ${ }^{16,67-69}$ These high-quality reviews found generally similar results as this review indicating some benefit in pain outcomes, primarily for short-term treatment in patients with neuropathic pain. These prior reviews combined all forms of cannabinoids in meta-analyses, hence our review has more stratified results based on the THC to CBD ratio, leading to a higher strength of evidence rating in some cases. ${ }^{16}$ Although these were high-quality reviews, they are not current and may be missing newer evidence. An additional four unrelated systematic reviews examining utility of cannabis for chronic pain were published in 2020; overall, these findings are also consistent with the present systematic review results. ${ }^{70-73}$ One of the reviews conducted metaregression, finding that the impact on pain was similar between neuropathic and non-neuropathic pain populations $\mathrm{s}^{72}$ and that pain reduction was of a small magnitude and similar across formulations (inhaled, oral, oromucosal spray).

Our review did not identify eligible evidence on kratom to treat chronic pain. Two recent reviews of kratom provided limited information, and are based on noncomparative data or pharmacological data. One evaluated surveys, cross-sectional studies, and poison-control center studies on the use of kratom; the other is a nonsystematic review covering pharmacology, pharmacokinetics, prevalence and type of usage, and harms evidence. ${ }^{23,24}$ Both found that patients report using kratom as a substitute for opioids apparently as a treatment for selfdiagnosed opioid addiction or dependence in Thailand and Malaysia. They reported growing use in the United States for chronic pain and for recreational purposes. They also suggested that kratom may have addictive properties itself with symptoms of physiological withdrawal being common. Nonserious adverse effects include hyperpigmentation of the skin, constipation, weight loss, insomnia, xerostomia, and loss of libido. Poison control center data indicated an increase in calls involving kratom over the past five years with multi-substance exposures involving kratom associated with a statistically significant increase in a serious medical event. In cases where kratom was the only substance involved $(\mathrm{N}=1,174)$, symptoms included agitation or irritability $(23 \%)$, tachycardia $(21 \%)$, nausea $(15 \%)$, drowsiness/lethargy $(14 \%)$, vomiting $(13.2 \%)$, confusion (11\%), hypertension $(10 \%)$, and seizures $(10 \%) .^{24}$

Tables 6 and 7 provide a summary of the evidence for primary outcomes and harms related to cannabis interventions. Additional details on the SOE for these outcomes are located in Appendix G.

Table 6. Key Question 1: Benefits of cannabinoids for chronic pain compared with placebo in the short term (4 weeks to $<6$ months)

\begin{tabular}{|c|c|c|c|}
\hline THC to CBD Ratio & $\begin{array}{l}\text { Pain Response } \\
\text { Effect Size (N Studies) } \\
\text { [SOE] }^{\mathrm{a}}\end{array}$ & $\begin{array}{l}\text { Pain Severity } \\
\text { Effect Size (N Studies) } \\
\text { [SOE] }^{\mathrm{a}}\end{array}$ & $\begin{array}{l}\text { Overall Function } \\
\text { Effect Size (N } \\
\text { Studies) } \\
\text { [SOE] }^{\mathrm{a}}\end{array}$ \\
\hline $\begin{array}{l}\text { Comparable THC/CBD } \\
\text { Oromucosal Spray }\end{array}$ & $\begin{array}{c}\text { Potential effect }(4)^{\mathrm{b}} \\
{[+]}\end{array}$ & $\begin{array}{c}\text { Small effect (7) } \\
{[++]}\end{array}$ & $\begin{array}{c}\text { Small effect (6) } \\
{[++]}\end{array}$ \\
\hline High-THC - Synthetic, Oral & Insufficient (1) & $\begin{array}{c}\text { Moderate effect (5) } \\
{[+]}\end{array}$ & $\begin{array}{l}\text { No effect (3) } \\
{[+]}\end{array}$ \\
\hline $\begin{array}{l}\text { High-THC - Extracted From } \\
\text { Whole-plant, Oral }\end{array}$ & No evidence & Insufficient (2) & Insufficient (1) \\
\hline Low-THC - Topical CBD & No evidence & Insufficient (1) & No evidence \\
\hline $\begin{array}{l}\text { Other Cannabinoids - CBDV, } \\
\text { Oral }\end{array}$ & Insufficient (1) & Insufficient (1) & No evidence \\
\hline
\end{tabular}




\begin{tabular}{|l|l|l|c|}
\hline & $\begin{array}{l}\text { Pain Response } \\
\text { Effect Size (N Studies) } \\
\text { [SOE] }\end{array}$ & $\begin{array}{l}\text { Pain Severity } \\
\text { Effect Size (N Studies) } \\
\text { [SOE] }]^{\mathrm{a}}\end{array}$ & $\begin{array}{l}\text { Overall Function } \\
\text { Effect Size (N } \\
\text { Studies) } \\
\text { [SOE] }^{\mathrm{a}}\end{array}$ \\
\hline $\begin{array}{l}\text { Whole CBD Ratio } \\
\text { THC) }\end{array}$ & No evidence & Insufficient (1) & No evidence \\
\hline
\end{tabular}

Abbreviations: $\mathrm{CBD}=$ cannabidiol; $\mathrm{CBDV}=$ cannabidivarin; $\mathrm{SOE}=$ strength of evidence; THC $=$ tetrahydrocannabinol.

${ }^{a}$ Effect size: none (i.e., no effect/no statistically significant effect), small, moderate, or large increased risk; SOE: $[+]=$ low, $[++]$

$=$ moderate, $[+++]=$ high.

${ }^{\mathrm{b}}$ Findings with small or larger magnitude of effect, not statistically significant; but with SOE rating of Low or higher (downgraded mainly for imprecision).

Table 7. Key Question 2: Harms of cannabinoids for chronic pain compared with placebo in the short term (4 weeks to $<6$ months)

\begin{tabular}{|c|c|c|c|c|c|}
\hline THC to CBD Ratio & $\begin{array}{l}\text { WAE } \\
\text { Effect Size (N } \\
\text { Studies) } \\
\text { [SOE] }^{\mathrm{a}}\end{array}$ & $\begin{array}{l}\text { SAE } \\
\text { Effect Size (N } \\
\text { Studies) } \\
\text { [SOE] }^{\mathrm{a}}\end{array}$ & $\begin{array}{l}\text { Dizziness } \\
\text { Effect Size (N } \\
\text { Studies) } \\
\text { [SOE] }^{\mathrm{a}}\end{array}$ & $\begin{array}{l}\text { Nausea } \\
\text { Effect Size (N } \\
\text { Studies) } \\
\text { [SOE] }^{\mathrm{a}}\end{array}$ & $\begin{array}{l}\text { Sedation } \\
\text { Effect Size (N } \\
\text { Studies) } \\
\text { [SOE] }^{\mathrm{a}}\end{array}$ \\
\hline $\begin{array}{l}\text { Comparable } \\
\text { THC/CBD } \\
\text { Oromucosal Spray }\end{array}$ & Insufficient (5) & $\begin{array}{c}\text { No effect (2) } \\
{[+]}\end{array}$ & $\begin{array}{l}\text { Large effect (6) } \\
\qquad[+]\end{array}$ & $\begin{array}{c}\text { Moderate effect } \\
(6) \\
{[+]}\end{array}$ & $\begin{array}{c}\text { Large effect } \\
(6) \\
{[+]} \\
\end{array}$ \\
\hline $\begin{array}{l}\text { High-THC - } \\
\text { Synthetic, Oral }\end{array}$ & $\begin{array}{c}\text { Potential } \\
\operatorname{effect}^{b}(4) \\
{[+]}\end{array}$ & Insufficient (1) & $\begin{array}{l}\text { Large effect (2) } \\
\qquad[++]\end{array}$ & $\begin{array}{c}\text { Potential effect }{ }^{b} \\
(2) \\
{[+]}\end{array}$ & $\begin{array}{c}\text { Moderate } \\
\text { effect (3) } \\
{[+]}\end{array}$ \\
\hline $\begin{array}{l}\text { High-THC - } \\
\text { Extracted From } \\
\text { Whole-plant, Oral }\end{array}$ & $\begin{array}{l}\text { Large effect (1) } \\
\qquad[+]\end{array}$ & Insufficient (1) & $\begin{array}{l}\text { Large effect (1) } \\
\qquad[+]\end{array}$ & No evidence & No evidence \\
\hline $\begin{array}{l}\text { Low-THC - Topical } \\
\text { CBD }\end{array}$ & No evidence & No evidence & No evidence & No evidence & No evidence \\
\hline $\begin{array}{l}\text { Other Cannabinoids } \\
\text { - CBDV, oral }\end{array}$ & Insufficient (1) & Insufficient (1) & No evidence & No evidence & No evidence \\
\hline $\begin{array}{l}\text { Whole Plant } \\
\text { Cannabis }(12 \% \\
\text { THC) }\end{array}$ & Insufficient (1) & Insufficient (1) & Insufficient (1) & Insufficient (1) & Insufficient (1) \\
\hline
\end{tabular}

Abbreviations: $\mathrm{CBD}=$ cannabidiol; $\mathrm{CBDV}=$ cannabidivarin; $\mathrm{SAE}=$ serious adverse event; $\mathrm{SOE}=$ strength of evidence; $\mathrm{THC}=$ tetrahydrocannabinol; WAE = withdrawal due to adverse event.

${ }^{a}$ Effect size: none (i.e., no effect/no statistically significant effect), small, moderate, or large increased risk; SOE: $[+]=$ low, $[++]$

$=$ moderate, $[+++]=$ high.

${ }^{\mathrm{b}}$ Findings with small or larger magnitude of effect, not statistically significant; but with SOE rating of Low or higher (downgraded mainly for imprecision).

\section{Strengths and Limitations}

The evidence base on cannabis and other plant-based treatments for chronic pain has multiple important limitations. Eighty percent of trials enrolled patients with chronic pain due to a neuropathic cause ( 7 in patients with multiple sclerosis, 4 with a mix of conditions or not specified, 2 with diabetic neuropathy, and 1 each with chemotherapy, HIV, or spinal cord injury). There is little or no evidence on other types of chronic pain, including low back pain, osteoarthritis, fibromyalgia, and inflammatory arthritis. In terms of age, there is limited evidence on younger and older populations, with most patients being middle-aged (mean age 52 years). Studies generally excluded patients with a history of psychiatric disorders other than prior history of depression or anxiety. Importantly, there was either no evidence or inadequate evidence to evaluate important patient populations based on sex/gender, race/ethnicity, age, or pregnancy/lactating status.

Another limitation is the lack of consistent nomenclature detailing the interventions and products studied. For example, products are described as extracted in some studies, but without a 
consistent way of describing the process or the resulting purity of the products. Other studies used words such as "standardized" to describe the amount of THC in a whole-plant cannabis product, again with lack of description of how this was defined or determined. Studies did not consistently report the ratio of THC to CBD in the products, particularly outside of the products that are close to a 1 to 1 ratio (oromucosal spray, Sativex). Other limitations include the complete lack of evidence on other plant-based compounds like kratom, no randomized controlled trial (RCT) evidence on whole-plant cannabis products, and only a single, small study each for topical CBD or cannabinoids other than THC or CBD.

Change in pain severity was the most commonly reported outcome. Other important outcomes were mainly not reported or inconsistently reported or defined. Pain response, defined as a 30 percent or greater improvement in pain, was reported in 5 of 23 studies $(22 \%) ; 6$ of 23 studies $(26 \%)$ reported specifically on pain interference, and 8 of $23(35 \%)$ reported measures of physical function or disability. The studies poorly reported baseline use of opioids for pain, and only one high risk of bias observational study reported the impact of cannabis interventions on changes to prescription opioid use. While almost all studies reported the number of patients who withdrew from studies due to adverse events, 30 percent did not report serious adverse events, and 65 percent did not report the overall adverse events, particularly by group. When serious adverse events were reported, studies either used a unique definition, or did not provide one. In reporting on specific adverse events, not all studies were clear about whether the events were the number of individuals with at least one event, or if a single patient could contribute to an event more than once. Other adverse events that have been reported in noncomparative observational studies and were prioritized for this review (development or exacerbation of psychosis, CUD, and cognitive deficits) were not reported.

Trials were limited by study design and small sample sizes (range 9 to 339; mean 89), particularly for assessing harms. The SOE of the findings was very commonly downgraded due to imprecise estimates as a result of too few patients enrolled (see Appendix G). There were also differences in some key baseline characteristics, including baseline pain scores, which were frequently not adjusted for in study analyses. Another methodologic concern is that many conclusions in the included studies were drawn from post-hoc analyses. Study durations were short-term and included less than 6 months followup; 37 percent of studies were 4 to 6 weeks long. This is a key limitation, as pain severity in patients with chronic pain may vary substantially in the short-term and may be influenced temporarily by an intervention or treatment; it is most useful to understand the enduring impact of a treatment on pain severity. Similarly, adverse events such as CUD, cognitive deficits, and serious adverse events may take time to develop and longer studies are required to capture such events. Well-designed head to head studies comparing a plant-based product with a standard of care treatment for chronic pain are lacking. The current evidence consists only of small, poorly designed, crossover or observational studies.

Despite limitations in the evidence base, our review has several strengths. First the living systematic review approach allows us to add new studies soon after they are published, thereby providing an opportunity to update conclusions in a rapid fashion. This may be important as cannabis and other plant-based treatments become more readily available to patients, providers and researchers. Also, using an organizational framework that categorizes cannabis-related products by both their THC and CBD ratios and their origin (plant-based versus synthetic) allows a way to conceptualize the evidence on these two prominent cannabinoids that is consistent with how they are available to consumers. A final strength that separates this review from others is the 
exclusion of very short-term studies (e.g., a small number of dosing sessions), improving the applicability of the findings to chronic pain.

There are also some limitations to our review process. We excluded non-English language publications and study results published only as abstracts. We categorized nabilone as a synthetic high-THC product though it is more accurately described as a synthetic cannabinoid - a chemical analog to THC, and could have differing effects to THC. To address this possibility, we performed stratified analyses among outcomes that were pooled for synthetic high-THC interventions. The effect size for change in pain severity was larger with nabilone than with dronabinol, but the difference between the effect sizes was not statistically significant. Our inclusion criteria required that the study population have chronic pain, or have subgroup analyses for this group, which may be why we did not find evidence related to kratom. We were unable to assess publication bias (small sample size bias) for most outcomes, as most meta-analyses included fewer than eight studies. The exception was the analysis of change in pain severity with high-THC interventions, where we were unable to rule out important publication bias. Additional studies are needed to clarify the effect size estimates and our confidence in the findings. Since this is a living systematic review, new evidence will be incorporated into the review and findings updated on a regular basis. As in other recent systematic reviews of interventions to treat chronic pain, we grouped the magnitude of effects into small, moderate and large effects, rather than according to published minimal clinically important difference (MCID) thresholds. Defining clinical significance in chronic pain is difficult because it is subjective and difficult to correlate with real-life experiences of patients. For example, the MCID for improvement in pain is 15 points on a 0 to 100 scale. However, interventions commonly used for chronic pain, including opioids and nonsteroidal anti-inflammatory drugs do not achieve this level of reduction. ${ }^{11,12}$ The typical reduction with opioids, nonopioid medications, nonpharmacological interventions, and cannabinoids is small, 5 to 10 points and may be considered a clinically important effect by patients and clinicians.

\section{Applicability}

A number of factors could impact the applicability of our findings. The evidence currently is most applicable to patients with neuropathic pain with mostly moderate to severe pain (mean baseline score was 6.6 on a 0 to 10 scale, with a range of 4 to 7.9 ). There is also considerable variability within the included studies among the types of neuropathic pain patients experience, and treatment effects might be different depending on the specific neuropathic pain condition.

The evidence base is generally applicable to women with around 71 percent of enrolled participants being female. While the age range across studies was broad, 18 to 84 years, the evidence is mainly applicable to middle-aged patients (mean age 50 years). Currently, the evidence is poorly applicable to patients of non-White race. It is also unclear how the evidence applies to patients currently taking prescription opioids to treat chronic pain or patients with serious mental illness or other comorbidities who are often excluded from trials. In terms of interventions, this evidence is applicable to comparable THC to CBD ratio oromucosal spray and to high-THC synthetic medications. The evidence for comparable THC to CBD oral spray is applicable to mean dosing of 8.4 sprays per day (21 mg THC/23 mg CBD). The evidence for high-THC to CBD ratio synthetic drugs applies to dosing that was titrated upward, with a maximum dose of 15 to $20 \mathrm{mg}$ per day of dronabinol and 0.5 to $2 \mathrm{mg}$ per day of nabilone (mean doses not reported). For high-THC to CBD products extracted from whole-plants, the evidence 
was too heterogeneous and limited (2 RCTs) to describe an applicable dose. Applicability to other products including whole plant cannabis is very low or non-existent.

This evidence applies to short-term treatment and mainly informs the impact on mean changes in pain severity and common adverse events. The outcomes after longer term treatment may be different and could influence other outcomes not considered in short-term studies included here (e.g. psychosis, CUD, cognitive deficits). None of the studies reported other information relevant for assessing applicability, such as the description of the source of potential study participants or the number of women randomized relative to the number of women enrolled.

Although 60 percent of studies were conducted in the United States, we were unable to assess the impact of country of study or other geographic location characteristics (e.g., rural, metropolitan) on the applicability of specific results.

A number of evidence gaps or limitations in the evidence potentially impacted the applicability of our findings including lack of evidence on extracted whole-plant or purified interventions, whole-plant cannabis, and kratom.

\section{Implications for Clinical Practice, Education, Research, or Health Policy}

The implications of the present findings for clinical practice are mixed. These results suggest that select individuals with chronic neuropathic pain may experience moderate short-term improvements in pain when using cannabis products (synthetic or extracted from whole-plant) that have a high-THC to CBD ratio. The impact of this intervention on moderate or long-term outcomes is unknown. Cannabis products with a comparable THC to CBD ratio may also result in small improvements in pain severity. Those who take products containing comparable or high ratios of $\mathrm{THC}$ are also at increased risk for adverse events, including dizziness, sedation and nausea. The expected benefit of this treatment is comparable to prescription opioids, several nonopioid medications, and nonpharmacological interventions. ${ }^{11-13}$ The evidence on adverse events with cannabis-related products is much less robust than the evidence on similar outcomes with opioids or nonopioid medications. The risk of sedation and dizziness appears similar with cannabis-related products, opioids, and the anticonvulsants pregabalin and gabapentin, while the risk for nausea appears to be larger with opioids and the antidepressant duloxetine than with cannabis-related products. These are only indirect comparisons, with very limited evidence on cannabis products relative to the other drugs, and comparisons of effects on serious and longterm harms are not possible even indirectly. Understanding how cannabis products' adverse event profiles compare with other available treatments for chronic pain, particularly opioid and non-opioid medications, is essential to determining the benefit to harm ratio. However, the strength of this evidence is mostly low, and more data are needed to confidently recommend this as a treatment for various chronic pain-related conditions or for patients with diverse demographic or clinical characteristics.

As noted in the limitations above, baseline use of opioids for pain and the impact of cannabinoids on the use of opioids for pain were very poorly reported. In an effort to address the opioid epidemic, a prominent goal of current research is to identify alternative treatments with equal or better benefits for pain while avoiding potential unintended consequences that could result in harms. Unfortunately, much of the findings to date are low SOE or insufficient evidence, and more high-quality studies are needed. 
Our synthesis of the evidence leads to several important additional questions that could be addressed most effectively in a clinical practice guideline. Examples of questions that could be best addressed through a guideline process include: At what point in the treatment decision tree should cannabis-based medicines be considered? How should patient preferences be taken into account? What are pragmatic dosing guidelines? And finally, what are the comparative effects on costs of care?

\section{Implications for Future Research}

The gaps in the research evidence that are outlined above lead to specific recommendations for conducting future studies that will improve the strength of the conclusions that can be drawn, and provide better guidance for policymakers, clinicians and patients alike. These are summarized in Table 8.

Table 8. Future research needs for cannabis and other plant-based treatments for chronic pain

\begin{tabular}{|c|c|c|}
\hline $\begin{array}{l}\text { PICOTS } \\
\text { Element }\end{array}$ & Gap in Evidence & Suggested Future Research \\
\hline Populations & $\begin{array}{l}\text { - Non-White } \\
\text { populations, older } \\
\text { adults, women } \\
\text { - Pain conditions other } \\
\text { than neuropathic } \\
\text { pain }\end{array}$ & $\begin{array}{l}\text { - Studies to assess possible differential effects in different races or } \\
\text { ethnicities } \\
\text { - Stratified analyses according to sex, including effects in pregnant } \\
\text { and lactating persons } \\
\text { - Studies to assess effects based on age differences } \\
\text { - Pain populations expanded to include persons with non-neuropathic } \\
\text { chronic pain, specifically back pain, other musculoskeletal pain, and } \\
\text { fibromyalgia }\end{array}$ \\
\hline Interventions & $\begin{array}{l}\text { - High THC to CBD } \\
\text { ratio from plant origin } \\
\text { (not synthetic) } \\
\text { - Comparable THC to } \\
\text { CBD ratio } \\
\text { formulations other } \\
\text { than oromucosal } \\
\text { spray } \\
\text { - Low THC to CBD } \\
\text { ratios, whole-plant } \\
\text { cannabis, and other } \\
\text { cannabinoids } \\
\text { - Kratom }\end{array}$ & $\begin{array}{l}\text { - Studies of high THC to CBD ratio products derived from whole-plant } \\
\text { cannabis, with clear description of extraction or purification process } \\
\text { and consistent nomenclature regarding the final product } \\
\text { - Studies to compare different routes of administration (e.g., } \\
\text { oromucosal spray, oral oil, oral capsule, smoked, etc.) } \\
\text { - Studies should include and compare standardized treatment plans } \\
\text { - Exploration of effects of different cannabinoids } \\
\text { - Studies to asses kratom and/or other plant-based treatments }\end{array}$ \\
\hline Comparators & $\begin{array}{l}\text { Head-to-head } \\
\text { comparisons }\end{array}$ & $\begin{array}{l}\text { - Studies comparing plant-based interventions with other plant-based } \\
\text { treatments, opioids, non-opioid medications, or nonpharmacological } \\
\text { interventions to evaluate active-control comparisons to provide } \\
\text { direct evidence on comparative effectiveness }\end{array}$ \\
\hline
\end{tabular}




\begin{tabular}{|c|c|c|}
\hline $\begin{array}{l}\text { PICOTS } \\
\text { Element }\end{array}$ & Gap in Evidence & Suggested Future Research \\
\hline Outcomes & $\begin{array}{l}\text { - Pain response } \\
\text { (>30\% improvement } \\
\text { in pain severity) } \\
\text { - Overall function, } \\
\text { quality of life } \\
\text { - Depression, anxiety, } \\
\text { sleep, opioid use } \\
\text { - Adverse event } \\
\text { outcomes }\end{array}$ & $\begin{array}{l}\text { - Outcomes should be consistently defined and reported across } \\
\text { studies; ideally a core set of outcomes should be developed for } \\
\text { future studies of treatments for chronic pain. } \\
\text { - Future studies should include pain response, measures of overall } \\
\text { function, and adverse events (overall, serious, and withdrawals due } \\
\text { to adverse events at a minimum), in addition to changes in pain } \\
\text { severity. } \\
\text { - Patient-centered and patient-reported outcomes (e.g., QOL, } \\
\text { depression, anxiety, and sleep) should be measured using validated } \\
\text { tools for diagnosis and measurement of change. } \\
\text { - In addition to reporting on opioid use prior to study enrollment, } \\
\text { future studies should report on use of opioids, and other pain } \\
\text { medications, during the trial. In particular, there is a need for more } \\
\text { information on possible opioid sparing effects of plant-based } \\
\text { treatments. } \\
\text { - Studies need to assess serious harms such as development of } \\
\text { cannabis use disorder, psychosis, and cognitive deficits. Other } \\
\text { adverse events (e.g. sexual dysfunction) may need to be studied as } \\
\text { new data emerge. }\end{array}$ \\
\hline Timing & $\begin{array}{l}\text { - Limited evidence on } \\
\text { studies }>6 \text { weeks in } \\
\text { duration }\end{array}$ & $\begin{array}{l}\text { - Considering the chronic nature of the conditions, studies should } \\
\text { provide followup assessments at longer timepoints, e.g., } \geq 3,6 \text { or } 12 \\
\text { months }\end{array}$ \\
\hline Study Design & $\begin{array}{l}\text { - RCTs and cohort } \\
\text { studies with } \\
\text { adequate sample } \\
\text { sizes to evaluate all } \\
\text { important outcomes } \\
\text { - Cohort studies with } \\
\text { adequate control for } \\
\text { confounding, } \\
\text { ascertainment of } \\
\text { exposures and } \\
\text { outcomes } \\
\text { - RCT and cohort } \\
\text { studies with low risk } \\
\text { of bias }\end{array}$ & $\begin{array}{l}\text { - All Designs: } \\
\text { Studies with larger sample sizes to adequately power statistical } \\
\text { analyses for key outcomes are needed across all interventions } \\
\text { except the synthetic medications } \\
\text { - Should be designed and powered a priori to conduct subgroup } \\
\text { analyses on important factors such as race, age, sex, and type } \\
\text { of product or dose where these are variable } \\
\text { - Cohort studies: } \\
\text { O Should be conducted prospectively where possible, and conduct } \\
\text { and report on ascertainment and validation of exposure and } \\
\text { outcomes following best-practice guidance } \\
\text { Should use appropriate methods to control for confounding on } \\
\text { prognostic factors (e.g., baseline pain, prior and continued use of } \\
\text { other interventions for pain, psychiatric illnesses) } \\
\text { - RCTs: } \\
\text { Should not use run-in periods, or enriched enrollment } \\
\text { randomized withdrawal designs that may overestimate effects } \\
\text { and limit the generalizability of the findings }{ }^{75} \\
\text { Should be conducted using the parallel design (not crossover) } \\
\text { Systematic Reviews } \\
\text { As more evidence emerges, analyses should stratify and } \\
\text { conduct subgroup analyses based on product specifics, pain } \\
\text { conditions, and population characteristics. }\end{array}$ \\
\hline
\end{tabular}

Abbreviations: $\mathrm{CBD}=$ cannabidiol; PICOTS = populations, interventions, comparators, outcomes, timing, and settings; RCT = randomized controlled trial; $\mathrm{THC}=$ tetrahydrocannabinol.

\section{Conclusions}

Only short-term evidence is available for cannabis-related interventions containing THC and/or CBD to treat primarily neuropathic chronic pain. Improvement in pain was small to moderate with high and comparable THC to CBD ratio products. Compared with placebo, these interventions resulted in greater risk of common adverse events (dizziness, nausea, sedation) and study withdrawal due to adverse events. Evidence for other interventions, including kratom, was insufficient or not found. Additional studies are needed to improve confidence in these findings 
and to provide evidence on longer-term followup, other outcomes, and other interventions including whole plant cannabis. 


\section{References}

1. Dowell D, Haegerich TM, Chou R. CDC

Guideline for Prescribing Opioids for

Chronic Pain- United States, 2016. Jama.

2016 Apr 19;315(15):1624-45. doi:

10.1001/jama.2016.1464. PMID: 26977696.

2. Dowell D, Haegerich TM, Chou R. CDC

Guideline for Prescribing Opioids for

Chronic Pain - United States, 2016. MMWR

Recomm Rep. 2016 Mar 18;65(1):1-49. doi:

10.15585/mmwr.rr6501e1. PMID:

26987082 .

3. Dahlhamer J LJ, Zelaya, C, et al. .

Prevalence of chronic pain and high-impact

chronic pain among adults - United States, 2016. MMWR Morb Mortal Wkly Rep

2018. doi: 10.15585/mmwr.mm6736a2.

4. Institute of Medicine Committee on Advancing Pain Research. Relieving Pain in America: A Blueprint for Transforming Prevention, Care, Education, and Research. Washington, DC: National Academies Press; National Academy of Sciences; 2011.

5. Ballantyne JC, Shin NS. Efficacy of opioids for chronic pain: a review of the evidence.

Clin J Pain. 2008 Jul-Aug;24(6):469-78. doi: 10.1097/AJP.0b013e31816b2f26. PMID: 18574357.

6. Eriksen J, Sjogren P, Bruera E, et al. Critical issues on opioids in chronic non-cancer pain: an epidemiological study. Pain. 2006

Nov;125(1-2):172-9. doi:

10.1016/j.pain.2006.06.009. PMID: 16842922 .

7. U.S. Centers for Disease Control and Prevention. Annual Surveillance Report of Drug-Related Risks and Outcomes--United States, 2017. Special Surveillance Special Report 1. Atlanta, GA: 2018. https://www.cdc.gov/drugoverdose/pdf/pubs 2017-cdc-drug-surveillance-report.pdf.

8. Vital signs: overdoses of prescription opioid pain relievers--United States, 1999-2008. MMWR Morb Mortal Wkly Rep. 2011;60(43):1487-92. PMID: 22048730.
9. Drug Abuse Warning Network. The DAWN Report: Highlights of the 2010 Drug Abuse Warning Network (DAWN) findings on drug-related emergency department visits. Rockville, MD: Substance Abuse and Mental Health Services Administration; Center for Behavioral Health Statistics and Quality; 2012.

https://www.samhsa.gov/data/sites/default/fi les/DAWN096/DAWN096/SR096EDHighli ghts2010.htm.

10. U.S. Department of Health and Human Services. HHS Acting Secretary Declares Public Health Emergency to Address National Opioid Crisis. HHS Press Office; 2017.

https://www.hhs.gov/about/news/2017/10/26 /hhs-acting-secretary-declares-public-healthemergency-address-national-opioidcrisis.html. Accessed Jul 302020.

11. Chou R, Hartung D, Turner J, et al. Opioid Treatments for Chronic Pain. Comparative Effectiveness Review No. 229. (Prepared by the Pacific Northwest Evidence-based Practice Center under Contract No. 2902015-00009-I.) AHRQ Publication No. 20EHC011. Rockville, MD: Agency for Healthcare Research and Quality; April 2020. PMID: 32338848.

12. McDonagh MS, Selph SS, Buckley DI, et al. Nonopioid Pharmacologic Treatments for Chronic Pain. Comparative Effectiveness Review No. 228. (Prepared by the Pacific Northwest Evidence-based Practice Center under Contract No. 290-2015-00009-I.) AHRQ Publication No. 20-EHC010. Rockville, MD: Agency for Healthcare Research and Quality; April 2020. PMID: 32338847.

13. Skelly AC, Chou R, Dettori JR, et al. Noninvasive Nonpharmacological Treatment for Chronic Pain: A Systematic Review Update. Comparative Effectiveness Review No. 227. (Prepared by the Pacific Northwest Evidence-based Practice Center under Contract No. 290-2015-00009-I.) AHRQ Publication No. 20-EHC009. Rockville, MD: Agency for Healthcare Research and Quality; April 2020. PMID: 32338846 . 
14. Stockings E, Campbell G, Hall WD, et al. Cannabis and cannabinoids for the treatment of people with chronic noncancer pain conditions: a systematic review and metaanalysis of controlled and observational studies. Pain. 2018 Oct;159(10):1932-54. doi:

https://dx.doi.org/10.1097/j.pain.000000000 0001293. PMID: 29847469.

15. Elikkottil J, Gupta P, Gupta K. The analgesic potential of cannabinoids. J Opioid Manag. 2009 Nov-Dec;5(6):341-57. PMID: 20073408.

16. Whiting PF, Wolff RF, Deshpande S, et al. Cannabinoids for Medical Use: A Systematic Review and Meta-analysis. Jama. 2015 Jun 23-30;313(24):2456-73. doi: https://dx.doi.org/10.1001/jama.2015.6358. PMID: 26103030.

17. Vučković S, Srebro D, Vujović KS, et al. Cannabinoids and Pain: New Insights From Old Molecules. Front Pharmacol.

2018;9:1259-. doi:

10.3389/fphar.2018.01259. PMID: 30542280 .

18. Morales P, Hurst DP, Reggio PH. Molecular Targets of the Phytocannabinoids: A Complex Picture. Prog Chem Org Nat Prod. 2017;103:103-31. doi: 10.1007/978-3-31945541-9_4. PMID: 28120232.

19. Boehnke KF, Litinas E, Clauw DJ. Medical Cannabis Use Is Associated With Decreased Opiate Medication Use in a Retrospective Cross-Sectional Survey of Patients With Chronic Pain. J Pain. 2016 06;17(6):739-44. doi:

https://dx.doi.org/10.1016/j.jpain.2016.03.00 2. PMID: 27001005.

20. Boehnke KF, Scott JR, Litinas E, et al. Pills to Pot: Observational Analyses of Cannabis Substitution Among Medical Cannabis Users With Chronic Pain. J Pain. 2019 07;20(7):830-41. doi: https://dx.doi.org/10.1016/j.jpain.2019.01.01 0. PMID: 30690169.

21. Piper BJ, DeKeuster RM, Beals ML, et al. Substitution of medical cannabis for pharmaceutical agents for pain, anxiety, and sleep. J Psychopharmacol. 2017 May;31(5):569-75. doi: 10.1177/0269881117699616. PMID: 28372506 .
22. Corroon JM, Jr., Mischley LK, Sexton M. Cannabis as a substitute for prescription drugs - a cross-sectional study. J Pain Res. 2017;10:989-98. doi: 10.2147/jpr.S134330. PMID: 28496355.

23. Swogger MT, Walsh Z. Kratom use and mental health: A systematic review. Drug Alcohol Depend. 2018 Feb 1;183:134-40. doi: 10.1016/j.drugalcdep.2017.10.012. PMID: 29248691.

24. White CM. Pharmacologic and clinical assessment of kratom: An update. Am J Health-Syst Pharm. 201911 13;76(23):1915-25. doi: https://dx.doi.org/10.1093/ajhp/zxz221. PMID: 31626272.

25. Risks of Adolescent Marijuana Use. U.S. Department of Health \& Human Services; Office of Population Affairs. https://www.hhs.gov/ash/oah/adolescentdevelopment/substanceuse/marijuana/risks/index.html. Accessed May 25, 2020.

26. Swetlitz I. HHS recommended that the DEA make kratom a Schedule I drug, like LSD or heroin. PBS; 2018.

https://www.pbs.org/newshour/nation/hhsrecommended-that-the-dea-make-kratom-aschedule-i-drug-like-lsd-or-heroin. Accessed Jul 142021.

27. Boehnke KF, Gangopadhyay S, Clauw DJ, et al. Qualifying Conditions Of Medical Cannabis License Holders In The United States. Health Aff (Millwood). 2019 02;38(2):295-302. doi: https://dx.doi.org/10.1377/hlthaff.2018.0526 6. PMID: 30715980 .

28. Jaeger K. Congressional Committee Slams Schedule I And Calls For Marijuana And Kratom Research. Marijuana Moment; 2019. https://www.marijuanamoment.net/congressi onal-committee-slams-schedule-i-and-callsfor-marijuana-and-kratom-research/. Accessed Jul 142021.

29. NIDA. Hearing on Cannabis Policies for the New Decade. 2020.

https://www.drugabuse.gov/aboutnida/legislative-activities/testimony-tocongress/2020/hearing-on-cannabis-policiesfor-the-new-decade. Accessed Jul 142021. 
30. Methods Guide for Effectiveness and Comparative Effectiveness Reviews. Rockville, MD: Agency for Healthcare Research and Quality; 2017. https://effectivehealthcare.ahrq.gov/topics/ce r-methods-guide/overview. Accessed June 1, 2019.

31. Chou R, Deyo R, Friedly J, et al. Noninvasive Treatments for Low Back Pain: Agency for Healthcare Research and Quality (US), Rockville (MD); 2016.

32. Skelly AC, Chou R, Dettori JR, et al. Noninvasive Nonpharmacological Treatment for Chronic Pain: A Systematic Review: Agency for Healthcare Research and Quality (US), Rockville (MD); 2018.

33. Morton SC, Murad MH, O’Connor E, et al. Quantitative Synthesis-An Update:

Agency for Healthcare Research and Quality (US), Rockville (MD); 2008.

34. Higgins JP, Thompson SG, Deeks JJ, et al. Measuring inconsistency in meta-analyses. BMJ. 2003 Sep 6;327(7414):557-60. doi: 10.1136/bmj.327.7414.557. PMID: 12958120 .

35. Hardy RJ, Thompson SG. A likelihood approach to meta-analysis with random effects. Stat Med. 1996 Mar 30;15(6):61929. doi: 10.1002/(sici)10970258(19960330)15:6<619::Aidsim188>3.0.Co;2-a. PMID: 8731004.

36. Berkman ND, Lohr KN, Ansari MT, et al. Grading the strength of a body of evidence when assessing health care interventions: an EPC update. J Clin Epidemiol. 2015

Nov;68(11):1312-24. doi: 10.1016/j.jclinepi.2014.11.023. PMID: 25721570 .

37. Gerrity M, Fiordalisi C, Pillay J, et al. Roadmap for Narratively Describing Effects of Interventions in Systematic Reviews. AHRQ Methods for Effective Health Care. 2020 PMID: 33180401.

38. Murad MH, Fiordalisi C, Pillay J, et al. Making Narrative Statements to Describe Treatment Effects. J Gen Intern Med. 2021 Jan;36(1):196-9. doi: 10.1007/s1 1606-02006330-y. PMID: 33111244.
39. Gerrity M, Fiordalisi C, Pillay J, et al. AHRQ Methods for Effective Health Care. Roadmap for Narratively Describing Effects of Interventions in Systematic Reviews. Rockville (MD): Agency for Healthcare Research and Quality (US); 2020.

40. Blake DR, Robson P, Ho M, et al. Preliminary assessment of the efficacy, tolerability and safety of a cannabis-based medicine (Sativex) in the treatment of pain caused by rheumatoid arthritis.

Rheumatology (Oxford). 2006 Jan;45(1):502. PMID: 16282192.

41. Langford RM, Mares J, Novotna A, et al. A double-blind, randomized, placebocontrolled, parallel-group study of $\mathrm{THC} / \mathrm{CBD}$ oromucosal spray in combination with the existing treatment regimen, in the relief of central neuropathic pain in patients with multiple sclerosis. J Neurol. 2013 Apr;260(4):984-97. doi: https://dx.doi.org/10.1007/s00415-0126739-4. PMID: 23180178.

42. Lynch ME, Cesar-Rittenberg P, Hohmann AG. A double-blind, placebo-controlled, crossover pilot trial with extension using an oral mucosal cannabinoid extract for treatment of chemotherapy-induced neuropathic pain. J Pain Symptom Manage. 2014 Jan;47(1):166-73. doi: https://dx.doi.org/10.1016/j.jpainsymman.20 13.02.018. PMID: 23742737.

43. Nurmikko TJ, Serpell MG, Hoggart B, et al. Sativex successfully treats neuropathic pain characterised by allodynia: a randomised, double-blind, placebo-controlled clinical trial. Pain. 2007 Dec 15;133(1-3):210-20. PMID: 17997224.

44. Rog DJ, Nurmikko TJ, Friede T, et al. Randomized, controlled trial of cannabisbased medicine in central pain in multiple sclerosis. Neurology. 2005 Sep 27;65(6):812-9. PMID: 16186518.

45. Selvarajah D, Gandhi R, Emery CJ, et al. Randomized placebo-controlled doubleblind clinical trial of cannabis-based medicinal product (Sativex) in painful diabetic neuropathy: depression is a major confounding factor. Diabetes Care. 2010 Jan;33(1):128-30. doi: 10.2337/dc09-1029. PMID: 19808912. 
46. Serpell M, Ratcliffe S, Hovorka J, et al. A double-blind, randomized, placebocontrolled, parallel group study of THC/CBD spray in peripheral neuropathic pain treatment. Eur J Pain. 2014 Aug;18(7):999-1012. doi: 10.1002/j.15322149.2013.00445.x. PMID: 24420962.

47. Chaves C, Bittencourt PCT, Pelegrini A. Ingestion of a THC-Rich Cannabis Oil in People with Fibromyalgia: A Randomized, Double-Blind, Placebo-Controlled Clinical Trial. Pain Med. 2020;21(10):2212-8. doi: https://dx.doi.org/10.1093/pm/pnaa303. PMID: 33118602.

48. Zajicek JP, Hobart JC, Slade A, et al. Multiple sclerosis and extract of cannabis: results of the MUSEC trial. J Neurol Neurosurg Psychiatry. 2012

Nov;83(11):1125-32. doi: https://dx.doi.org/10.1136/jnnp-2012302468. PMID: 22791906.

49. de Vries M, van Rijckevorsel DCM, Vissers $\mathrm{KCP}$, et al. Tetrahydrocannabinol Does Not Reduce Pain in Patients With Chronic Abdominal Pain in a Phase 2 Placebocontrolled Study. Clin Gastroenterol Hepatol. 2017 Jul;15(7):1079-86.e4. doi: https://dx.doi.org/10.1016/j.cgh.2016.09.147 . PMID: 27720917.

50. Frank B, Serpell MG, Hughes J, et al. Comparison of analgesic effects and patient tolerability of nabilone and dihydrocodeine for chronic neuropathic pain: randomised, crossover, double blind study. BMJ. 2008 Jan 26;336(7637):199-201. doi: https://dx.doi.org/10.1136/bmj.39429.61965 3.80. PMID: 18182416.

51. Pini LA, Guerzoni S, Cainazzo MM, et al. Nabilone for the treatment of medication overuse headache: results of a preliminary double-blind, active-controlled, randomized trial. J Headache Pain. 2012 Nov;13(8):67784. doi: https://dx.doi.org/10.1007/s10194012-0490-1. PMID: 23070400.

52. Rintala DH, Fiess RN, Tan G, et al. Effect of dronabinol on central neuropathic pain after spinal cord injury: a pilot study. Am J Phys Med Rehabil. 2010 Oct;89(10):840-8. doi:

https://dx.doi.org/10.1097/PHM.0b013e318 1flc4ec. PMID: 20855984.
53. Schimrigk S, Marziniak M, Neubauer C, et al. Dronabinol Is a Safe Long-Term Treatment Option for Neuropathic Pain Patients. Eur Neurol. 2017;78(5-6):320-9. doi: 10.1159/000481089. PMID: 29073592.

54. Skrabek RQ, Galimova L, Ethans K, et al. Nabilone for the treatment of pain in fibromyalgia. J Pain. 2008 Feb;9(2):164-73. PMID: 17974490.

55. Toth C, Mawani S, Brady S, et al. An enriched-enrolment, randomized withdrawal, flexible-dose, double-blind, placebo-controlled, parallel assignment efficacy study of nabilone as adjuvant in the treatment of diabetic peripheral neuropathic pain. Pain. 2012 Oct;153(10):2073-82. doi: https://dx.doi.org/10.1016/j.pain.2012.06.02 4. PMID: 22921260 .

56. Turcotte D, Doupe M, Torabi M, et al. Nabilone as an adjunctive to gabapentin for multiple sclerosis-induced neuropathic pain: a randomized controlled trial. Pain Med. 2015 Jan;16(1):149-59. doi: https://dx.doi.org/10.1111/pme.12569. PMID: 25288189.

57. Wissel J, Haydn T, Muller J, et al. Low dose treatment with the synthetic cannabinoid Nabilone significantly reduces spasticityrelated pain : a double-blind placebocontrolled cross-over trial. J Neurol. 2006 Oct;253(10):1337-41. PMID: 16988792.

58. Xu DH, Cullen BD, Tang M, et al. The Effectiveness of Topical Cannabidiol Oil in Symptomatic Relief of Peripheral Neuropathy of the Lower Extremities. Curr Pharm Biotechnol. 2020;21(5):390-402. doi: https://dx.doi.org/10.2174/13892010206661 91202111534. PMID: 31793418.

59. Eibach L, Scheffel S, Cardebring M, et al. Cannabidivarin for HIV-Associated Neuropathic Pain: A Randomized, Blinded, Controlled Clinical Trial. Clin Pharmacol Ther. 2020 Aug 08;08:08. doi: https://dx.doi.org/10.1002/cpt.2016. PMID: 32770831. 
60. Bestard JA, Toth CC. An open-label comparison of nabilone and gabapentin as adjuvant therapy or monotherapy in the management of neuropathic pain in patients with peripheral neuropathy. Pain Pract. 2011 Jul-Aug;11(4):353-68. doi: https://dx.doi.org/10.1111/j.15332500.2010.00427.x. PMID: 21087411.

61. Ware MA, Wang T, Shapiro S, et al. Cannabis for the Management of Pain: Assessment of Safety Study (COMPASS). J Pain. 2015 Dec;16(12):1233-42. doi: https://dx.doi.org/10.1016/j.jpain.2015.07.01 4. PMID: 26385201.

62. Lee C, Lin M, Martins KJB, et al. Opioid use in medical cannabis authorization adult patients from 2013 to 2018: Alberta, Canada. BMC Public Health.

2021;21(1):843. doi: https://dx.doi.org/10.1186/s12889-02110867-w. PMID: 33933061.

63. Vigil JM, Stith SS, Adams IM, et al. Associations between medical cannabis and prescription opioid use in chronic pain patients: A preliminary cohort study. PLoS ONE. 2017;12(11):e0187795. doi: 10.1371/journal.pone.0187795. PMID: 29145417.

64. Gruber SA, Smith RT, Dahlgren MK, et al. No pain, all gain? Interim analyses from a longitudinal, observational study examining the impact of medical cannabis treatment on chronic pain and related symptoms. Experimental and clinical psychopharmacology. 2021doi: https://dx.doi.org/10.1037/pha0000435. PMID: 33764103.

65. Campbell G, Hall WD, Peacock A, et al. Effect of cannabis use in people with chronic non-cancer pain prescribed opioids: findings from a 4-year prospective cohort study. Lancet Public Health. 2018 Jul;3(7):e341-e50. doi: 10.1016/s24682667(18)30110-5. PMID: 29976328.

66. Merlin JS, Long D, Becker WC, et al. Marijuana Use Is Not Associated With Changes in Opioid Prescriptions or Pain Severity Among People Living With HIV and Chronic Pain. J Acquir Immune Defic Syndr. 201906 01;81(2):231-7. doi: https://dx.doi.org/10.1097/QAI.0000000000 001998. PMID: 30865181.
67. Kansagara D, O'Neil M, Nugent S, et al. Benefits and Harms of Cannabis in Chronic Pain or Post-traumatic Stress Disorder: A Systematic Review. Department of Veterans Affairs (US), Washington (DC); 2017.

68. Mucke M, Phillips T, Radbruch L, et al. Cannabis-based medicines for chronic neuropathic pain in adults. Cochrane Database Syst Rev. 201803 07;3:CD012182. doi: https://dx.doi.org/10.1002/14651858.CD012 182.pub2. PMID: 29513392.

69. Nugent SM, Morasco BJ, O'Neil ME, et al. The Effects of Cannabis Among Adults With Chronic Pain and an Overview of General Harms: A Systematic Review. Ann Intern Med. 2017 Sep 05;167(5):319-31. doi: https://dx.doi.org/10.7326/M17-0155. PMID: 28806817.

70. Okusanya BO, Asaolu IO, Ehiri JE, et al. Medical cannabis for the reduction of opioid dosage in the treatment of non-cancer chronic pain: a systematic review. Syst. 2020 Jul 28;9(1):167. doi: https://dx.doi.org/10.1186/s13643-02001425-3. PMID: 32723354.

71. Longo R, Oudshoorn A, Befus D. Cannabis for Chronic Pain: A Rapid Systematic Review of Randomized Control Trials. Pain Manag Nurs. 2020doi: 10.1016/j.pmn.2020.11.006. PMID: 33353819 .

72. Wong SSC, Chan WS, Cheung CW. Analgesic Effects of Cannabinoids for Chronic Non-cancer Pain: a Systematic Review and Meta-Analysis with MetaRegression. J Neuroimmune Pharmacol. 2020 Mar 14;14:14. doi: https://dx.doi.org/10.1007/s11481-02009905-y. PMID: 32172501.

73. Kurlyandchik I, Tiralongo E, Schloss J. Safety and Efficacy of Medicinal Cannabis in the Treatment of Fibromyalgia: A Systematic Review. Journal of alternative and complementary medicine (New York, N.Y.). 2020doi: https://dx.doi.org/10.1089/acm.2020.0331. PMID: 33337931. 
74. Berger ML, Mamdani M, Atkins D, et al. Good research practices for comparative effectiveness research: defining, reporting and interpreting nonrandomized studies of treatment effects using secondary data sources: the ISPOR Good Research Practices for Retrospective Database Analysis Task Force Report--Part I. Value Health. 2009 Nov-Dec;12(8):1044-52. doi: 10.1111/j.1524-4733.2009.00600.x. PMID: 19793072.
75. Furlan A, Chaparro LE, Irvin E, et al. A comparison between enriched and nonenriched enrollment randomized withdrawal trials of opioids for chronic noncancer pain. Pain Res Manag. 2011 SepOct;16(5):337-51. doi:

10.1155/2011/465281. PMID: 22059206. 


\section{Abbreviations and Acronyms}

AHRQ

ANCOVA

BPI-SF

$\mathrm{CBC}$

CBD

CBDV

CBG

CI

CUD

DAS28

EPC

FIQ

FM

GHQ-12

GNDS

HADS-D

IA

KQ

MCID

MCP

MD

MS

NA

NPP

NR

NRS

ODI

OME

OR

PBC

PDI

PICOTS

QOL

RA

RCT

RDQ
Agency for Healthcare Research and Quality

analysis of covariance

Brief Pain Inventory - Short Form

cannabichromene

cannabidiol

cannabidivarin

cannabigerol

confidence interval

cannabis use disorder

28-Joiny Disease Activity Scale

Evidence-based Practice Center

Fibromyalgia Impact Questionnaire

fibromyalgia

Short General Health Questionnaire

Guy's Neurological Disability Scale

Hospital Anxiety and Depression Scale

inflammatory arthritis

Key Question

minimal clinically important difference

New Mexico Medical Cannabis Program

mean difference

multiple sclerosis

not applicable

neuropathic pain

not reported

numerical rating scale

Oswestry Disability Index

oral morphine equivalent

odds ratio

plant-based compound

Pain Disability Index

populations, interventions, comparators, outcomes, timing, and settings

quality of life

rheumatoid arthritis

randomized controlled trial

Roland-Morris Disability Questionnaire 


$\begin{array}{ll}\text { ROB } & \text { risk of bias } \\ \text { RR } & \text { relative risk } \\ \text { SAE } & \text { serious adverse event } \\ \text { SD } & \text { standard deviation } \\ \text { SEADS } & \text { Supplemental Evidence and Data for Systematic review } \\ \text { SF-36 } & \text { Short Form-36 } \\ \text { SMD } & \text { standardized mean difference } \\ \text { SOE } & \text { strength of evidence } \\ \text { SRDR+ } & \text { Systematic Review Data Repository Plus } \\ \text { THC } & \text { tetrahydrocannabinol } \\ \text { TOO } & \text { Task Order Officer } \\ \text { VAS } & \text { visual analogue scale } \\ \text { VP } & \text { visceral pain } \\ \text { WAE } & \text { withdrawal due to adverse events } \\ \text { WP } & \text { whole plant }\end{array}$




\section{Appendix A. Literature Search Strategies}

Database: Ovid MEDLINE(R) ALL 1946 to July 16, 2021

1 Chronic Pain/

2 exp arthralgia/ or exp back pain/ or exp headache/ or exp musculoskeletal pain/ or neck pain/

or exp neuralgia/ or exp nociceptive pain/ or pain, intractable/ or fibromyalgia/ or myalgia/

3 Pain/

4 chronic.ti,ab,kw.

53 and 4

6 ((chronic or persistent or intractable or refractory) adj3 pain).ti,ab,kw.

7 (((back or spine or spinal or leg or musculoskeletal or neuropathic or nociceptive or radicular) adj 1 pain) or headache or arthritis or fibromyalgia or osteoarthritis).ti,ab,kw.

81 or 2 or 5 or 6 or 7

9 Cannabis/

10 exp Cannabinoids/

11 Medical Marijuana/

12 Mitragyna/

13 (cannabis or cannabinoid* or cannabinol or marijuana or cannabidiol or phytocannabinoid* or tetrahydrocannabinol or dronabinol or nabilone or sativex or "CBD" or "THC" or kratom or khat or qat or psilocybin or hemp or hydroxymitragynine).ti,ab,kf.

14 or $/ 9-13$

158 and 14

16 limit 15 to english language

17 (Animals/ or Models, Animal/ or Disease Models, Animal/) not Humans/

18 ((animal or animals or avian or bird or birds or bovine or canine or cow* or dog or dogs or cat or cats or feline or hamster* or horse* or lamb or lamb* or mouse or mice or monkey or monkeys or murine or pig or piglet* or pigs or porcine or primate* or rabbit* or rat or rats or rodent* or songbird* or veterinar*) not (human* or patient*)).ti,kf,jw.

19 or/ $17-18$

$20 \quad 16 \operatorname{not} 19$

Database: EBM Reviews - Cochrane Central Register of Controlled Trials March 2021

1 Chronic Pain/

2 exp arthralgia/ or exp back pain/ or exp headache/ or exp musculoskeletal pain/ or neck pain/

or exp neuralgia/ or exp nociceptive pain/ or pain, intractable/ or fibromyalgia/ or myalgia/

3 Pain/

4 chronic.ti,ab,kw.

$5 \quad 3$ and 4

6 ((chronic or persistent or intractable or refractory) adj3 pain).ti,ab,hw.

7 (((back or spine or spinal or leg or musculoskeletal or neuropathic or nociceptive or radicular) adj1 pain) or headache or arthritis or fibromyalgia or osteoarthritis).ti,ab,hw.

81 or 2 or 5 or 6 or 7

9 (cannabis or cannabinoid* or cannabinol or marijuana or cannabidiol or phytocannabinoid* or tetrahydrocannabinol or dronabinol or nabilone or sativex or "CBD" or "THC" or kratom or khat or qat or psilocybin or hemp or hydroxymitragynine).ti,ab,hw.

108 and 9 
11 conference abstract.pt.

12 "journal: conference abstract".pt.

13 "journal: conference review".pt.

14 "http://.www.who.int/trialsearch*".so.

15 "https://clinicaltrials.gov*".so.

1611 or 12 or 13 or 14 or 15

$17 \quad 10$ not 16

Database: EBM Reviews - Cochrane Database of Systematic Reviews 2005 to July 16, 2021

1 ((chronic or persistent or intractable or refractory) adj3 pain).ti,ab.

2 (((back or spine or spinal or leg or musculoskeletal or neuropathic or nociceptive or radicular) adj1 pain) or headache or arthritis or fibromyalgia or osteoarthritis).ti,ab.

3 (cannabis or cannabinoid* or cannabinol or marijuana or cannabidiol or phytocannabinoid* or tetrahydrocannabinol or dronabinol or nabilone or sativex or "CBD" or "THC" or kratom or khat or qat or psilocybin or hemp or hydroxymitragynine).ti,ab.

4 (1 or 2$)$ and 3

Database: APA PsycInfo 1806 to July 16, 2021

1 Chronic Pain/

2 exp arthralgia/ or exp back pain/ or exp headache/ or exp musculoskeletal pain/ or neck pain/ or exp neuralgia/ or exp nociceptive pain/ or pain, intractable/ or fibromyalgia/ or myalgia/

3 Pain/

4 chronic.ti,ab.

$5 \quad 3$ and 4

6 ((chronic or persistent or intractable or refractory) adj3 pain).ti,ab.

7 (((back or spine or spinal or leg or musculoskeletal or neuropathic or nociceptive or radicular) adj1 pain) or headache or arthritis or fibromyalgia or osteoarthritis).ti,ab.

81 or 2 or 5 or 6 or 7

9 Cannabis/

10 exp Cannabinoids/

11 (cannabis or cannabinoid* or cannabinol or marijuana or cannabidiol or phytocannabinoid* or tetrahydrocannabinol or dronabinol or nabilone or sativex or "CBD" or "THC" or kratom or khat or qat or psilocybin or hemp or hydroxymitragynine).ti,ab.

12 or $/ 9-11$

138 and 12

14 limit 13 to english language

Database: Elsevier Embase to July 5, 2021

('cannabis'/exp OR cannabis OR cannabinoid* OR 'cannabinol'/exp OR cannabinol OR 'marijuana'/exp OR marijuana OR 'cannabidiol'/exp OR cannabidiol OR phytocannabinoid* OR 'tetrahydrocannabinol'/exp OR tetrahydrocannabinol OR 'dronabinol'/exp OR dronabinol OR 'nabilone'/exp OR nabilone OR 'sativex'/exp OR sativex OR 'cbd' OR 'thc' OR 'kratom'/exp OR kratom OR 'khat'/exp OR khat OR 'qat'/exp OR qat OR 'psilocybin'/exp OR psilocybin OR 'hemp'/exp OR hemp OR hydroxymitragynine) AND ('chronic pain'/exp OR arthralgia OR 'back pain' OR headache OR 'musculoskeletal pain' OR 'neck pain' OR neuralgia OR 'nociceptive pain' 
OR 'intractable pain' OR fibromyalgia OR myalgia OR arthritis OR osteoarthrtis) AND [embase]/lim NOT ([embase]/lim AND [medline]/lim)

\section{Database: Elsevier Scopus to July 12, 2021}

( TITLE ( cannabis OR cannabinoid* OR cannabinol OR marijuana OR cannabidiol OR phytocannabinoid* OR tetrahydrocannabinol OR dronabinol OR nabilone OR sativex OR "CBD" OR "THC" OR kratom OR khat OR qat OR psilocybin OR hemp OR

hydroxymitragynine ) ) AND ( TITLE ( "chronic pain" OR arthralgia OR "back pain" OR headache OR "musculoskeletal pain" OR "neck pain" OR neuralgia OR "nociceptive pain" OR "intractable pain" OR fibromyalgia OR myalgia OR arthritis OR osteoarthritis OR "neuropathic pain" ) ) 


\section{Appendix B. Methods}

\section{Inclusion and Exclusion Criteria}

Table B-1 outlines the inclusion and exclusion criteria related to populations, interventions, comparators, outcomes, timing, and settings (PICOTS), and study designs of interest for each Key Question (KQ):

KQ1. In adults with chronic pain, what are the benefits of cannabinoids for treatment of chronic pain?

KQ2. In adults with chronic pain, what are the harms of cannabinoids for treatment of chronic pain?

KQ3. In adults with chronic pain, what are the benefits of kratom or other plant-based substances for treatment of chronic pain?

KQ4. In adults with chronic pain, what are the harms of kratom or other plant-based substances for treatment of chronic pain?

Table B-1. PICOTS

\begin{tabular}{|c|c|c|}
\hline PICOTS Element & Inclusion Criteria & Exclusion Criteria \\
\hline Interventions & $\begin{array}{l}\text { KQs } 1 \text { and 2: Cannabinoids (including synthetics) } \\
\text { using different delivery mechanisms such as oral, } \\
\text { buccal, inhalational, topical, or other administration } \\
\text { routes } \\
\text { KQs } 3 \text { and 4: Kratom or other plant-based } \\
\text { substances; co-use of kratom or other plant-based } \\
\text { substances and opioids } \\
\text { All KQs: Co-use of other drugs for pain }\end{array}$ & $\begin{array}{l}\text { All KQs: Non-plant-based interventions, } \\
\text { capsaicin, herbal supplements }\end{array}$ \\
\hline Comparators & All KQs: Any comparator or usual care & All KQs: No comparison \\
\hline Time of followup & $\begin{array}{l}\text { All KQs: short term ( } 4 \text { weeks to }<6 \text { months), } \\
\text { intermediate term ( } 6 \text { to }<12 \text { months), long term }(\geq 1 \\
\text { year) }\end{array}$ & $\begin{array}{l}\text { All KQs: studies with <1-month ( } 4 \text { weeks) of } \\
\text { treatment or followup after treatment }\end{array}$ \\
\hline Setting & $\begin{array}{l}\text { All KQs: Any nonhospital setting or setting of self- } \\
\text { directed care }\end{array}$ & $\begin{array}{l}\text { All KQs: Hospital care, hospice care, emergency } \\
\text { department care }\end{array}$ \\
\hline Study design & $\begin{array}{l}\text { All KQs: RCTs; observational studies with a } \\
\text { concurrent control group for harms, and to fill gaps } \\
\text { in the evidence for benefits }\end{array}$ & All KQs: Other study designs \\
\hline
\end{tabular}

Abbreviations: KQ = Key Question; PICOTS = populations, interventions, comparators, outcomes, timing, and settings; RCT = randomized controlled trial.

Important subgroups to consider in evaluating this evidence are: 
- Specific types of pain: neuropathic pain (including nociceptive and centralized; patients with multiple sclerosis and painful skin disorders are included in this category), musculoskeletal pain (including low-back pain), visceral pain, fibromyalgia, inflammatory arthritis, headache disorders, sickle cell disease, and cancer pain (non-end of life)

- Degree of nociplasticity/central sensitization

- Patient demographics (e.g., age, race, ethnicity, sex, socioeconomic status)

- Comorbidities, including past or current substance use disorders, mental health disorders, medical comorbidities, and high risk for opioid use disorder)

- Plant-based compound characteristics: route of administration, frequency of administration, potency of product, dose or estimated dose, specific compounds (e.g. tetrahydrocannabinol, cannabidiol, terpenes, flavonoids), and specific formulations used

- Co-use of other interventions for pain: opioids, nonopioids (e.g., nonsteroidal antiinflammatory drugs, acetaminophen, gabapentin, pregabalin)

Below are additional details on the scope of this project:

Study Design: For all Key Questions, we included randomized controlled trials (RCTs) of at least 4 weeks duration. Initially, in the base-year of this living systematic review, we included observational studies for both benefits (to address gaps in evidence where RCTs are not available) and harms. Eligible observational studies must have assessed a mean duration of treatment of at least 4 weeks, and have concurrent controls (e.g., cohort and case-control studies). Those controlling for potential confounders were prioritized. As the evidence grows, and more RCTs become available throughout the project, we will reassess the need to include observational studies, specifically to address benefits. A decision to discontinue including them will be made based on the strength of the RCT evidence. When the RCT evidence on a given Key Question and outcome is insufficient, we will include observational studies that meet inclusion criteria. When the strength of evidence is low, moderate, or high based on RCTs, we will update our protocol to exclude observational studies. We do not anticipate excluding observational studies assessing harms. For all Key Questions, we excluded uncontrolled observational studies, case series, and case reports. Systematic reviews were used to supplement searches and identify primary studies.

Non-English Language Studies: We restricted to English-language articles, but reviewed English-language abstracts of non-English language articles to identify studies that would otherwise meet inclusion criteria in order to help assess for the likelihood of language bias.

\section{Study Selection}

Electronic searches for evidence were conducted in Ovid $\AA$ MEDLINE®, PsycINFO ${ }^{\circledR}$, Embase ${ }^{\circledR}$, the Cochrane Library, and SCOPUS ${ }^{\circledR}$ databases through July 5, 2021. Searches were initially run in September 2020 with ongoing, automated monthly searches to identify newly published studies. Search strategies are available in Appendix A. Electronic searches were supplemented with review of reference lists of relevant studies and reviewing the two prior AHRQ pain reports ${ }^{1,2}$ for studies that met our inclusion criteria. A Federal Register Notice was posted, and a Supplemental Evidence And Data for Systematic review (SEADS) portal was available for submission of unpublished studies. As part of living systematic review methods, the 
electronic searches were automated to be run on a biweekly basis, with results emailed directly to the EPC librarian and the research team for processing. Citations were uploaded into DistillerSR ${ }^{\circledR}$ software for study selection management.

The pre-established criteria listed above were used to determine eligibility for inclusion and exclusion of abstracts. Using Distiller ${ }^{\circledR}$ SR, the review team conducted manual online assessment of study citations. All citations deemed potentially relevant by at least one of the reviewers were retrieved for full-text review. To ensure accuracy, any citation deemed not relevant for full-text review were reviewed by a second researcher. We initially planned to explore using the Distiller ${ }^{\circledR}$ AI feature to automate exclusion of abstracts that are clearly not relevant. Briefly, Distiller®SR AI is training in the background, learning from the human decisions on abstract eligibility. When the Distiller ${ }^{\circledR}$ AI decisions reach a level of 95 percent accuracy, we will deploy the system to assist with dual review (this typically takes 2000 citations, but varies by topic). ${ }^{3}$ To date, the biweekly citation counts have been low, and the AI feature has not been utilized.

\section{Data Extraction}

After studies were selected for inclusion, data were abstracted into categories that included but are not limited to: study design, year, setting, country, sample size, eligibility criteria, population and clinical characteristics, intervention characteristics, and results relevant to each Key Question as outlined in the previous inclusion and exclusion criteria section. Information that was abstracted that was relevant for assessing applicability included the number of patients randomized relative to the number of patients enrolled, use of run-in or wash-out periods, and characteristics of the population, intervention, and care settings. All study data were verified for accuracy and completeness by a second team member. On a quarterly basis, any newly identified studies were abstracted and evidence tables updated. Quarterly reports were published to the Agency for Healthcare Research and Quality (AHRQ) website, and evidence tables will be updated in AHRQ's Systematic Review Data Repository Plus (SRDR+).

\section{Risk of Bias Assessment of Individual Studies}

Predefined criteria were used to assess the risk of bias of individual controlled trials, systematic reviews, and observational studies. RCTs were evaluated using criteria and methods developed by the Cochrane Back Review Group ${ }^{4}$ and cohort and case-control studies were evaluated using criteria developed by the U.S. Preventive Services Task Force. ${ }^{5}$ These criteria and methods were used in accordance with the approach recommended in the chapter, Assessing the Risk of Bias of Individual Studies When Comparing Medical Interventions in the Methods Guide for Effectiveness and Comparative Effectiveness Reviews developed by AHRQ. ${ }^{6}$ Studies were given an overall rating of "low," "medium," or "high" risk of bias. We used DistillerSR ${ }^{\circledR}$ software to conduct these assessments, using dual review by two independent reviewers. Disagreements identified by DistillerSR ${ }^{\circledR}$ were resolved through consensus. Assessments and final ratings were converted to evidence tables, and will be uploaded on a quarterly basis to SRDR+.

\section{Data Synthesis and Analysis}

We constructed evidence tables showing study characteristics (as discussed above), results, and risk of bias ratings for all included studies, and summary tables to highlight the main 
findings. Data were qualitatively summarized in tables, using ranges and descriptive analysis and interpretation of the results. Studies identified in prior AHRQ chronic pain reports ${ }^{1,2}$ that meet inclusion criteria are included in this review. We evaluated the persistence of benefits or harms by evaluating the three periods identified in prior AHRQ pain reports ( 3 to 6 months, 6 to 12 months, and $\geq 12$ months). ${ }^{1,2,7-9}$

Meta-analyses were conducted to summarize data and obtain more precise estimates on outcomes for which studies were homogeneous enough to provide a meaningful combined estimate. ${ }^{10}$ The decision to conduct quantitative synthesis depends on presence of at least two studies, completeness of reported outcomes and a lack of heterogeneity among the reported results. To determine whether meta-analyses were indicated, we considered the risk of bias of the studies and the heterogeneity among studies in design, patient population, interventions, and outcomes. Meta-analyses were conducted using a random effects model, and statistical heterogeneity was assessed using the $\mathrm{I}^{2}$ method. Publication bias (small sample size bias) is assessed using funnel plots when there are eight or more studies in meta-analyses. To evaluate subgroup effects, we summarized within-study analyses of subgroup differences and performed study-level analyses on key demographic and clinical factors. Sensitivity analyses were conducted on study risk of bias.

The magnitude of effects for pain and function is classified using the same system used in other recent AHRQ Evidence-based Practice Center (EPC) reviews conducted on chronic pain $^{1,2,7-9}$ to provide a consistent benchmark for comparing results of pain interventions across reviews. Table B-2 provides thresholds for determining the magnitude of effect. A small effect is defined for pain as a mean between-group difference following treatment of 5 to 10 points on a 0 - to 100 -point visual analog scale (VAS), 0.5 to 1.0 points on a 0 - to 10 -point numeric rating scale, or equivalent; for function as a mean difference of 5 to 10 points on the 0 - to 100-point Oswestry Disability Index (ODI) or 1 to 2 points on the 0- to 24-point Roland-Morris Disability Questionnaire (RDQ), or equivalent; and for any outcome as a standardized mean difference (SMD) of 0.2 to 0.5 . A moderate effect is defined for pain as a mean difference of 10 to 20 points on a 0 - to 100-point VAS, for function as a mean difference of 10 to 20 points on the ODI or 2 to 5 points on the RDQ, and for any outcome as an SMD of 0.5 to 0.8. Large effects are defined as greater than moderate. We apply similar thresholds to other outcomes measures. Small effects using this system may be below published thresholds for clinically meaningful effects; however, there is variability across individual patients regarding what constitutes a clinically meaningful effect, which is influenced by a number of factors such as preferences, duration and type of chronic pain, baseline symptom severity, harms, and costs. For some patients a small improvement in pain or function using a treatment with low cost or no serious harms may be important.

Table B-2. Definitions of effect sizes

\begin{tabular}{|l|l|}
\hline Effect Size & Definition \\
\hline Small effect & $\begin{array}{l}\text { - MD } 0.5 \text { to } 1.0 \text { points on a } 0 \text { to } 10 \text {-point scale, } 5 \text { to } 10 \text { points on a } 0 \text { to } 100 \text {-point scale } \\
\text { - SMD } 0.2 \text { to } 0.5 \\
\text { - RR/OR } 1.2 \text { to } 1.4\end{array}$ \\
\hline Moderate effect & $\begin{array}{l}\text { - MD }>1 \text { to } 2 \text { points on a } 0 \text { to10-point scale, }>10 \text { to } 20 \text { points on a } 0 \text { to 100-point scale } \\
\text { - SMD }>0.5 \text { to } 0.8 \\
\text { - RR/OR } 1.5 \text { to } 1.9\end{array}$ \\
\hline Large effect & $\begin{array}{l}\text { - MD }>2 \text { points on a } 0 \text { to10-point scale, }>20 \text { points on a } 0 \text { to } 100 \text {-point scale } \\
\text { - SMD }>0.8\end{array}$ \\
\hline
\end{tabular}

Abbreviations: $\mathrm{MD}=$ mean difference; $\mathrm{OR}=$ odds ratio; $\mathrm{RR}=$ relative risk; $\mathrm{SMD}=$ standardized mean difference. 
Findings that were not statistically significant were interpreted as follows:

- In determining the strength of evidence (SOE), the precision of evidence was downgraded two levels if inadequate sample size (optimal information size) and the $95 \%$ confidence interval includes both potentially meaningful benefit and harm (e.g. for a relative effect, the lower bound is $\leq 0.75$ and the upper bound is $\geq 1.25)^{11}$

- If the magnitude of effect is below the threshold for a small effect, the finding is considered to have "No effect"

- If the magnitude of effect is small or greater, and SOE is at least Low, the finding is considered to have a "Potential effect, not statistically significant"

- If the magnitude of effect is small or greater, and SOE is insufficient, the finding is considered to have "failed to demonstrate or exclude a beneficial/detrimental effect."12

\section{Grading the Strength of the Body of Evidence}

We assessed the SOE for all primary comparisons and outcomes listed in Table B-1. Regardless of whether evidence is synthesized quantitatively or qualitatively, the strength of evidence for each Key Question/body of evidence is initially assessed by one researcher for each clinical outcome by using the approach described in the AHRQ Methods Guide. ${ }^{6}$ To ensure consistency and validity of the evaluation, the strength of evidence is reviewed by the entire team of investigators prior to assigning a final grade on the following factors:

- Study limitations (low, medium, or high level of study limitations)

- Consistency (consistent, inconsistent, or unknown/not applicable)

- Directness (direct or indirect)

- Precision (precise or imprecise)

- Reporting/publication bias (suspected or undetected)

The SOE was assigned an overall grade of high, moderate, low, or insufficient according to a four-level scale by evaluating and weighing the combined results of the above domains:

- High-We are very confident that the estimate of effect lies close to the true effect for this outcome. The body of evidence has few or no deficiencies. We believe that the findings are stable, i.e., another study would not change the conclusions.

- Moderate - We are moderately confident that the estimate of effect lies close to the true effect for this outcome. The body of evidence has some deficiencies. We believe that the findings are likely to be stable, but some doubt remains.

- Low-We have limited confidence that the estimate of effect lies close to the true effect for this outcome. The body of evidence has major or numerous deficiencies (or both). We believe that additional evidence is needed before concluding either that the findings are stable or that the estimate of effect is close to the true effect.

- Insufficient -We have no evidence, we are unable to estimate an effect, or we have no confidence in the estimate of effect for this outcome. No evidence is available or the body of evidence has unacceptable deficiencies, precluding reaching a conclusion.

Plain-language statements are used in the Main Points, the Evidence Summary and the Discussion to convey the SOE. High SOE is described as "is associated with" or simply 
"reduces/increases;" moderate SOE is described as "probably;" and low SOE is described as "may be."13

\section{Peer Review and Public Commentary}

Peer reviewers are invited to provide written comments on the draft report based on their clinical, content, or methodological expertise. The EPC considers all peer review comments on the draft report in preparation of the final report. Peer reviewers do not participate in writing or editing of the final report or other products. The final report does not necessarily represent the views of individual reviewers. The EPC will complete a disposition of all peer review comments. The disposition of comments for systematic reviews and technical briefs will be published 3 months after the publication of the evidence report.

Potential Peer Reviewers must disclose any financial conflicts of interest greater than $\$ 5,000$ and any other relevant business or professional conflicts of interest. Invited Peer Reviewers may not have any financial conflict of interest greater than $\$ 5,000$. Peer reviewers who disclose potential business or professional conflicts of interest may submit comments on draft reports through the public comment mechanism.

\section{Assessing Applicability}

Applicability is assessed in accordance with the AHRQ Methods Guide, ${ }^{14}$ which is based on the PICOTS framework. Applicability addresses the extent to which outcomes associated with an intervention are likely to be similar across different patients and settings in clinical practice based on the populations, interventions, comparisons, and outcomes evaluated in the studies. For example, exclusion of chronic pain patients with psychiatric comorbidities reduces applicability to clinical practice since many patients with chronic pain have such comorbidities and may respond more poorly to treatment. Similarly, trials that use active run-in periods evaluate highly selected populations who tolerated and responded well to the study intervention, rather than the general population of chronic pain patients being considered for the intervention. Factors that may affect applicability which we have identified a priori include eligibility criteria and patient factors (e.g., demographic characteristics, duration or severity of pain, underlying pain condition, presence of medical and psychiatric comorbidities, event rates and symptom severity in treatment and control groups), intervention factors (e.g., dose and duration of therapy, intensity and frequency of monitoring, level of adherence, use of co-interventions), comparisons (e.g., type and dosing of comparison), outcomes (e.g., use of unvalidated or nonstandardized outcomes, measurement of short-term or surrogate outcomes), settings (e.g., primary care vs. specialty setting, country), and study design features (e.g., use of run-in periods) relevant to applicability. We use this information to assess the situations in which the evidence is most relevant and to evaluate applicability to real-world clinical practice in typical U.S. settings, summarizing applicability assessments qualitatively. 


\section{Appendix B References}

1. Chou R, Hartung D, Turner J, et al. Opioid

Treatments for Chronic Pain. Comparative

Effectiveness Review No. 229. (Prepared by

the Pacific Northwest Evidence-based

Practice Center under Contract No. 290-

2015-00009-I.) AHRQ Publication No. 20-

EHC011. Rockville, MD: Agency for

Healthcare Research and Quality; April

2020. PMID: 32338848.

2. McDonagh MS, Selph SS, Buckley DI, et al.

Nonopioid Pharmacologic Treatments for Chronic Pain. Comparative Effectiveness Review No. 228. (Prepared by the Pacific Northwest Evidence-based Practice Center under Contract No. 290-2015-00009-I.)

AHRQ Publication No. 20-EHC010.

Rockville, MD: Agency for Healthcare Research and Quality; April 2020. PMID: 32338847.

3. Taieb V, Smela-Lipińska B, O'Blenis P, et al. Use of Artificial Intelligence with DistillerSR Software for a Systematic Literature Review of Utilities in Infectious Disease. Value in Health. 2018;21:S387.

4. Furlan AD, Pennick V, Bombardier C, et al. 2009 updated method guidelines for systematic reviews in the Cochrane Back Review Group. Spine (Phila Pa 1976). 2009 Aug 15;34(18):1929-41. doi: 10.1097/BRS.0b013e3181b1c99f. PMID: 19680101.

5. U.S. Preventive Services Task Force. Methods and processes. 2018. https://www.uspreventiveservicestaskforce.o $\mathrm{rg} /$ Page/Name/methods-and-processes.

6. Methods Guide for Effectiveness and Comparative Effectiveness Reviews. Rockville, MD: Agency for Healthcare Research and Quality; 2017. https://effectivehealthcare.ahrq.gov/topics/ce r-methods-guide/overview. Accessed June 1, 2019.
7. Skelly AC, Chou R, Dettori JR, et al. Noninvasive Nonpharmacological Treatment for Chronic Pain: A Systematic Review Update. Comparative Effectiveness Review No. 227. (Prepared by the Pacific Northwest Evidence-based Practice Center under Contract No. 290-2015-00009-I.) AHRQ Publication No. 20-EHC009. Rockville, MD: Agency for Healthcare Research and Quality; April 2020. PMID: 32338846 .

8. Chou R, Deyo R, Friedly J, et al. Noninvasive Treatments for Low Back Pain: Agency for Healthcare Research and Quality (US), Rockville (MD); 2016.

9. Skelly AC, Chou R, Dettori JR, et al. Noninvasive Nonpharmacological Treatment for Chronic Pain: A Systematic Review: Agency for Healthcare Research and Quality (US), Rockville (MD); 2018.

10. Morton SC, Murad MH, O'Connor E, et al. Quantitative Synthesis-An Update: Agency for Healthcare Research and Quality (US), Rockville (MD); 2008.

11. Guyatt GH, Oxman AD, Kunz R, et al. GRADE guidelines 6. Rating the quality of evidence--imprecision. J Clin Epidemiol. 2011 Dec;64(12):1283-93. doi: 10.1016/j.jclinepi.2011.01.012. PMID: 21839614.

12. Guyatt GH, Norris SL, Schulman S, et al. Methodology for the development of antithrombotic therapy and prevention of thrombosis guidelines: Antithrombotic Therapy and Prevention of Thrombosis, 9th ed: American College of Chest Physicians Evidence-Based Clinical Practice Guidelines. Chest. 2012 Feb;141(2 Suppl):53s-70s. doi: 10.1378/chest.11-2288. PMID: 22315256.

13. Gerrity M, Fiordalisi C, Pillay J, et al. AHRQ Methods for Effective Health Care. Roadmap for Narratively Describing Effects of Interventions in Systematic Reviews. Rockville (MD): Agency for Healthcare Research and Quality (US); 2020. 
14. Atkins D, Chang SM, Gartlehner G, et al. Assessing applicability when comparing medical interventions: AHRQ and the Effective Health Care Program. J Clin Epidemiol. 2011 Nov;64(11):1198-207. doi: 10.1016/j.jclinepi.2010.11.021. PMID: 21463926. 


\section{Appendix C. Included Studies List}

1. Bestard JA, Toth CC. An open-label comparison of nabilone and gabapentin as adjuvant therapy or monotherapy in the management of neuropathic pain in patients with peripheral neuropathy. Pain Pract. 2011 Jul-Aug;11(4):353-68. doi: https://dx.doi.org/10.1111/j.15332500.2010.00427.x. PMID: 21087411.

2. Blake DR, Robson P, Ho M, et al. Preliminary assessment of the efficacy, tolerability and safety of a cannabis-based medicine (Sativex) in the treatment of pain caused by rheumatoid arthritis. Rheumatology (Oxford). 2006 Jan;45(1):502. PMID: 16282192 .

3. Campbell G, Hall WD, Peacock A, et al. Effect of cannabis use in people with chronic non-cancer pain prescribed opioids: findings from a 4-year prospective cohort study. Lancet Public Health. 2018 Jul;3(7):e341-e50. doi: 10.1016/s24682667(18)30110-5. PMID: 29976328.

4. Chaves C, Bittencourt PCT, Pelegrini A. Ingestion of a THC-Rich Cannabis Oil in People with Fibromyalgia: A Randomized, Double-Blind, Placebo-Controlled Clinical Trial. Pain Med. 2020;21(10):2212-8. doi: https://dx.doi.org/10.1093/pm/pnaa303. PMID: 33118602.

5. de Vries M, van Rijckevorsel DCM, Vissers $\mathrm{KCP}$, et al. Tetrahydrocannabinol Does Not Reduce Pain in Patients With Chronic Abdominal Pain in a Phase 2 Placebocontrolled Study. Clin Gastroenterol Hepatol. 2017 Jul;15(7):1079-86.e4. doi: https://dx.doi.org/10.1016/j.cgh.2016.09.147 . PMID: 27720917.

6. Eibach L, Scheffel S, Cardebring M, et al. Cannabidivarin for HIV-Associated Neuropathic Pain: A Randomized, Blinded, Controlled Clinical Trial. Clin Pharmacol Ther. 2020 Aug 08;08:08. doi: https://dx.doi.org/10.1002/cpt.2016. PMID: 32770831 .
7.

Frank B, Serpell MG, Hughes J, et al. Comparison of analgesic effects and patient tolerability of nabilone and dihydrocodeine for chronic neuropathic pain: randomised, crossover, double blind study. BMJ. 2008 Jan 26;336(7637):199-201. doi: https://dx.doi.org/10.1136/bmj.39429.61965 3.80. PMID: 18182416 .

8. Gruber SA, Smith RT, Dahlgren MK, et al. No pain, all gain? Interim analyses from a longitudinal, observational study examining the impact of medical cannabis treatment on chronic pain and related symptoms. Experimental and clinical psychopharmacology. 2021doi: https://dx.doi.org/10.1037/pha0000435. PMID: 33764103.

9. Langford RM, Mares J, Novotna A, et al. A double-blind, randomized, placebocontrolled, parallel-group study of THC/CBD oromucosal spray in combination with the existing treatment regimen, in the relief of central neuropathic pain in patients with multiple sclerosis. J Neurol. 2013 Apr;260(4):984-97. doi: https://dx.doi.org/10.1007/s00415-0126739-4. PMID: 23180178.

10. Lee C, Lin M, Martins KJB, et al. Opioid use in medical cannabis authorization adult patients from 2013 to 2018: Alberta, Canada. BMC Public Health. 2021;21(1):843. doi: https://dx.doi.org/10.1186/s12889-02110867-w. PMID: 33933061.

11. Lynch ME, Cesar-Rittenberg P, Hohmann AG. A double-blind, placebo-controlled, crossover pilot trial with extension using an oral mucosal cannabinoid extract for treatment of chemotherapy-induced neuropathic pain. J Pain Symptom Manage. 2014 Jan;47(1):166-73. doi: https://dx.doi.org/10.1016/j.jpainsymman.20 13.02.018. PMID: 23742737.

12. Merlin JS, Long D, Becker WC, et al. Marijuana Use Is Not Associated With Changes in Opioid Prescriptions or Pain Severity Among People Living With HIV and Chronic Pain. J Acquir Immune Defic Syndr. 201906 01;81(2):231-7. doi: https://dx.doi.org/10.1097/QAI.0000000000 001998. PMID: 30865181. 
13. Nurmikko TJ, Serpell MG, Hoggart B, et al. Sativex successfully treats neuropathic pain characterised by allodynia: a randomised, double-blind, placebo-controlled clinical trial. Pain. 2007 Dec 15;133(1-3):210-20. PMID: 17997224.

14. Pini LA, Guerzoni S, Cainazzo MM, et al. Nabilone for the treatment of medication overuse headache: results of a preliminary double-blind, active-controlled, randomized trial. J Headache Pain. 2012 Nov;13(8):67784. doi: https://dx.doi.org/10.1007/s10194012-0490-1. PMID: 23070400.

15. Rintala DH, Fiess RN, Tan G, et al. Effect of dronabinol on central neuropathic pain after spinal cord injury: a pilot study. Am J Phys Med Rehabil. 2010 Oct;89(10):840-8. doi:

https://dx.doi.org/10.1097/PHM.0b013e318 1flc4ec. PMID: 20855984.

16. Rog DJ, Nurmikko TJ, Friede T, et al. Randomized, controlled trial of cannabisbased medicine in central pain in multiple sclerosis. Neurology. 2005 Sep 27;65(6):812-9. PMID: 16186518.

17. Schimrigk S, Marziniak M, Neubauer C, et al. Dronabinol Is a Safe Long-Term Treatment Option for Neuropathic Pain Patients. Eur Neurol. 2017;78(5-6):320-9. doi: 10.1159/000481089. PMID: 29073592.

18. Selvarajah D, Gandhi R, Emery CJ, et al. Randomized placebo-controlled doubleblind clinical trial of cannabis-based medicinal product (Sativex) in painful diabetic neuropathy: depression is a major confounding factor. Diabetes Care. 2010 Jan;33(1):128-30. doi: 10.2337/dc09-1029. PMID: 19808912.

19. Serpell M, Ratcliffe S, Hovorka J, et al. A double-blind, randomized, placebocontrolled, parallel group study of THC/CBD spray in peripheral neuropathic pain treatment. Eur J Pain. 2014 Aug;18(7):999-1012. doi: 10.1002/j.15322149.2013.00445.x. PMID: 24420962.

20. Skrabek RQ, Galimova L, Ethans K, et al. Nabilone for the treatment of pain in fibromyalgia. J Pain. 2008 Feb;9(2):164-73. PMID: 17974490.
21. Toth C, Mawani S, Brady S, et al. An enriched-enrolment, randomized withdrawal, flexible-dose, double-blind, placebo-controlled, parallel assignment efficacy study of nabilone as adjuvant in the treatment of diabetic peripheral neuropathic pain. Pain. 2012 Oct;153(10):2073-82. doi: https://dx.doi.org/10.1016/j.pain.2012.06.02 4. PMID: 22921260.

22. Turcotte D, Doupe M, Torabi M, et al. Nabilone as an adjunctive to gabapentin for multiple sclerosis-induced neuropathic pain: a randomized controlled trial. Pain Med. 2015 Jan;16(1):149-59. doi: https://dx.doi.org/10.1111/pme.12569. PMID: 25288189.

23. Vigil JM, Stith SS, Adams IM, et al. Associations between medical cannabis and prescription opioid use in chronic pain patients: A preliminary cohort study. PLoS ONE. 2017;12(11):e0187795. doi: 10.1371/journal.pone.0187795. PMID: 29145417.

24. Ware MA, Wang T, Shapiro S, et al. Cannabis for the Management of Pain: Assessment of Safety Study (COMPASS). J Pain. 2015 Dec;16(12):1233-42. doi: https://dx.doi.org/10.1016/j.jpain.2015.07.01 4. PMID: 26385201.

25. Wissel J, Haydn T, Muller J, et al. Low dose treatment with the synthetic cannabinoid Nabilone significantly reduces spasticityrelated pain : a double-blind placebocontrolled cross-over trial. J Neurol. 2006 Oct;253(10):1337-41. PMID: 16988792.

26. Xu DH, Cullen BD, Tang M, et al. The Effectiveness of Topical Cannabidiol Oil in Symptomatic Relief of Peripheral Neuropathy of the Lower Extremities. Curr Pharm Biotechnol. 2020;21(5):390-402. doi: https://dx.doi.org/10.2174/13892010206661 91202111534. PMID: 31793418.

27. Zajicek JP, Hobart JC, Slade A, et al. Multiple sclerosis and extract of cannabis: results of the MUSEC trial. J Neurol Neurosurg Psychiatry. 2012 Nov;83(11):1125-32. doi: https://dx.doi.org/10.1136/jnnp-2012302468. PMID: 22791906. 


\section{Appendix D. Results}

\section{Appendix D-1. Individual Study Summary Tables}

Tables D-1 through D-5 present details and results for primary outcomes, serious adverse events and withdrawals due to adverse events for each included study. Tables D-1 through D-3 provide information for randomized controlled trials and are organized by their respective ratio of tetrahydrocannabinol to cannabidiol. Table D-4 includes details for studies of other cannabinoids, and Table D-5 presents details of observational studies.

\begin{tabular}{|c|c|c|c|c|}
\hline $\begin{array}{l}\text { Author, Year } \\
\text { Risk of Bias } \\
\text { Study Design } \\
\text { Pain Condition }\end{array}$ & $\begin{array}{l}\text { Comparison }(\mathrm{n}) \\
\text { Followup Duration } \\
\text { Derivative }\end{array}$ & $\begin{array}{l}\text { Primary Pain Outcomes } \\
\text { (Response, Severity) }\end{array}$ & $\begin{array}{l}\text { Overall } \\
\text { Function/Disability } \\
\text { (Including Pain } \\
\text { Interference) }\end{array}$ & $\begin{array}{l}\text { Serious Adverse } \\
\text { Events and } \\
\text { Withdrawals Due to } \\
\text { Adverse Events }^{a}\end{array}$ \\
\hline $\begin{array}{l}\text { Blake, } 2006 \\
\text { Moderate } \\
\text { RCT } \\
\text { Inflammatory arthritis- } \\
\text { rheumatoid arthritis }\end{array}$ & $\begin{array}{l}\text { A: } 2.7 \mathrm{mg} \mathrm{THC} / 2.5 \mathrm{mg} \\
\text { CBD/100 mcl } \\
\text { oromucosal spray, } \\
\text { mean dose } 5.4 \\
\text { sprays/day ( } 31) \\
\text { B: Placebo (27) } \\
5 \text { weeks } \\
\text { Whole plant extracted }\end{array}$ & $\begin{array}{l}\text { Pain severity (mean [SD NR] } 0 \text { to } 10 \\
\text { NRS scale): } 3.1 \text { vs. } 4.1, \mathrm{MD}-1.04^{\mathrm{b}} \\
(95 \% \mathrm{Cl}-1.9 \text { to }-0.18)\end{array}$ & $\begin{array}{l}\text { Function (mean [SD } \\
\text { NR] } 0 \text { to } 1028-\text {-Joint } \\
\text { Disease Activity Score } \\
\text { scale): } 5 \text { vs. } 5.9, \mathrm{MD} \\
-0.76^{c}(95 \% \mathrm{Cl}-1.23 \\
\text { to }-0.28)\end{array}$ & $\begin{array}{l}\text { SAE: } 0 / 31(0 \%) \text { vs. } \\
2 / 27(7.41 \%) \\
\text { WAE: } 0 / 31(0 \%) \text { vs. } \\
3 / 27(11.11 \%)\end{array}$ \\
\hline $\begin{array}{l}\text { Langford, } 2013 \\
\text { Low } \\
\text { RCT } \\
\text { Neuropathic pain- } \\
\text { multiple sclerosis }\end{array}$ & $\begin{array}{l}\text { A: } 2.7 \mathrm{mg} \mathrm{THC} / 2.5 \mathrm{mg} \\
\text { CBD/100 mcl } \\
\text { oromucosal spray, } \\
\text { mean dose } 8.8 \\
\text { sprays/day (167) } \\
\text { B: Placebo (172) } \\
15 \text { weeks } \\
\text { Whole plant extracted }\end{array}$ & $\begin{array}{l}\text { Pain response } \geq 30 \% \text { (NRS scale): } \\
83 / 167(49.75 \%) \text { vs. } 77 / 172 \\
(44.77 \%) \text {, RR } 1.11 \text { ( } 95 \% \text { Cl } 0.89 \text { to } \\
1.39) \\
\text { Pain severity (mean [SD] } 0 \text { to } 10 \\
\text { NRS scale): } 4.54(2.24) \text { vs. } 4.73 \\
\text { (2.26), MD }-0.19 \text { (SE } 0.24)(95 \% \mathrm{Cl} \\
-0.67 \text { to } 0.29)\end{array}$ & $\begin{array}{l}\text { Pain interference ( } 0 \text { to } \\
10 \mathrm{BPI}-\mathrm{SF} \text { scale): } \\
\text { Treatment difference } \\
-0.12, p=0.56 \\
\\
\text { Function ( } 0 \text { to } 100 \\
\text { SF-36 Physical } \\
\text { Functioning scale): } \\
\text { Treatment difference } \\
-0.45, p=0.785\end{array}$ & $\begin{array}{l}\text { WAE: } 14 / 167(8.38 \%) \\
\text { vs. } 9 / 172(5.23 \%)\end{array}$ \\
\hline $\begin{array}{l}\text { Lynch, } 2014 \\
\text { High } \\
\text { RCT (crossover) } \\
\text { Neuropathic pain- } \\
\text { chemotherapy induced }\end{array}$ & $\begin{array}{l}\text { A: THC/CBD } \\
\text { oromucosal spray } \\
\text { (dose NR), mean dose } \\
8 \text { sprays/day (8) } \\
\text { B: Placebo (8) } \\
4 \text { weeks } \\
\text { Whole plant extracted }\end{array}$ & $\begin{array}{l}\text { Pain severity (mean, } 0 \text { to } 10 \\
\text { NRS-PI scale): } 6(95 \% \mathrm{Cl} 6.98 \text { to } \\
5.02) \text { vs. } 6.38 \text { ( } 95 \% \mathrm{Cl} 5.67 \text { to } 7.09)\end{array}$ & $\begin{array}{l}\text { Function (mean [SD] } 0 \\
\text { to } 100 \mathrm{SF}-36 \text { Physical } \\
\text { Functioning scale): } \\
35.5(9.19) \text { vs. } 46.5 \\
(8.5), \mathrm{MD}-11(4.43) \\
(95 \% \mathrm{Cl} \\
-20.49 \text { to }-1.51)\end{array}$ & $\begin{array}{l}\text { SAE: } 0 / 8(0 \%) \text { vs. } 0 / 8 \\
(0 \%) \\
\text { WAE: } 0 / 8(0 \%) \text { vs. } 0 / 8 \\
(0 \%)\end{array}$ \\
\hline
\end{tabular}




\begin{tabular}{|c|c|c|c|c|}
\hline $\begin{array}{l}\text { Author, Year } \\
\text { Risk of Bias } \\
\text { Study Design } \\
\text { Pain Condition }\end{array}$ & $\begin{array}{l}\text { Comparison }(\mathrm{n}) \\
\text { Followup Duration } \\
\text { Derivative }\end{array}$ & $\begin{array}{l}\text { Primary Pain Outcomes } \\
\text { (Response, Severity) }\end{array}$ & $\begin{array}{l}\text { Overall } \\
\text { Function/Disability } \\
\text { (Including Pain } \\
\text { Interference) }\end{array}$ & $\begin{array}{l}\text { Serious Adverse } \\
\text { Events and } \\
\text { Withdrawals Due to } \\
\text { Adverse Events }^{\mathrm{a}}\end{array}$ \\
\hline $\begin{array}{l}\text { Nurmikko, } 2007 \\
\text { Moderate } \\
\text { RCT } \\
\text { Neuropathic pain- } \\
\text { mixed }\end{array}$ & $\begin{array}{l}\text { A: } 2.7 \mathrm{mg} \mathrm{THC} / 2.5 \mathrm{mg} \\
\text { CBD/100 mcl } \\
\text { oromucosal spray, } \\
\text { mean dose } 10.9 \\
\text { sprays/day (63) } \\
\text { B: Placebo (62) } \\
5 \text { weeks } \\
\text { Whole plant extracted }\end{array}$ & $\begin{array}{l}\text { Pain response } \geq 30 \% \text { (NRS scale): } \\
16 / 73(25.4 \%) \text { vs. } 9 / 62(14.52 \%) \text {, } \\
\text { RR } 1.75(95 \% \text { Cl } 0.84 \text { to } 3.66) \\
\text { Pain severity (mean [SD NR] } 0 \text { to } 10 \\
\text { NRS scale): } 5.82 \text { vs. } 6.68 \text {, treatment } \\
\text { difference }-0.96 \text { ( } 95 \% \mathrm{Cl}-1.59 \text { to } \\
-0.32)\end{array}$ & $\begin{array}{l}\text { Function (0 to } 70 \text { Pain } \\
\text { Disability Index scale): } \\
\text { MD } \\
-5.85(95 \% \mathrm{Cl}-9.62 \\
\text { to }-2.09)\end{array}$ & $\begin{array}{l}\text { SAE: } 1 / 63(1.6 \%) \text { vs. } \\
\text { 0/62 (0\%) } \\
\text { WAE: } 11 / 63(17.46 \%) \\
\text { vs. } 2 / 62(3.23 \%)\end{array}$ \\
\hline $\begin{array}{l}\text { Rog, } 2005 \\
\text { Moderate } \\
\text { RCT } \\
\text { Neuropathic pain- } \\
\text { multiple sclerosis }\end{array}$ & $\begin{array}{l}\text { A: } 2.7 \mathrm{mg} \mathrm{THC} / 2.5 \mathrm{mg} \\
\mathrm{CBD} / 100 \mathrm{mcl} \\
\text { oromucosal spray, } \\
\text { mean dose } 9.6 \\
\text { sprays/day (34) } \\
\text { B: Placebo (32) } \\
5 \text { weeks } \\
\text { Whole plant extracted }\end{array}$ & $\begin{array}{l}\text { Pain severity (mean }[95 \% \mathrm{Cl}] 0 \text { to } 10 \\
\text { NRS scale): } 3.85(3.13 \text { to } 4.58) \text { vs. } \\
4.96(4.19 \text { to } 5.72) \text {, treatment } \\
\text { difference }-1.25(95 \% \mathrm{Cl}-2.11 \text { to } \\
-0.39)\end{array}$ & NR & $\begin{array}{l}\text { SAE: } 0 / 34(0 \%) \text { vs. } \\
\text { 0/32 }(0 \%) \\
\text { WAE: } 2 / 34(5.88 \%) \text { vs. } \\
0 / 32(0 \%)\end{array}$ \\
\hline $\begin{array}{l}\text { Selvarajah, } 2010 \\
\text { High } \\
\text { RCT } \\
\text { Neuropathic pain- } \\
\text { diabetic neuropathy }\end{array}$ & $\begin{array}{l}\text { A: } 2.7 \mathrm{mg} \mathrm{THC} / 2.5 \mathrm{mg} \\
\text { CBD/100 mcl } \\
\text { oromucosal spray, } \\
\text { mean dose } 7 \\
\text { sprays/day }{ }^{\mathrm{d}}(15) \\
\text { B: Placebo (14) } \\
12 \text { weeks } \\
\text { Whole plant extracted }\end{array}$ & $\begin{array}{l}\text { Pain severity (mean [SD] } 0 \text { to } 100 \\
\text { NPS scale): } 51.6 \text { (21.9) vs. } 51.9 \\
\text { (24.1), MD }-0.3 \text { (SE } 8.54)(95 \% \mathrm{Cl} \\
-17.83 \text { to } 17.23)\end{array}$ & $\begin{array}{l}\text { Function (mean [SD] } 0 \\
\text { to } 100 \text { SF-36 Physical } \\
\text { Functioning scale): } \\
30.5(16.6) \text { vs. } 36.5 \\
(27.9), \mathrm{MD} 6 \text { (SE } 8.5) \\
(95 \% \mathrm{Cl} \\
-11.35 \text { to } 23.35)\end{array}$ & NR \\
\hline $\begin{array}{l}\text { Serpell, } 2014 \\
\text { Moderate } \\
\text { RCT } \\
\text { Neuropathic pain- } \\
\text { mixed }\end{array}$ & $\begin{array}{l}\text { A: } 2.7 \mathrm{mg} \mathrm{THC} / 2.5 \mathrm{mg} \\
\mathrm{CBD} / 100 \mathrm{mcl} \\
\text { oromucosal spray, } \\
\text { mean dose } 8.9 \\
\text { sprays/day }(128) \\
\text { B: Placebo }(118) \\
15 \text { weeks } \\
\text { Whole plant extracted }\end{array}$ & $\begin{array}{l}\text { Pain response } \geq 30 \% \text { (NRS scale): } \\
34 / 123(27.64 \%) \text { vs. } 19 / 117 \\
(16.24 \%), \mathrm{RR} 1.7(95 \% \mathrm{Cl} 1.03 \text { to } \\
2.91) \\
\text { Pain severity (mean [SE NR] } 0 \text { to } 10 \\
\text { NRS scale): Mean reduction }-0.34 \\
(0.23)(95 \% \mathrm{Cl}-0.79 \text { to } 0.11)\end{array}$ & $\begin{array}{l}\text { Pain interference (0 to } \\
10 \mathrm{BPI}-\mathrm{SF} \text { scale): } \\
\text { Treatment difference } \\
-0.32 \text { (SE } 0.241)(95 \% \\
\mathrm{Cl}-0.8 \text { to } 0.15)\end{array}$ & $\begin{array}{l}\text { SAE: } 10 / 128(7.81 \%) \\
\text { vs. } 6 \% \\
\text { WAE: } 25 / 128(19.53 \%) \\
\text { vs. } 25 / 118(21.19 \%)\end{array}$ \\
\hline
\end{tabular}

Abbreviations: BPI-SF = brief pain inventory-short form; $\mathrm{CBD}=$ cannabidiol; $\mathrm{CI}=$ confidence interval; $\mathrm{MD}=$ mean difference; NPS = neuropathic pain scale; NR = not reported; $\mathrm{NRS}=$ numeric rating scale; NRS $-\mathrm{PI}=$ numeric rating scale for pain intensity; $\mathrm{SAE}=$ serious adverse events; $\mathrm{SD}=$ standard deviation; $\mathrm{SE}=$ standard error; $\mathrm{SF}-36=$ short

form-36; THC = tetrahydrocannabinol; RCT $=$ randomized controlled trial; $\mathrm{RR}=$ relative risk; WAE $=$ withdrawal due to due adverse events

a Other serious adverse events (i.e., psychosis and cannabis use disorder) not reported in any study.

${ }^{b}$ Difference in median differences.

Difference in mean differences.

${ }^{\mathrm{d}}$ Mean sprays calculated by systematic review team. 
Table D-2. High-THC to CBD ratio study primary outcomes

\begin{tabular}{|c|c|c|c|c|}
\hline $\begin{array}{l}\text { Author, Year } \\
\text { Risk of Bias } \\
\text { Study Design } \\
\text { Pain Condition }\end{array}$ & $\begin{array}{l}\text { Comparison (n) } \\
\text { Followup Duration } \\
\text { Derivative }\end{array}$ & $\begin{array}{l}\text { Primary Pain Outcomes } \\
\text { (Response, Severity) }\end{array}$ & $\begin{array}{l}\text { Overall Function/Disability } \\
\text { (Including Pain } \\
\text { Interference) }\end{array}$ & $\begin{array}{l}\text { Serious Adverse Events } \\
\text { and Withdrawals Due to } \\
\text { Adverse Events }^{\mathrm{a}}\end{array}$ \\
\hline $\begin{array}{l}\text { Chaves, } 2020 \\
\text { Low } \\
\text { RCT } \\
\text { Fibromyalgia }\end{array}$ & $\begin{array}{l}\text { A: } 1.2 \mathrm{mg} \text { THC/0.02 mg } \\
\text { CBD sublingual drops, } \\
\text { mean } 3.6 \text { drops/day ( } 8) \\
\text { B: Placebo (9) } \\
8 \text { weeks } \\
\text { Whole plant extracted }\end{array}$ & $\begin{array}{l}\text { Pain severity (mean [SD] } 0 \text { to } 10 \\
\text { FIQ scale): } 3.75(2.49) \text { vs. } 7.67 \\
(1.84), \mathrm{MD}-3.92(1.05)(95 \% \mathrm{Cl} \\
-6.17 \text { to }-1.68)\end{array}$ & $\begin{array}{l}\text { Function (mean [SD] } 0 \text { to } 10 \\
\text { FIQ scale): } 5.83(2.02) \text { vs. } \\
4.07(2.25), \mathrm{MD} 1.76(1.04) \\
(95 \% \mathrm{Cl}-0.46 \text { to } 3.98)\end{array}$ & WAE: 0/8 (0\%) vs. 0/9 (0\%) \\
\hline $\begin{array}{l}\text { de Vries, } 2017 \\
\text { Moderate } \\
\text { RCT } \\
\text { Visceral pain- chronic } \\
\text { pancreatitis and } \\
\text { postsurgical abdominal } \\
\text { pain }\end{array}$ & $\begin{array}{l}\text { A: THC oral tablet } \\
\text { (Dronabinol), range } 15 \text { to } \\
24 \text { mg/day }(30) \\
\text { B: Placebo (32) } \\
7 \text { weeks } \\
\text { Synthetic }\end{array}$ & $\begin{array}{l}\text { Pain severity (mean [SD] } 0 \text { to } 10 \\
\text { VAS scale): } 2.4 \text { (2.28) vs. } 3.5 \\
\text { (2.42), MD }-1.1 \text { (SE } 0.68)(95 \% \mathrm{Cl} \\
-2.46 \text { to } 0.26)\end{array}$ & NR & $\begin{array}{l}\text { WAE: } 7 / 30(23.33 \%) \text { vs. } 2 / 32 \\
(6.25 \%)\end{array}$ \\
\hline $\begin{array}{l}\text { Frank, } 2008 \\
\text { Moderate } \\
\text { RCT (crossover) } \\
\text { Neuropathic pain }\end{array}$ & $\begin{array}{l}\text { A: THC oral capsule } \\
\text { (Nabilone), max dose } 2 \\
\text { mg/day (48) } \\
\text { B: Dihydrocodeine } 30 \\
\text { mg, max dose } 240 \\
\text { mg/day (48) } \\
6 \text { weeks } \\
\text { Synthetic }\end{array}$ & $\begin{array}{l}\text { Pain severity (mean [SD NR] } 0 \text { to } \\
100 \text { VAS scale): Treatment effect } \\
5.7(95 \% \mathrm{Cl} 0.5 \text { to } 10.9)\end{array}$ & $\begin{array}{l}\text { Function (mean [SD NR] } 0 \text { to } \\
100 \text { SF-36 Physical } \\
\text { Functioning scale): Treatment } \\
\text { effect } 10.8 \text { ( } 95 \% \text { Cl } 2.3 \text { to } \\
19.2)\end{array}$ & $\begin{array}{l}\text { SAE: } 0 / 48(0 \%) \text { vs. } 0 / 48(0 \%) \\
\text { WAE: } 2 / 48(4 \%) \text { vs. } 6 / 48 \\
(12.5 \%)\end{array}$ \\
\hline
\end{tabular}




\begin{tabular}{|c|c|c|c|c|}
\hline $\begin{array}{l}\text { Author, Year } \\
\text { Risk of Bias } \\
\text { Study Design } \\
\text { Pain Condition }\end{array}$ & $\begin{array}{l}\text { Comparison (n) } \\
\text { Followup Duration } \\
\text { Derivative }\end{array}$ & $\begin{array}{l}\text { Primary Pain Outcomes } \\
\text { (Response, Severity) }\end{array}$ & $\begin{array}{l}\text { Overall Function/Disability } \\
\text { (Including Pain } \\
\text { Interference) }\end{array}$ & $\begin{array}{l}\text { Serious Adverse Events } \\
\text { and Withdrawals Due to } \\
\text { Adverse Events }^{\mathrm{a}}\end{array}$ \\
\hline $\begin{array}{l}\text { Pini, } 2012 \\
\text { Low } \\
\text { RCT (crossover) } \\
\text { Headache- medication } \\
\text { overuse headache }\end{array}$ & $\begin{array}{l}\text { A: THC } 0.5 \mathrm{mg} \text { oral } \\
\text { capsule (Nabilone) daily } \\
(26) \\
\text { B: Ibuprofen } 400 \mathrm{mg} / \mathrm{day} \\
(26) \\
8 \text { weeks } \\
\text { Synthetic }\end{array}$ & $\begin{array}{l}\text { Pain severity (mean [SD] } 0 \text { to } 10 \\
\text { VAS scale): } 5.55(2.5) \text { vs. } 6.75 \\
(2.4), \mathrm{MD}-1.2(0.68)(95 \% \mathrm{Cl}-2.57 \\
\text { to } 0.17)\end{array}$ & NR & $\begin{array}{l}\text { WAE: } 1 / 30(3.33 \%) \text { vs. } 1 / 30 \\
(3.33 \%)\end{array}$ \\
\hline $\begin{array}{l}\text { Rintala, } 2010 \\
\text { High } \\
\text { RCT (crossover) } \\
\text { Neuropathic pain- spinal } \\
\text { cord injury }\end{array}$ & $\begin{array}{l}\text { A: THC } 5 \text { mg oral } \\
\text { capsule (Dronabinol), } \\
\text { max dose } 20 \text { mg/day (7) } \\
\text { B: Diphenhydramine } 25 \\
\text { mg, max dose } 75 \mathrm{mg} / \text { day } \\
(5) \\
47 \text { weeks } \\
\text { Synthetic }\end{array}$ & $\begin{array}{l}\text { Pain severity (mean [SD NR] } 0 \text { to } \\
10 \text { BPI scale): } 5.8 \text { vs. } 5.8\end{array}$ & NR & $\begin{array}{l}\text { SAE: } 1 / 7(14.29 \%) \text { vs. } 1 / 5 \\
(20 \%) \\
\text { WAE: } 1 / 7(14.29 \%) \text { vs. } 0 / 5 \\
(0 \%)\end{array}$ \\
\hline $\begin{array}{l}\text { Schimrigk, } 2017 \\
\text { Low } \\
\text { RCT } \\
\text { Neuropathic pain- multiple } \\
\text { sclerosis }\end{array}$ & $\begin{array}{l}\text { A: THC } 2.5 \mathrm{mg} \text { oral } \\
\text { capsule (Dronabinol), } \\
\text { mean dose } 13 \mathrm{mg} / \mathrm{day} \\
(124) \\
\text { B: Placebo }(116) \\
16 \text { weeks } \\
\text { Synthetic }\end{array}$ & $\begin{array}{l}\text { Pain severity (mean [SD] } 0 \text { to } 10 \\
\text { NRS scale): } 4.48(2.04) \text { vs. } 4.92 \\
(2.04), M D N R, p=0.676\end{array}$ & NR & $\begin{array}{l}\text { SAE: } 12 / 124(9.68 \%) \text { vs. } \\
7 / 116(6.03 \%) \\
\text { WAE: } 19 / 124(15.32 \%) \text { vs. } \\
12 / 116(10.34 \%)\end{array}$ \\
\hline $\begin{array}{l}\text { Skrabek, } 2008 \\
\text { Moderate } \\
\text { RCT } \\
\text { Fibromyalgia }\end{array}$ & $\begin{array}{l}\text { A: THC } 0.5 \mathrm{mg} \text { oral } \\
\text { capsule (Nabilone), } \\
\text { endpoint dose } 2 \mathrm{mg} / \text { day } \\
(15) \\
\text { B: Placebo (18) } \\
4 \text { weeks } \\
\text { Synthetic }\end{array}$ & $\begin{array}{l}\text { Pain severity (mean [SD NR] } 0 \text { to } \\
10 \text { VAS scale): } 4.8 \text { vs. } 5.6, M D \\
-1.43, p<0.05\end{array}$ & NR & $\begin{array}{l}\text { SAE: } 0 / 15(0 \%) \text { vs. } 0 / 18(0 \%) \\
\text { WAE: } 1 / 20(5 \%) \text { vs. } 1 / 20(5 \%)\end{array}$ \\
\hline $\begin{array}{l}\text { Toth, } 2012 \\
\text { Low } \\
\text { RCT } \\
\text { Neuropathic pain- diabetic } \\
\text { neuropathy }\end{array}$ & $\begin{array}{l}\text { A: THC } 0.5 \mathrm{mg} \text { oral } \\
\text { capsule (Nabilone), max } \\
\text { dose } 4 \mathrm{mg} / \text { day (13) } \\
\text { B: Placebo (13) } \\
5 \text { weeks } \\
\text { Synthetic }\end{array}$ & $\begin{array}{l}\text { Pain response } \geq 30 \% \text { (NRS scale): } \\
11 / 13(84.62 \%) \text { vs. } 5 / 13(38.46 \%) \\
\text { RR } 2.2(95 \% \text { Cl } 1.06 \text { to } 4.55) \\
\text { Pain severity (mean }[S D] 0 \text { to } 10 \\
\text { NRS scale): } 3.5(1.3) \text { vs. } 5.4(1.7) \text {, } \\
\text { MD }-1.9(0.59)(95 \% \mathrm{Cl}-3.13 \text { to } \\
-0.68)\end{array}$ & $\begin{array}{l}\text { Pain interference (mean [SD] } \\
0 \text { to } 10 \mathrm{MBPI} \text { scale): } 2.5(1.6) \\
\text { vs. } 3.6(0.9), \mathrm{MD}-1.1(0.51) \\
(95 \% \mathrm{Cl}-2.15 \text { to }-0.05)\end{array}$ & NR \\
\hline
\end{tabular}




\begin{tabular}{|c|c|c|c|c|}
\hline $\begin{array}{l}\text { Author, Year } \\
\text { Risk of Bias } \\
\text { Study Design } \\
\text { Pain Condition }\end{array}$ & $\begin{array}{l}\text { Comparison (n) } \\
\text { Followup Duration } \\
\text { Derivative }\end{array}$ & $\begin{array}{l}\text { Primary Pain Outcomes } \\
\text { (Response, Severity) }\end{array}$ & $\begin{array}{l}\text { Overall Function/Disability } \\
\text { (Including Pain } \\
\text { Interference) }\end{array}$ & $\begin{array}{l}\text { Serious Adverse Events } \\
\text { and Withdrawals Due to } \\
\text { Adverse Events }^{\mathrm{a}}\end{array}$ \\
\hline $\begin{array}{l}\text { Turcotte, } 2015 \\
\text { Moderate } \\
\text { RCT } \\
\text { Neuropathic pain- multiple } \\
\text { sclerosis }\end{array}$ & $\begin{array}{l}\text { A: THC } 0.5 \text { mg oral } \\
\text { capsule (Nabilone), max } \\
\text { dose } 2 \text { mg/day (8) } \\
\text { B: Placebo (7) } \\
9 \text { weeks } \\
\text { Synthetic }\end{array}$ & $\begin{array}{l}\text { Pain severity (mean [SD NR] } 0 \text { to } \\
100 \text { VAS scale): } 35 \text { vs. } 57^{\mathrm{b}}\end{array}$ & $\begin{array}{l}\text { Pain interference (mean [SD } \\
\text { NR] } 0 \text { to } 100 \text { VAS impact } \\
\text { scale): } 41 \text { vs. } 40^{\mathrm{b}}\end{array}$ & $\begin{array}{l}\text { SAE: } 0 / 8(0 \%) \text { vs. } 0 / 7(0 \%) \\
\text { WAE: } 1 / 8(12.5 \%) \text { vs. } 0 / 7 \\
(0 \%)\end{array}$ \\
\hline $\begin{array}{l}\text { Wissel, } 2006 \\
\text { High } \\
\text { RCT (crossover) } \\
\text { Neuropathic pain- multiple } \\
\text { sclerosis }\end{array}$ & $\begin{array}{l}\text { A: THC } 0.5 \mathrm{mg} \text { oral } \\
\text { capsule (Nabilone), } \\
\text { endpoint dose } 1 \mathrm{mg} / \text { day } \\
(13) \\
\text { B: Placebo (13) } \\
4 \text { weeks } \\
\text { Synthetic }\end{array}$ & $\begin{array}{l}\text { Pain severity (median [SD NR] } 11 \\
\text { Point Box Test): } 4 \text { vs. } 6, p<0.05\end{array}$ & NR & $\begin{array}{l}\text { WAE: } 2 / 13(15.38 \%) \text { vs. } 0 / 13 \\
(0 \%)\end{array}$ \\
\hline $\begin{array}{l}\text { Zajicek, } 2012 \\
\text { Moderate } \\
\text { RCT } \\
\text { Neuropathic pain- multiple } \\
\text { sclerosis }\end{array}$ & $\begin{array}{l}\text { A: THC } 2.5 \mathrm{mg} \text { capsule, } \\
\text { max dose } 25 \mathrm{mg} / \text { day } \\
(143) \\
\text { B: Placebo (134) } \\
12 \text { weeks } \\
\text { Whole plant extracted }\end{array}$ & $\begin{array}{l}\text { Pain severity (mean [SD] } 0 \text { to } 10 \\
\text { CRS scale): } 4.1(2.9) \text { vs. } 4.7(3.0) \text {, } \\
\text { MD }-0.6(95 \% \mathrm{Cl}-1.3 \text { to } 0.1)\end{array}$ & NR & $\begin{array}{l}\text { SAE: } 7 / 143(4.9 \%) \text { vs. } 3 / 134 \\
(2.24 \%) \\
\text { WAE: } 30 / 143(20.98 \%) \text { vs. } \\
9 / 134(6.72 \%)\end{array}$ \\
\hline
\end{tabular}

Abbreviations: $\mathrm{BPI}=$ brief pain inventory; $\mathrm{CBD}=$ cannabidiol; $\mathrm{CI}=$ confidence interval; $\mathrm{CRS}=$ category rating scale; FIQ = fibromyalgia impact questionnaire; $\mathrm{MBPI}=$ modified brief pain inventory; $\mathrm{MD}=$ mean difference; $\mathrm{NR}=$ not reported; $\mathrm{NRS}=$ numeric rating scale; $\mathrm{RCT}=$ randomized controlled trial; $\mathrm{SAE}=$ serious adverse events; $\mathrm{SD}=$ standard deviation; $\mathrm{SE}=$ standard error; $\mathrm{THC}=$ tetrahydrocannabinol; $\mathrm{RR}=$ relative risk; VAS $=$ visual analog scale; WAE $=$ withdrawal due to due adverse events

${ }^{a}$ Other serious adverse events (i.e., psychosis and cannabis use disorder) not reported in any study.

${ }^{\mathrm{b}}$ Estimated from graph. 
Table D-3. Low-THC to CBD ratio study primary outcomes

\begin{tabular}{|c|c|c|c|c|}
\hline $\begin{array}{l}\text { Author, Year } \\
\text { Risk of Bias } \\
\text { Study Design } \\
\text { Pain Condition }\end{array}$ & $\begin{array}{l}\text { Comparison }(\mathrm{n}) \\
\text { Followup Duration } \\
\text { Derivative }\end{array}$ & $\begin{array}{l}\text { Primary Pain Outcomes } \\
\text { (Response, Severity) }\end{array}$ & $\begin{array}{l}\text { Overall Function/Disability } \\
\text { (Including Pain Interference) }\end{array}$ & $\begin{array}{l}\text { Serious Adverse Events and } \\
\text { Withdrawals Due to Adverse } \\
\text { Events }^{\text {a }}\end{array}$ \\
\hline $\begin{array}{l}\text { Xu, } 2020 \\
\text { High } \\
\text { RCT (crossover) } \\
\text { Neuropathic pain- } \\
\text { mixed }\end{array}$ & $\begin{array}{l}\text { A: CBD cream (250 } \\
\text { mg/3 oz) up to } 4 \text { times } \\
\text { daily (15) } \\
\text { B: Placebo (14) } \\
4 \text { weeks } \\
\text { Whole plant extracted }\end{array}$ & $\begin{array}{l}\text { Pain severity (mean [SD] } 0 \text { to } 10 \\
\text { NPS scale): } 3.33(2.02) \text { vs. } 5.55 \\
(2.81), \mathrm{MD}-2.22(95 \% \mathrm{Cl}-4.07 \\
\text { to }-0.37)\end{array}$ & NR & SAE: $0 / 15(0 \%)$ vs. 0/14 (0\%) \\
\hline
\end{tabular}

Abbreviations: $\mathrm{CBD}=$ cannabidiol; $\mathrm{MD}=$ mean difference; NPS = neuropathic pain scale; $\mathrm{NR}=$ not reported; RCT = randomized controlled trial; $\mathrm{SAE}=$ serious adverse event; $\mathrm{SD}=$ standard deviation; $\mathrm{THC}=$ tetrahydrocannabinol.

${ }^{a}$ Other serious adverse events (i.e., psychosis and cannabis use disorder) not reported in any study.

\section{Table D-4. Other cannabinoids study primary outcomes}

\begin{tabular}{|c|c|c|c|c|}
\hline $\begin{array}{l}\text { Author, Year } \\
\text { Risk of Bias } \\
\text { Study Design } \\
\text { Pain Condition }\end{array}$ & $\begin{array}{l}\text { Comparison }(\mathrm{n}) \\
\text { Followup Duration } \\
\text { Derivative }\end{array}$ & $\begin{array}{l}\text { Primary Pain Outcomes } \\
\text { (Response, Severity) }\end{array}$ & $\begin{array}{l}\text { Overall Function/Disability } \\
\text { (Including Pain Interference) }\end{array}$ & $\begin{array}{l}\text { Serious Adverse Events and } \\
\text { Withdrawals Due to Adverse } \\
\text { Events }^{\mathrm{a}}\end{array}$ \\
\hline $\begin{array}{l}\text { Eibach, } 2020 \\
\text { Moderate } \\
\text { RCT (crossover) } \\
\text { Neuropathic pain- HIV } \\
\text { associated }\end{array}$ & $\begin{array}{l}\text { A: CBDV oral solution } \\
(50 \mathrm{mg} / \mathrm{mL}) 400 \\
\mathrm{mg} / \mathrm{day}(16) \\
\text { B: Placebo (16) } \\
4 \text { weeks } \\
\text { Whole plant extracted }\end{array}$ & $\begin{array}{l}\text { Pain response } \geq 30 \% \text { (NRS } \\
\text { scale): } 6 / 16(37.5 \%) \text { vs. } 13 / 16 \\
(81.25 \%) \text {, RR NR } \\
\text { Pain severity (mean [SD] } 0 \text { to } 10 \\
\text { NRS scale): } 2.74(1.47) \text { vs. } 3.67 \\
\text { (2.62), MD }-0.62(95 \% \mathrm{Cl}-0.27 \\
\text { to } 1.51)\end{array}$ & $\begin{array}{l}\text { Pain interference (0 to } 10 \mathrm{BPI}-\mathrm{SF} \\
\text { scale): } \mathrm{MD}-0.35(95 \% \mathrm{Cl}-1.36 \text { to } \\
0.43)\end{array}$ & $\begin{array}{l}\text { SAE: } 1 / 16(6.25 \%) \text { vs. } 0 / 16(0 \%) \\
\text { WAE: } 1 / 16(6.25 \%) \text { vs. } 0 / 16(0 \%)\end{array}$ \\
\hline
\end{tabular}

Abbreviations: $\mathrm{CBDV}=$ cannabidivarin; $\mathrm{HIV}=$ human immunodeficiency virus; $\mathrm{MD}=$ mean difference; $\mathrm{NR}=$ not reported; $\mathrm{RCT}=$ randomized controlled trial; $\mathrm{RR}=$ relative risk;

$\mathrm{SAE}=$ serious adverse event; $\mathrm{SD}=$ standard deviation.

${ }^{a}$ Other serious adverse events (i.e., psychosis and cannabis use disorder) not reported in any study. 
Table D-5. Observational study primary outcomes

\begin{tabular}{|c|c|c|c|c|}
\hline $\begin{array}{l}\text { Author, Year } \\
\text { Risk of Bias } \\
\text { Study Design } \\
\text { Pain Condition }\end{array}$ & $\begin{array}{l}\text { Comparison (n) } \\
\text { Followup Duration } \\
\text { Derivative }\end{array}$ & $\begin{array}{l}\text { Primary Pain Outcomes } \\
\text { (Response, Severity) }\end{array}$ & $\begin{array}{l}\text { Overall Function/Disability } \\
\text { (including Pain Interference) }\end{array}$ & $\begin{array}{l}\text { Serious Adverse Events and } \\
\text { Withdrawals Due to Adverse } \\
\text { Events }\end{array}$ \\
\hline $\begin{array}{l}\text { Bestard, } 2011 \\
\text { Moderate } \\
\text { Prospective cohort } \\
\text { Neuropathic pain- } \\
\text { mixed }\end{array}$ & $\begin{array}{l}\text { A: THC oral capsule } \\
\text { (Nabilone), mean dose } \\
3.05 \text { mg/day (49) } \\
\text { B: Gabapentin, mean } \\
\text { dose } 2,295.5 \text { mg/day } \\
\text { (52) } \\
\text { C: Gabapentin + THC } \\
\text { capsule, mean dose } \\
\text { NR + 3.02 mg/day (55) } \\
6 \text { months } \\
\text { Synthetic }\end{array}$ & $\begin{array}{l}\text { Pain intensity (mean [SD] } 0 \text { to } \\
100 \text { VAS scale): } 28.0(10.5) \text { vs. } \\
33.8(11.6) \text { vs. } 33.1(20.2), \mathrm{MD} \\
-5.8(95 \% \mathrm{Cl}-10.18 \text { to }-1.42) \\
\text { for A vs. B, }-5.1(95 \% \mathrm{Cl}-11.48 \\
\text { to } 1.28) \text { for A vs. C }\end{array}$ & $\begin{array}{l}\text { Pain interference (mean [SD] } 0 \text { to } \\
10 \mathrm{BPI} \text { scale): } 4.5(2.3) \text { vs. } 4.6(2.2) \\
\text { vs. } 4.5(2.2), \mathrm{MD}-0.1(95 \% \mathrm{Cl} \\
-0.99 \text { to } 0.79) \text { for } \mathrm{A} \text { vs. } \mathrm{B}, 0.00 \\
(95 \% \mathrm{Cl}-0.88 \text { to } 0.88) \text { for A vs. C } \\
\text { Function (mean [SD] } 0 \text { to } 100 \text { SF- } \\
36 \text { scale): } 48.3(27.2) \text { vs. } 46.5 \\
(25.1) \text { vs. } 43.7(26.4), \mathrm{MD} 1.80 \\
(95 \% \mathrm{Cl}-8.53 \text { to } 12.13) \text { for } \mathrm{A} \text { vs. } \\
\mathrm{B}, 4.60(95 \% \mathrm{Cl}-5.83 \text { to } 15.03) \text { for } \\
\text { A vs. C }\end{array}$ & $\begin{array}{l}\text { SAE: } 0 / 49(0 \%) \text { vs. } 0 / 52(0 \%) \text { vs. } \\
\text { 0/55 }(0 \%) \\
\text { WAE: } 5 / 49(10 \%) \text { vs. } 12 / 52(23 \%) \\
\text { vs. } 5 / 55(9 \%)\end{array}$ \\
\hline $\begin{array}{l}\text { Campbell, } 2018 \\
\text { Moderate }\end{array}$ & $\begin{array}{l}\text { A: Self-reported } \\
\text { frequent cannabis use } \\
\text { of } \geq 20 \text { days/mo } \\
\text { B: No cannabis use } \\
\text { Overall N } \\
\text { Baseline: } 1,514 \\
\text { 4-year followup: } 1,217 \\
\text { Groups unclear } \\
4 \text { years } \\
\text { Unclear THC } \\
\text { concentration; patient- } \\
\text { driven choice }\end{array}$ & $\begin{array}{l}\text { A vs. B (reference) } \\
\text { Pain intensity (Adjusted mean } \\
\text { [SE]; BPI, } 0-10 \text { scale): } 5.2(0.14) \\
\text { vs. } 4.9(0.03) ; \text { Beta: } 0.37(95 \% \\
\text { Cl, }-0.23 \text { to } 1.10), p=0.20\end{array}$ & $\begin{array}{l}\text { A vs. B } \\
\text { Pain Interference (Adjusted mean } \\
\text { [SE]; BPI pain interference, } 0-10 \\
\text { Scale): } 5.2(0.19) \text { vs. } 5.4(0.04) ; \\
\text { Beta: }-0.63(95 \% \mathrm{Cl},-1.46 \text { to } \\
0.19), p=0.13\end{array}$ & NR \\
\hline $\begin{array}{l}\text { Gruber, } 2021 \\
\text { High } \\
\text { Prospective cohort } \\
\text { Mixed (primarily } \\
\text { musculoskeletal) }\end{array}$ & $\begin{array}{l}\text { A: THC/CBD: } \\
\text { Medicinal cannabis } \\
\text { program, mean dose } \\
\text { THC } 13.3 \mathrm{mg} / \text { day, } \\
\text { CBD } 28.9 \mathrm{mg} / \text { day (37) } \\
\text { B: Usual care, dose } \\
\text { NA (9) } \\
12 \text { weeks } \\
\text { Mixed cannabis } \\
\text { products }\end{array}$ & $\begin{array}{l}\text { Pain intensity (mean [SD] } 0 \text { to } \\
100 \text { VAS scale): } 34.07(22.36) \\
\text { vs. } 48.78 \text { (30.42); MD }-14.71 \\
(95 \% \mathrm{Cl},-32.71 \text { to } 3.29)\end{array}$ & $\begin{array}{l}\text { A vs. B } \\
\text { Function (mean [SD], } 0 \text { to } 10 \text { PDI } \\
\text { scale): } 18.13(12.26) \text { vs. } 19.22 \\
(12.73) ; \mathrm{MD}-1.09(95 \% \mathrm{Cl}-10.33 \\
\text { to } 8.16) \\
\text { SF-36 Function (mean [SD], } 0 \text { to } \\
\left.100 \text { scale }^{\mathrm{a}}\right): 70.00(22.87) \text { vs. } \\
69.44(26.98) ; \mathrm{MD} 0.56(95 \% \mathrm{Cl} \\
-17.17 \text { to } 18.29)\end{array}$ & NR \\
\hline
\end{tabular}




\begin{tabular}{|c|c|c|c|c|}
\hline $\begin{array}{l}\text { Author, Year } \\
\text { Risk of Bias } \\
\text { Study Design } \\
\text { Pain Condition }\end{array}$ & $\begin{array}{l}\text { Comparison }(\mathrm{n}) \\
\text { Followup Duration } \\
\text { Derivative }\end{array}$ & $\begin{array}{l}\text { Primary Pain Outcomes } \\
\text { (Response, Severity) }\end{array}$ & $\begin{array}{l}\text { Overall Function/Disability } \\
\text { (including Pain Interference) }\end{array}$ & $\begin{array}{l}\text { Serious Adverse Events and } \\
\text { Withdrawals Due to Adverse } \\
\text { Events }\end{array}$ \\
\hline $\begin{array}{l}\text { Lee, } 2021^{\mathrm{b}} \\
\text { Moderate } \\
\text { Matched cohort } \\
\text { NR }\end{array}$ & $\begin{array}{l}\text { A: Chronic opioid } \\
\text { users authorized to } \\
\text { use medical cannabis } \\
\text { in Canada }(5,373) \\
\mathrm{B} \text { : Controls who did } \\
\text { not receive } \\
\text { authorization for } \\
\text { medical cannabis in } \\
\text { Canada }(5,373) \\
20 \text { months } \\
\text { Unknown THC } \\
\text { concentration; patient- } \\
\text { driven choice }\end{array}$ & NR & NR & NR \\
\hline $\begin{array}{l}\text { Merlin, 2019b } \\
\text { High } \\
\text { Prospective cohort } \\
\text { Chronic non-cancer } \\
\text { pain (HIV) }\end{array}$ & $\begin{array}{l}\text { A: Daily or weekly use } \\
\text { of marijuana (55) } \\
\text { B: Monthly or } 1-2 \text { times } \\
\text { a month use of } \\
\text { marijuana (65) } \\
\text { C: No use (313) } \\
52 \text { weeks } \\
\text { Unknown THC } \\
\text { concentration; patient- } \\
\text { driven choice }\end{array}$ & NR & NR & NR \\
\hline $\begin{array}{l}\text { Vigil, } 2017^{\mathrm{b}} \\
\text { High } \\
\text { Preliminary historical } \\
\text { cohort } \\
\text { Mixed musculoskeletal } \\
\text { pain }\end{array}$ & $\begin{array}{l}\text { A: THC/CBD: } \\
\text { Participation in New } \\
\text { Mexico Medical } \\
\text { Cannabis Program } \\
\text { (37) } \\
\text { B: Not participating in } \\
\text { medical marijuana } \\
\text { program and not using } \\
\text { cannabis (29) } \\
21 \text { months } \\
\text { Unknown THC } \\
\text { concentration }\end{array}$ & NR & NR & NR \\
\hline
\end{tabular}




\begin{tabular}{|c|c|c|c|c|}
\hline $\begin{array}{l}\text { Author, Year } \\
\text { Risk of Bias } \\
\text { Study Design } \\
\text { Pain Condition }\end{array}$ & $\begin{array}{l}\text { Comparison }(\mathrm{n}) \\
\text { Followup Duration } \\
\text { Derivative }\end{array}$ & $\begin{array}{l}\text { Primary Pain Outcomes } \\
\text { (Response, Severity) }\end{array}$ & $\begin{array}{l}\text { Overall Function/Disability } \\
\text { (including Pain Interference) }\end{array}$ & $\begin{array}{l}\text { Serious Adverse Events and } \\
\text { Withdrawals Due to Adverse } \\
\text { Events }\end{array}$ \\
\hline $\begin{array}{l}\text { Ware, } 2015 \\
\text { High } \\
\text { Prospective cohort } \\
\text { Chronic non-cancer } \\
\text { pain }\end{array}$ & $\begin{array}{l}\text { A: THC } 12.5+/-1.5 \% \\
\text { herbal cannabis, } \\
\text { median dose } 2.5 \mathrm{~g} / \text { day } \\
(215) \\
\text { B: Usual care }(216) \\
13 \text { months } \\
\text { Whole plant non- } \\
\text { extracted }\end{array}$ & NR & NR & $\begin{array}{l}\text { SAE: } 28 / 215(13 \%) \text { vs. } 42 / 216 \\
(19.4 \%) \\
\text { WAE: } 10 / 215(4.65 \%) \text { vs. NR } \\
\text { (assumed 0) }\end{array}$ \\
\hline
\end{tabular}

Abbreviations: $\mathrm{BPI}=$ brief pain inventory; $\mathrm{CI}=$ confidence interval; $\mathrm{MD}=$ mean difference; $\mathrm{NR}=$ not reported; $\mathrm{SAE}=$ serious adverse events; $\mathrm{SD}=$ standard deviation; $\mathrm{SF}-36=$ short form-36; THC = tetrahydrocannabinol; VAS = visual analog scale; WAE = withdrawal due to due adverse events.

${ }^{a}$ Higher scores indicate better outcomes.

${ }^{\mathrm{b}}$ Only included outcome reported was opioid-use. 


\section{Appendix D-2. Meta-Analyses}

\section{Comparable THC to CBD Ratio Studies}

Pooled results and the forest plot for the sensitivity analysis conducted for improvement in pain severity are available upon request by emailing wagnerje@ohsu.edu.

Figure D-1. Proportion of patients with pain response ( $\geq 30 \%$ improvement) with comparable THC to CBD ratio versus placebo (short term, 1 to 6 months followup)

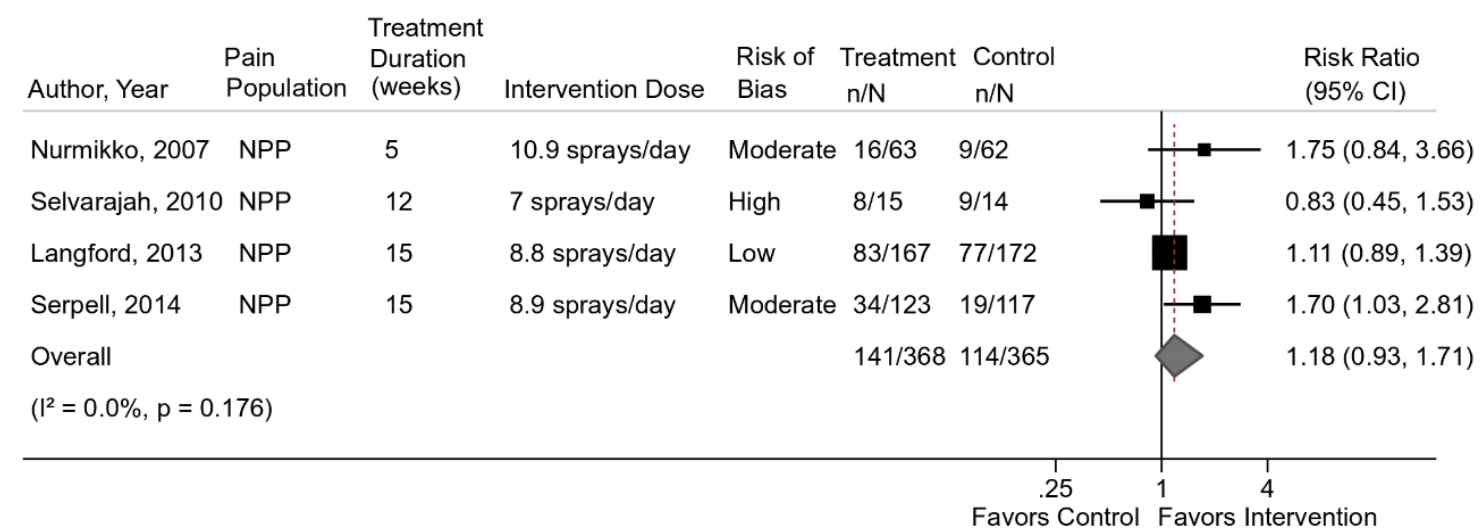

Abbreviations: $\mathrm{CI}=$ confidence interval; $\mathrm{NPP}=$ neuropathic pain

${ }^{a}$ Calculated by review team 
Figure D-2. Adverse events for comparable THC to CBD ratio versus placebo (short term, 1 to 6 months followup)

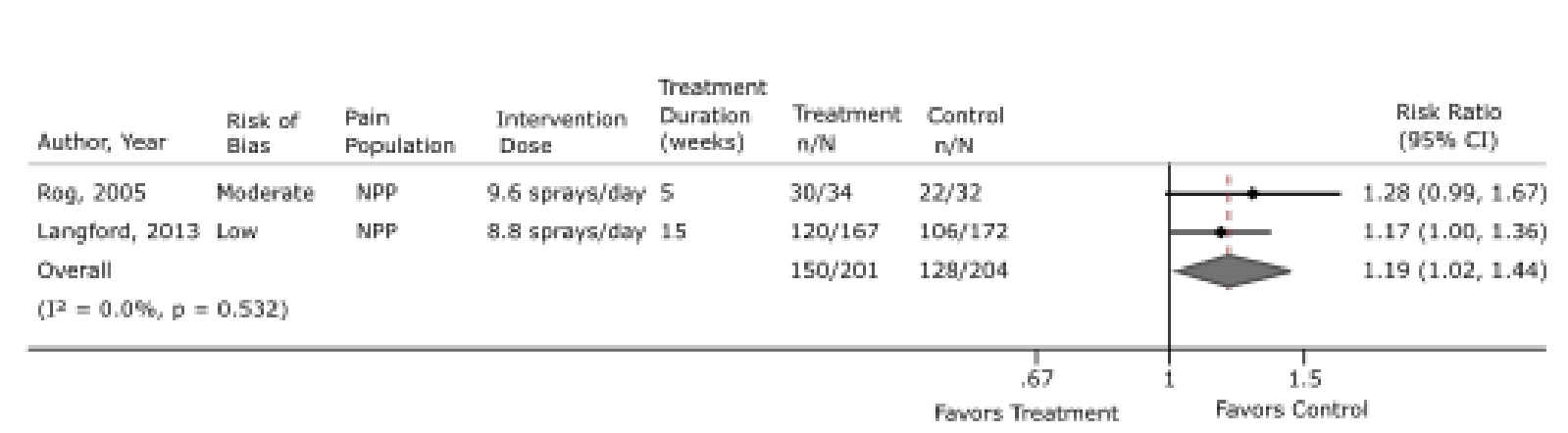

Abbreviations: $\mathrm{CI}=$ confidence interval; NPP = neuropathic pain

Figure D-3. Serious adverse events for comparable THC to CBD ratio versus placebo (short term, 1 to 6 months followup)

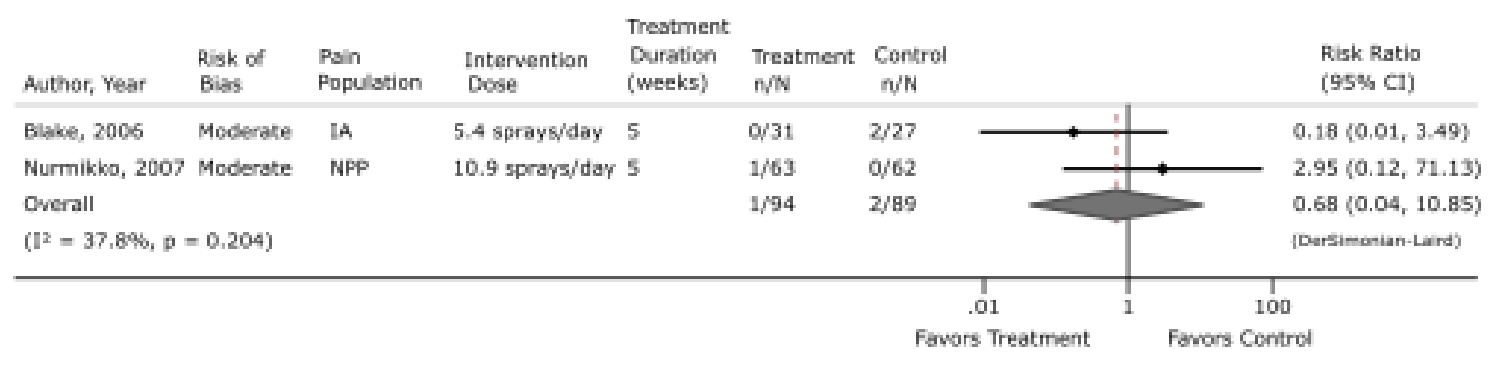

Abbreviations: $\mathrm{CI}=$ confidence interval; IA = inflammatory arthritis; NPP = neuropathic pain 
Figure D-4. Withdrawal due to adverse events for comparable THC to CBD ratio versus placebo (short term, 1 to 6 months followup)

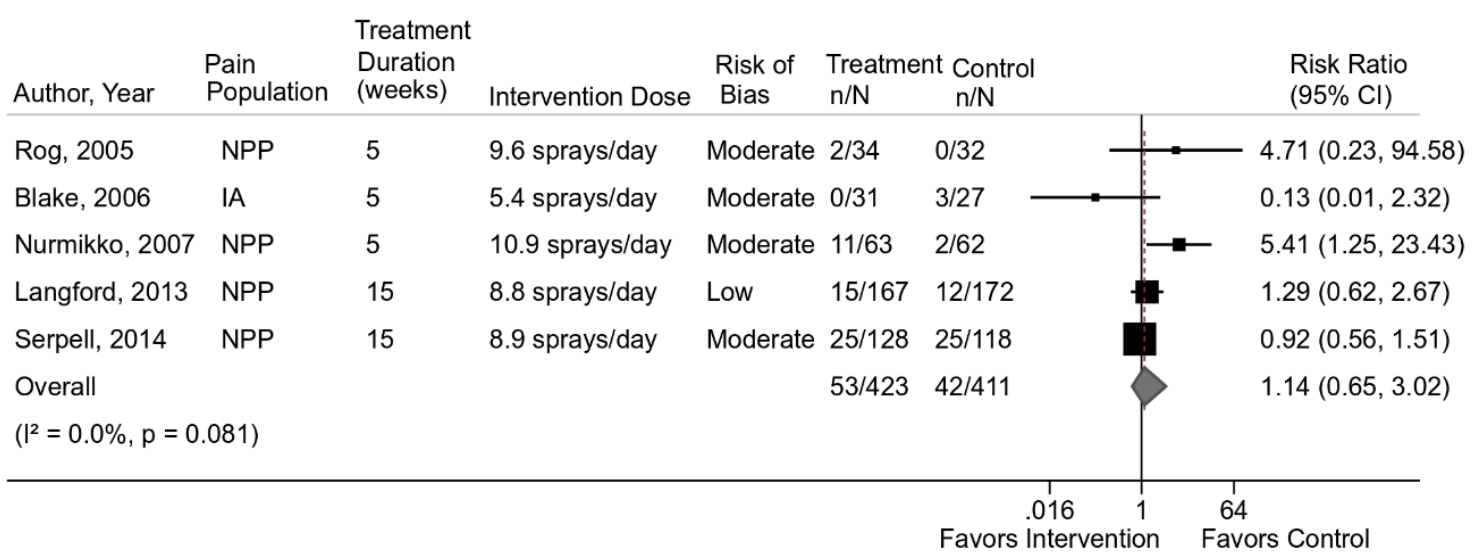

Abbreviations: $\mathrm{CI}=$ confidence interval; IA = inflammatory arthritis; NPP = neuropathic pain

\section{Figure D-5. Dizziness for comparable THC to CBD ratio versus placebo (short term, 1 to 6 months followup)}

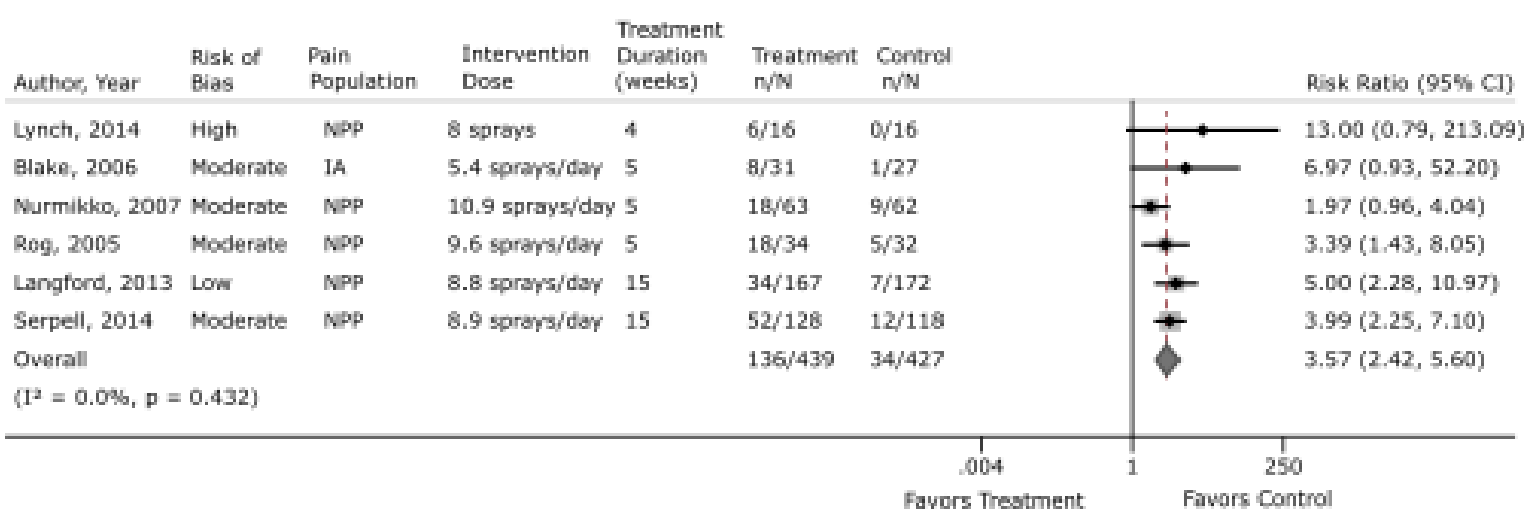

Abbreviations: $\mathrm{CI}=$ confidence interval; $\mathrm{IA}=$ inflammatory arthritis; NPP = neuropathic pain 
Figure D-6. Nausea for comparable THC to CBD ratio versus placebo (short term, 1 to 6 months followup)

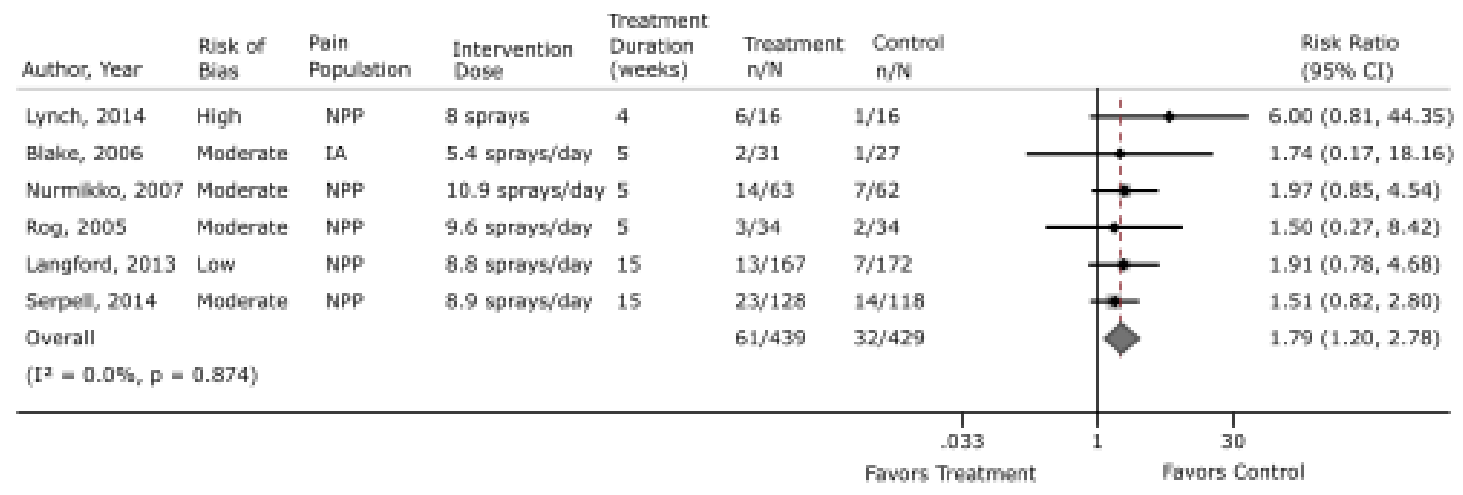

Abbreviations: $\mathrm{CI}=$ confidence interval; $\mathrm{IA}=$ inflammatory arthritis; NPP = neuropathic pain

Figure D-7. Sedation for comparable THC to CBD ratio versus placebo (short term, 1 to 6 months followup)

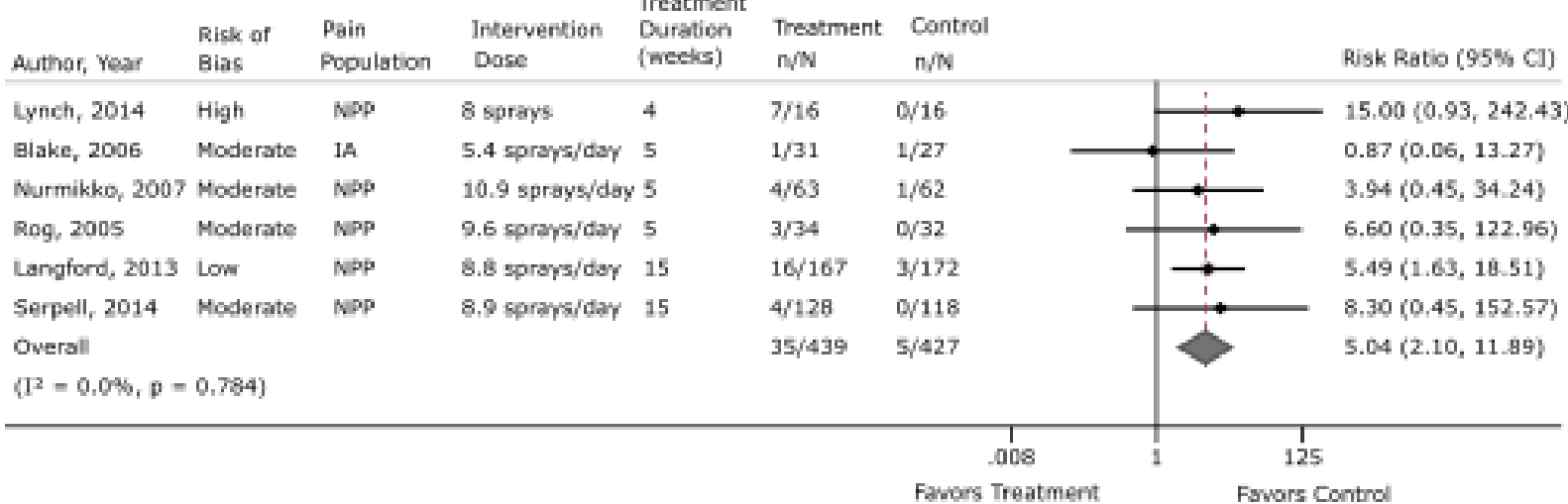

Abbreviations: $\mathrm{CI}=$ confidence interval; IA = inflammatory arthritis; $\mathrm{NPP}=$ neuropathic pain 


\section{High-THC to CBD Ratio Studies}

Figure D-8. Stratified results on pain severity of RCTs using dronabinol and nabilone (short term, 1 to 6 months followup)

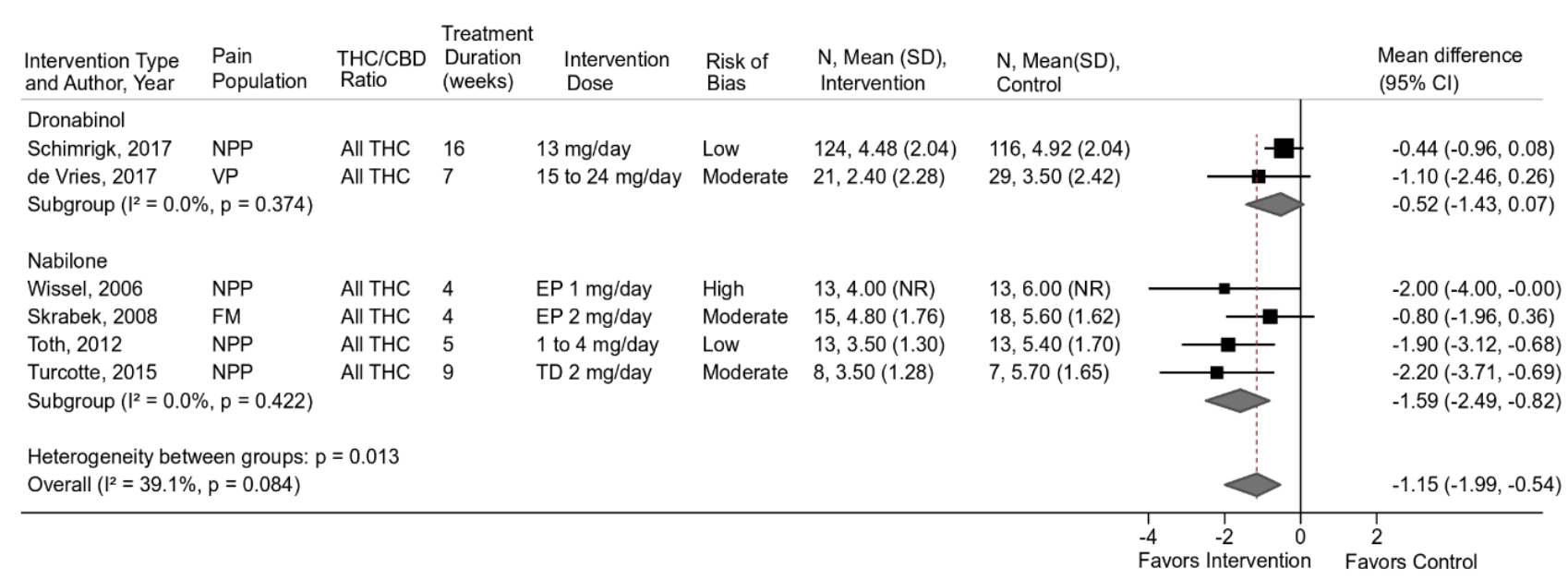

Abbreviations: $\mathrm{CBD}=$ cannabidiol $; \mathrm{CI}=$ confidence interval; $\mathrm{EP}=$ end point $\mathrm{FM}=$ fibromyalgia $\mathrm{NPP}=$ neuropathic pain; $\mathrm{SD}=$ standard deviation; $\mathrm{TD}=$ total dose; $\mathrm{THC}=$ tetrahydrocannabinol; $\mathrm{VP}=$ visceral pain

Table D-6. Interaction effect of RCTs assessing synthetic cannabinoids: nabilone versus dronabinol

\begin{tabular}{|l|l|l|l|l|l|}
\hline $\begin{array}{l}\text { Group } \\
\text { Difference }\end{array}$ & Coefficient & Standard Error & t-Test & p-Value & $\mathbf{9 5 \%}$ Confidence Interval \\
\hline Result & -1.06 & 0.445 & -2.37 & 0.077 & -2.29 to 0.18 \\
\hline
\end{tabular}

Table D-7. Interaction effect of RCTs: synthetic versus plant-based interventions

\begin{tabular}{|l|l|l|l|l|l|}
\hline $\begin{array}{l}\text { Group } \\
\text { Difference }\end{array}$ & Coefficient & Standard Error & t-Test & $\mathbf{p}$-Value & $\mathbf{9 5 \%}$ Confidence Interval \\
\hline Result & -0.682 & 0.81 & -0.84 & 0.423 & -2.55 to 1.18 \\
\hline
\end{tabular}


Figure D-9. Overall function for high-THC versus placebo (short term, 1-6 months followup)

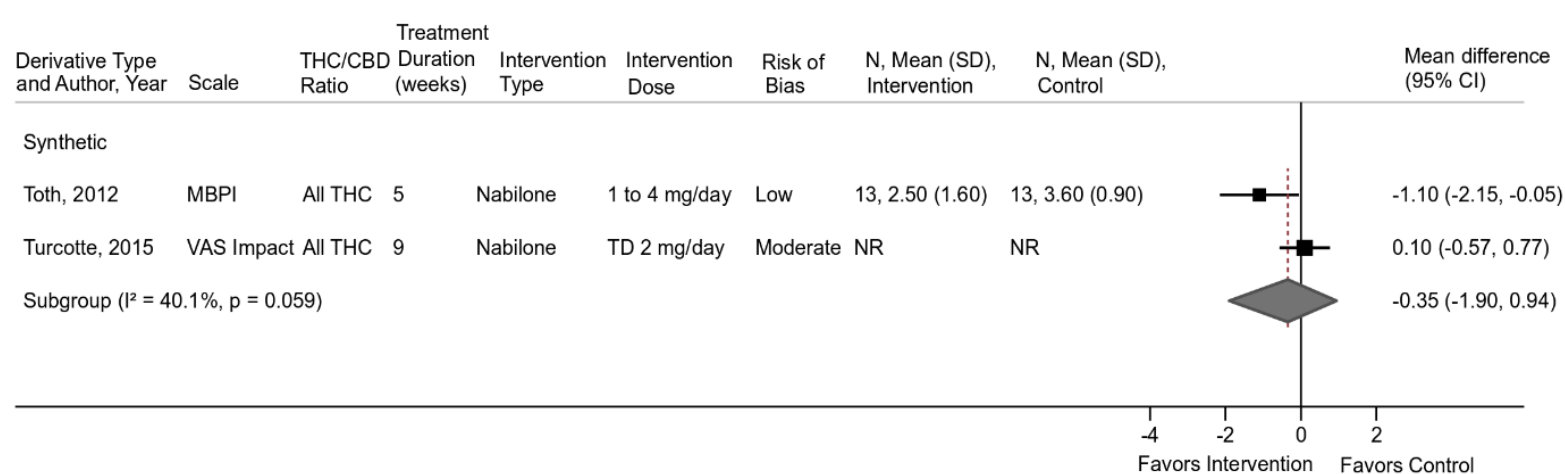

Abbreviations: $\mathrm{CBD}=$ cannabidiol; $\mathrm{CI}=$ confidence interval; MBPI = Modified Brief Pain Inventory; NPP = neuropathic pain; $\mathrm{NR}=$ not reported; $\mathrm{SD}=$ standard deviation; THC $=$ tetrahydrocannabinol; VAS $=$ Visual Analogue Scale

\section{Figure D-10. Withdrawal due to adverse events for high-THC versus placebo (short term, 1 to 6 months followup)}

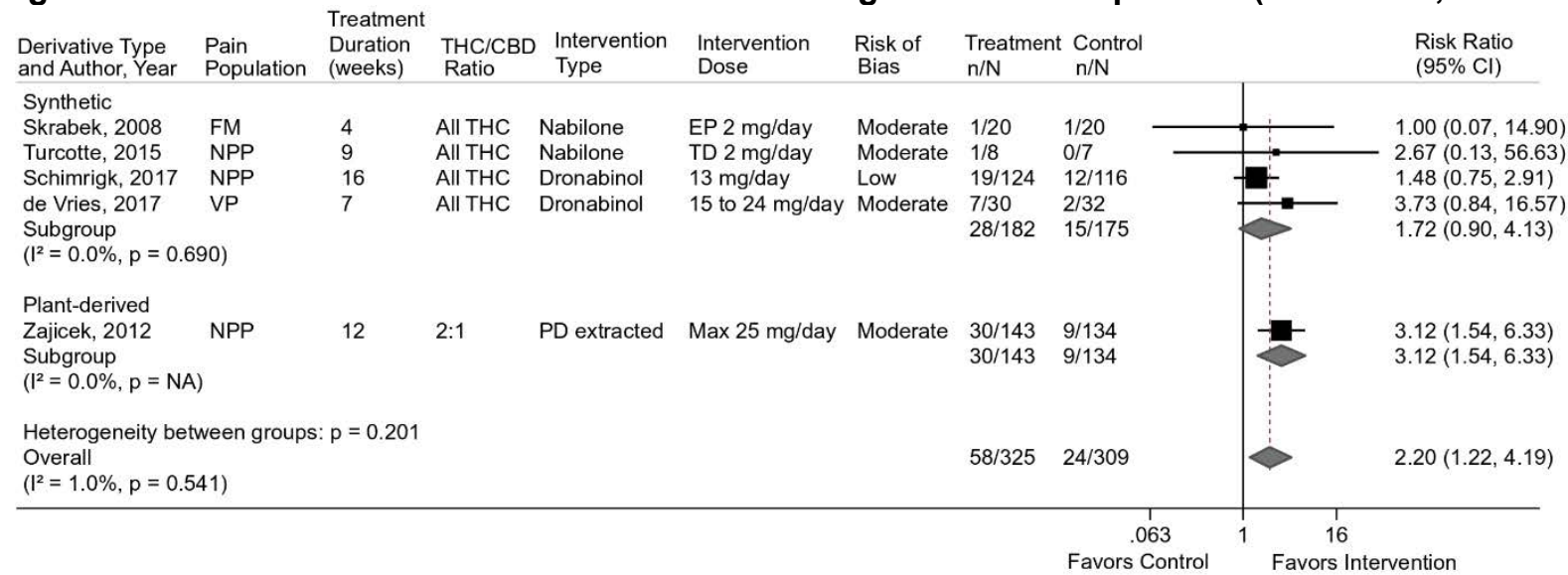

Abbreviations: $\mathrm{CI}=$ confidence interval; $\mathrm{FM}=$ fibromyalgia; $\mathrm{NPP}=$ neuropathic pain; $\mathrm{THC}=$ tetrahydrocannabinol; $\mathrm{WP}=$ whole plant 
Figure D-11. Any adverse event for high-THC versus placebo (short term, 1 to 6 months followup)

\begin{tabular}{|c|c|c|c|c|c|c|c|c|}
\hline $\begin{array}{l}\text { Derivative Type } \\
\text { and Author, Year }\end{array}$ & $\begin{array}{l}\text { Pain } \\
\text { Population }\end{array}$ & $\begin{array}{l}\text { Treatmen } \\
\text { Duration } \\
\text { (weeks) }\end{array}$ & $\begin{array}{l}\text { Intervention } \\
\text { Type }\end{array}$ & $\begin{array}{l}\text { Intervention } \\
\text { Dose }\end{array}$ & $\begin{array}{l}\text { Risk of } \\
\text { Bias }\end{array}$ & $\begin{array}{l}\text { Treatment } \\
\mathrm{n} / \mathrm{N}\end{array}$ & $\begin{array}{l}\text { Control } \\
\mathrm{n} / \mathrm{N}\end{array}$ & $\begin{array}{l}\text { Risk Ratio } \\
(95 \% \mathrm{Cl})\end{array}$ \\
\hline \multicolumn{9}{|l|}{ Synthetic } \\
\hline Toth, 2012 & NPP & 5 & Nabilone & 1 to $4 \mathrm{mg} / \mathrm{day}$ & Low & $7 / 13$ & $6 / 13$ & $1.17(0.54,2.53)$ \\
\hline Schimrigk, 2017 & NPP & 16 & Dronabinol & $13 \mathrm{mg} / \mathrm{day}$ & Low & $109 / 124$ & $85 / 116$ & $1.20(1.06,1.36)$ \\
\hline Subgroup & & & & & & $116 / 137$ & $91 / 129$ & $1.20(0.96,1.48)$ \\
\hline \multicolumn{9}{|c|}{$\left(1^{2}=0.0 \%, p=0.943\right)$} \\
\hline
\end{tabular}

Abbreviations: $\mathrm{CI}=$ confidence interval; $\mathrm{NPP}=$ neuropathic pain; $\mathrm{THC}=$ tetrahydrocannabinol

Figure D-12. Dizziness for high-THC versus placebo (short term, 1 to 6 months followup)

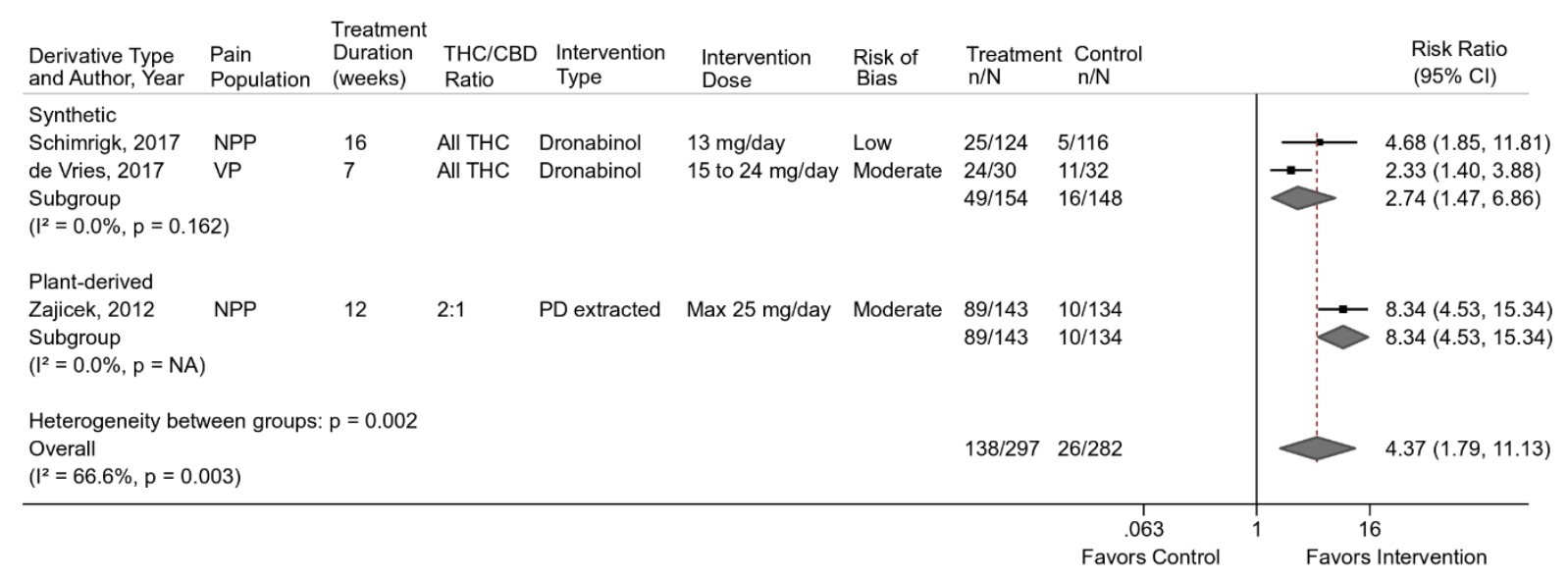

Abbreviations: $\mathrm{CI}=$ confidence interval; $\mathrm{NPP}=$ neuropathic pain $; \mathrm{THC}=$ tetrahydrocannabinol; $\mathrm{VP}=$ visceral pain; $\mathrm{WP}=$ whole plant 


\section{Figure D-13. Sedation for high-THC versus placebo (short term, 1 to 6 months followup)}

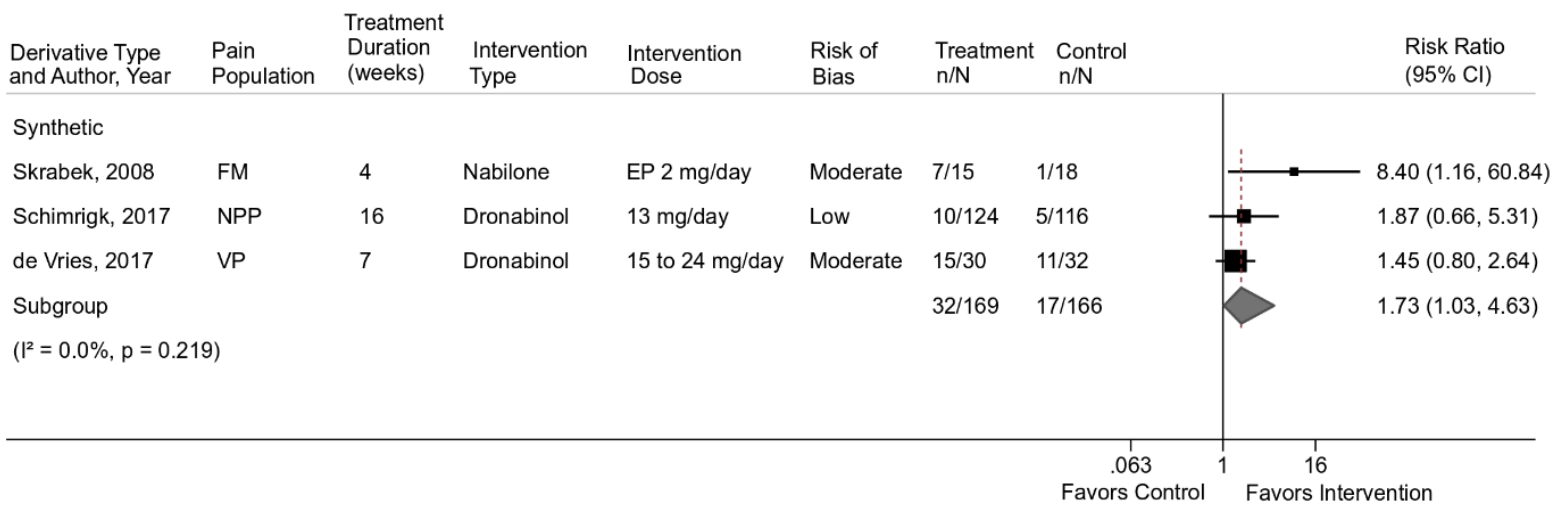

Abbreviations: $\mathrm{CI}=$ confidence interval; $\mathrm{FM}=$ fibromyalgia; $\mathrm{NPP}=$ neuropathic pain; $\mathrm{VP}=$ visceral pain

\section{Figure D-14. Nausea for high-THC versus placebo (short term, 1 to 6 months followup)}

\begin{tabular}{|c|c|c|c|c|c|c|c|c|}
\hline $\begin{array}{l}\text { Derivative Type } \\
\text { and Author, Year }\end{array}$ & $\begin{array}{l}\text { Pain } \\
\text { Population }\end{array}$ & $\begin{array}{l}\text { Treatment } \\
\text { Duration } \\
\text { (weeks) }\end{array}$ & $\begin{array}{l}\text { Intervention } \\
\text { Type }\end{array}$ & $\begin{array}{l}\text { Intervention } \\
\text { Dose }\end{array}$ & $\begin{array}{l}\text { Risk of } \\
\text { Bias }\end{array}$ & $\begin{array}{l}\text { Treatment } \\
\mathrm{n} / \mathrm{N}\end{array}$ & $\begin{array}{l}\text { Control } \\
\mathrm{n} / \mathrm{N}\end{array}$ & $\begin{array}{l}\text { Risk Ratio } \\
(95 \% \mathrm{Cl})\end{array}$ \\
\hline \multicolumn{9}{|l|}{ Synthetic } \\
\hline Schimrigk, 2017 & NPP & 16 & Dronabinol & $13 \mathrm{mg} / \mathrm{day}$ & Low & $6 / 124$ & $4 / 116$ & $1.40(0.41,4.85)$ \\
\hline de Vries, 2017 & VP & 7 & Dronabinol & 15 to $24 \mathrm{mg} /$ day & Moderate & $13 / 30$ & $5 / 32$ & $2.77(1.12,6.84)$ \\
\hline Subgroup & & & & & & $19 / 154$ & 9/148 & $2.19(0.77,5.39)$ \\
\hline \multicolumn{9}{|c|}{$\left(I^{2}=0.0 \%, p=0.383\right)$} \\
\hline
\end{tabular}

Abbreviations: $\mathrm{CI}=$ confidence interval; $\mathrm{NPP}=$ neuropathic pain; $\mathrm{VP}=$ visceral pain 


\section{Appendix E. Evidence Tables}

Shown in associated Excel files. 


\section{Appendix F. Risk of Bias Assessment}

Shown in associated Excel files. 


\section{Appendix G. Details on Strength of Evidence}

Table G-1. KQ1 and 2: Cannabinoids to treat chronic pain - comparable THC to CBD ratio

\begin{tabular}{|c|c|c|c|c|c|c|c|c|c|}
\hline Comparison & Outcome & $\begin{array}{l}\text { Number of } \\
\text { Studies } \\
\text { (N) and Total } \\
\text { Participants }\end{array}$ & \begin{tabular}{|l} 
Study \\
Limitations
\end{tabular} & Directness & Consistency & Precision & $\begin{array}{l}\text { Publication } \\
\text { Bias }\end{array}$ & $\begin{array}{l}\text { Main Findings } \\
\text { Effect Size }(95 \% \mathrm{Cl})\end{array}$ & $\begin{array}{l}\text { SOE } \\
\text { Grade }\end{array}$ \\
\hline $\begin{array}{l}\text { Comparable } \\
\text { THC to CBD } \\
\text { Ratio vs. } \\
\text { Placebo }\end{array}$ & $\begin{array}{l}\text { Pain response } \\
(\geq 30 \% \\
\text { improvement } \\
\text { from baseline })\end{array}$ & $\begin{array}{l}4 \text { RCTs } \\
(\mathrm{N}=733)^{1-4}\end{array}$ & Moderate & Direct & Consistent & Imprecise & Unknown & $\begin{array}{l}\text { Potential small effect, } \\
\text { not statistically } \\
\text { significant, with } \\
\text { THC:CBD } \\
38 \% \text { versus } 31 \%, \text { RR } \\
1.18(0.93 \text { to } 1.71) ; \\
\text { I2=0\% }\end{array}$ & Low \\
\hline $\begin{array}{l}\text { Comparable } \\
\text { THC to CBD } \\
\text { Ratio vs. } \\
\text { Placebo }\end{array}$ & $\begin{array}{l}\text { Pain severity } \\
\text { (change) }\end{array}$ & 7 RCTs $(\mathrm{N}=878)^{1-7}$ & Moderate & Direct & Consistent & Precise & Unknown & $\begin{array}{l}\text { Small benefit with } \\
\text { THC:CBD } \\
0 \text { to } 10 \text { scale, MD } \\
-0.54(-0.95 \text { to }-0.19 ; \\
\left.1^{2}=30 \%\right) \\
\text { Subgroup analysis } \\
\text { removing high risk of } \\
\text { bias studies: } \\
\text { Moderate benefit MD - } \\
0.64(-1.15 \text { to }-0.24)\end{array}$ & Moderate \\
\hline $\begin{array}{l}\text { Comparable } \\
\text { THC to CBD } \\
\text { Ratio vs. } \\
\text { Placebo }\end{array}$ & $\begin{array}{l}\text { Function or } \\
\text { Disability }\end{array}$ & ${ }_{5,7}^{6}$ RCTs $(\mathrm{N}=616)^{1-}$ & Moderate & Direct & Consistent & Precise & Unknown & $\begin{array}{l}\text { Small benefit with } \\
\text { THC:CBD, MD }-0.42 \text {, } \\
95 \% \mathrm{Cl}-0.73 \text { to }-0.16 \text {, } \\
\mathrm{I}^{2}=24 \% \text { (scale } 0 \text { to } 10 \text { ) }\end{array}$ & Moderate \\
\hline $\begin{array}{l}\text { Comparable } \\
\text { THC to CBD } \\
\text { Ratio vs. } \\
\text { Placebo }\end{array}$ & WAEs & \begin{tabular}{|l|}
5 RCTs \\
$(\mathrm{N}=834)^{1,2,4,5,7}$
\end{tabular} & Moderate & Direct & Consistent & Imprecise & Unknown & $\begin{array}{l}\text { Failed to demonstrate } \\
\text { or exclude a } \\
\text { detrimental effect } \\
13 \% \text { vs. } 10 \%, \text { RR } 1.14 \\
(0.65 \text { to } 3.02) ; I^{2}=0 \%\end{array}$ & Low \\
\hline $\begin{array}{l}\text { Comparable } \\
\text { THC to CBD } \\
\text { Ratio vs. } \\
\text { Placebo }\end{array}$ & SAEs & 2 RCTs $(\mathrm{N}=183)^{2,5}$ & Moderate & Direct & Consistent & Imprecise & Unknown & $\begin{array}{l}\text { No effect } \\
1.1 \% \text { vs. } 2.2 \%, \mathrm{RR} \\
0.68(0.04 \text { to } 10.85 \\
\left.1^{2}=38 \%\right)\end{array}$ & Low \\
\hline
\end{tabular}




\begin{tabular}{|c|c|c|c|c|c|c|c|c|c|}
\hline Comparison & Outcome & $\begin{array}{l}\text { Number of } \\
\text { Studies } \\
\text { (N) and Total } \\
\text { Participants }\end{array}$ & $\begin{array}{l}\text { Study } \\
\text { Limitations }\end{array}$ & Directness & Consistency & Precision & $\begin{array}{l}\text { Publication } \\
\text { Bias }\end{array}$ & $\begin{array}{l}\text { Main Findings } \\
\text { Effect Size }(95 \% \mathrm{Cl})\end{array}$ & $\begin{array}{l}\text { SOE } \\
\text { Grade }\end{array}$ \\
\hline $\begin{array}{l}\text { Comparable } \\
\text { THC to CBD } \\
\text { Ratio vs. } \\
\text { Placebo }\end{array}$ & Dizziness & $\begin{array}{l}6 \text { RCTs } \\
(\mathrm{N}=866)^{1,2,4-7}\end{array}$ & Moderate & Direct & Consistent & Imprecise & Unknown & $\begin{array}{l}\text { Large effect with } \\
\text { THC:CBD } \\
30 \% \text { vs. } 8 \% \text {, RR } 3.57 \\
\left(2.42 \text { to } 5.60 ;\left.\right|^{2}=0 \%\right)\end{array}$ & Low \\
\hline $\begin{array}{l}\text { Comparable } \\
\text { THC to CBD } \\
\text { ratio vs. } \\
\text { Placebo }\end{array}$ & Nausea & $\begin{array}{l}6 \mathrm{RCTs} \\
(\mathrm{N}=866)^{1,2,4-7}\end{array}$ & Moderate & Direct & Consistent & Imprecise & Unknown & $\begin{array}{l}\text { Moderate effect with } \\
\text { THC:CBD } \\
14 \% \text { vs. } 7.5 \% \text { RR } 1.79 \\
\left(1.20 \text { to } 2.78 ; I^{2}=0 \%\right)\end{array}$ & Low \\
\hline $\begin{array}{l}\text { Comparable } \\
\text { THC to CBD } \\
\text { Ratio vs. } \\
\text { Placebo }\end{array}$ & Sedation & $\begin{array}{l}6 \text { RCTs } \\
(\mathrm{N}=866)^{1,2,4-7}\end{array}$ & Moderate & Direct & Consistent & Imprecise & Unknown & $\begin{array}{l}\text { Large effect with } \\
\text { THC:CBD } \\
\text { RR 5.04 (2.10 to 11.89; } \\
\left.\text { I }^{2}=0 \%\right)\end{array}$ & Low \\
\hline
\end{tabular}

Abbreviations: BPI-SF = Brief Pain Inventory (Short Form); CBD = cannabidiol; CI = confidence interval; KQ = Key Question; MD = mean difference; RCT = randomized controlled trial; $\mathrm{RR}=$ relative risk; $\mathrm{SAE}=$ serious adverse event; $\mathrm{SOE}=$ strength of evidence; $\mathrm{THC}=$ tetrahydrocannabinol; $\mathrm{WAE}=$ withdrawal due to adverse event. 
Table G-2. KQ1 and 2: Cannabinoids to treat chronic pain - high-THC to CBD ratio, synthetic THC

\begin{tabular}{|c|c|c|c|c|c|c|c|c|c|}
\hline Comparison & Outcome & $\begin{array}{l}\text { Number of } \\
\text { Studies and } \\
\text { Total } \\
\text { Participants (N) }\end{array}$ & \begin{tabular}{|l} 
Study \\
Limitations
\end{tabular} & Directness & Consistency & Precision & $\begin{array}{l}\text { Publication } \\
\text { Bias }\end{array}$ & $\begin{array}{l}\text { Main Findings } \\
\text { Effect Size }(95 \% \mathrm{CI})\end{array}$ & $\begin{array}{l}\text { Strength } \\
\text { of } \\
\text { Evidence } \\
\text { Grade } \\
\end{array}$ \\
\hline \multirow[t]{7}{*}{$\begin{array}{l}\text { Synthetic THC } \\
\text { vs. Placebo }\end{array}$} & $\begin{array}{l}\text { Pain response } \\
(\geq 30 \% \\
\text { improvement } \\
\text { from baseline })\end{array}$ & $\begin{array}{l}1 \mathrm{RCT} \\
(\mathrm{N}=26)^{8}\end{array}$ & Low & Direct & Unknown & Imprecise & Unknown & $\begin{array}{l}\text { Large effect with } \\
\text { nabilone } \\
85 \% \text { vs. } 38 \%, \text { RR } \\
2.20 \text { (Cl } 1.06 \text { to } \\
4.55) \\
\end{array}$ & Insufficient \\
\hline & Pain severity & $\begin{array}{l}\text { 5 RCTs } \\
(\mathrm{N}=364)^{8-12}\end{array}$ & Moderate & Direct & Consistent & Imprecise & Unknown & $\begin{array}{l}\text { Moderate effect with } \\
\text { synthetic THC } \\
0 \text { to } 10 \text { scale, MD } \\
-1.08(-1.96 \text { to } \\
\left.-0.43 ; I^{2}=42 \%\right)\end{array}$ & Low \\
\hline & Function/disability & $\begin{array}{l}2 \text { RCTs } \\
(\mathrm{N}=41)^{8,12} \\
1 \mathrm{RCT}(\mathrm{N}=13) \text { not } \\
\text { Included in meta- } \\
\text { analysis }^{13}\end{array}$ & Moderate & Direct & Consistent & Imprecise & Unknown & $\begin{array}{l}\text { No effect (scale } 0 \text { to } \\
10) \text { MD : }-0.35,95 \% \\
\text { Cl }-1.9 \text { to } 0.94,0 \text { to } \\
10 \text { scale, }\left.\right|^{2}=40 \%\end{array}$ & Low \\
\hline & WAEs & $\begin{array}{l}4 \text { RCTs } \\
(\mathrm{N}=357)^{9-12} 6\end{array}$ & Moderate & Direct & Consistent & Imprecise & Unknown & $\begin{array}{l}\text { Potential Moderate } \\
\text { effect, not } \\
\text { statistically } \\
\text { significant } \\
13 \% \text { vs. } 9 \%, \text { RR } \\
1.72(0.90 \text { to } 4.13 ; \\
\left.\left.\right|^{2}=0 \%\right)\end{array}$ & Low \\
\hline & SAEs & $1 \mathrm{RCT}(\mathrm{N}=240)^{10}$ & Low & Direct & Unknown & Imprecise & Unknown & \begin{tabular}{|l|} 
Failed to \\
demonstrate or \\
exclude a \\
detrimental effect \\
$10 \%$ vs. $6 \%$, RR \\
$1.60(0.65$ to 3.93$)$ \\
\end{tabular} & Insufficient \\
\hline & Dizziness & $\begin{array}{l}2 \mathrm{RCTs} \\
(\mathrm{N}=302)^{9,10}\end{array}$ & Low & Direct & Consistent & Imprecise & Unknown & $\begin{array}{l}\text { Large effect with } \\
\text { dronabinol } \\
32 \% \text { vs. } 11 \%, \text { RR } \\
2.74(1.47 \text { to } 6.86 ; \\
\left.I^{2}=0 \%\right)\end{array}$ & Moderate \\
\hline & Nausea & $\begin{array}{l}2 \mathrm{RCTs} \\
(\mathrm{N}=302)^{9,10}\end{array}$ & Low & Direct & Consistent & Imprecise & Unknown & $\begin{array}{l}\text { Potential large effect } \\
\text { with dronabinol, not } \\
\text { statistically } \\
\text { significant }\end{array}$ & Low \\
\hline
\end{tabular}




\begin{tabular}{|c|c|c|c|c|c|c|c|c|}
\hline & & & & & & & $\begin{array}{l}12 \% \text { vs. } 6 \%, \text { RR } \\
2.19(0.77 \text { to } 5.39 ; \\
\left.\left.\right|^{2}=0 \%\right)\end{array}$ & \\
\hline Sedation & $\begin{array}{l}3 \text { RCTs }(\mathrm{N}=335)^{9-} \\
{ }_{11}\end{array}$ & Moderate & Direct & Consistent & Imprecise & Unknown & $\begin{array}{l}\text { Moderate effect with } \\
\text { dronabinol } \\
19 \% \text { vs. } 10 \%, \text { RR } \\
1.73(1.03 \text { to } 4.63 ; \\
\left.I^{2}=0 \%\right)\end{array}$ & Low \\
\hline
\end{tabular}

Abbreviations: $\mathrm{CBD}=$ cannabidiol; $\mathrm{CI}=$ confidence interval; $\mathrm{KQ}=$ Key Question; $\mathrm{MD}=$ mean difference; $\mathrm{RCT}=$ randomized controlled trial; $\mathrm{RR}=$ relative risk; $\mathrm{SAE}=$ serious adverse event; $\mathrm{SOE}=$ strength of evidence; $\mathrm{THC}=$ tetrahydrocannabinol; $\mathrm{WAE}=$ withdrawal due to adverse event. 
Table G-3. KQ1 and 2: Cannabinoids to treat chronic pain - high-THC to CBD ratio, extracted from whole plant

\begin{tabular}{|c|c|c|c|c|c|c|c|c|c|}
\hline Comparison & Outcome & $\begin{array}{l}\text { Number of } \\
\text { Studies and Total } \\
\text { Participants (N) }\end{array}$ & $\begin{array}{l}\text { Study } \\
\text { Limitations }\end{array}$ & Directness & Consistency & Precision & $\begin{array}{l}\text { Publication } \\
\text { Bias }\end{array}$ & $\begin{array}{l}\text { Main Findings } \\
\text { Effect Size }(95 \% \mathrm{Cl})\end{array}$ & $\begin{array}{l}\text { Strength } \\
\text { of } \\
\text { Evidence } \\
\text { Grade }\end{array}$ \\
\hline \multirow[t]{5}{*}{$\begin{array}{l}\text { Extracted THC } \\
\text { vs. Placebo }\end{array}$} & Pain severity & $\begin{array}{l}2 \text { RCTs } \\
(\mathrm{N}=297)^{14,15}\end{array}$ & Moderate & Direct & Inconsistent & Imprecise & Unknown & $\begin{array}{l}\text { Failed to demonstrate } \\
\text { or exclude a } \\
\text { detrimental effect } \\
\text { MD }-2.05(-5.94 \text { to } \\
\left.1.26 ;\left.\right|^{2}=72 \%\right)\end{array}$ & Insufficient \\
\hline & Function/disability & $\begin{array}{l}1 \mathrm{RCT} \\
(\mathrm{N}=18)^{15}\end{array}$ & High & Direct & Unknown & Imprecise & Unknown & $\begin{array}{l}\text { Failed to demonstrate } \\
\text { or exclude a } \\
\text { detrimental effect } \\
\text { MD } 1.75 \text { (-0.46 to } \\
3.98)\end{array}$ & Insufficient \\
\hline & WAEs & $1 \mathrm{RCT}(\mathrm{N}=277)^{14}$ & Moderate & Direct & Unknown & Imprecise & Unknown & $\begin{array}{l}\text { Large increased risk } \\
13.9 \% \text { vs. } 5.7 \%, \mathrm{RR} \\
3.12(1.54 \text { to } 6.33)\end{array}$ & Low \\
\hline & SAEs & $1 \mathrm{RCT}(\mathrm{N}=277)^{14}$ & Moderate & Direct & Unknown & Imprecise & Unknown & $\begin{array}{l}\text { Failed to demonstrate } \\
\text { or exclude a } \\
\text { detrimental effect } \\
4.9 \% \text { vs. } 2.2 \%, \mathrm{RR} \\
2.19(0.58 \text { to } 8.28) \\
\end{array}$ & Insufficient \\
\hline & Dizziness & $1 \mathrm{RCT}(\mathrm{N}=277)^{14}$ & Moderate & Direct & Unknown & Imprecise & Unknown & \begin{tabular}{|l|} 
Large effect \\
$62.2 \%$ vs. $7.5 \%$, RR \\
$8.34(4.53$ to 15.34$)$
\end{tabular} & Low \\
\hline
\end{tabular}

Abbreviations: $\mathrm{CBD}=$ cannabidiol $\mathrm{CI}=$ confidence interval; $\mathrm{KQ}=$ Key Question; $\mathrm{MD}=$ mean difference; $\mathrm{RCT}=$ randomized controlled trial; $\mathrm{RR}=$ relative risk; $\mathrm{SAE}=$ serious adverse event; $\mathrm{SOE}=$ strength of evidence; $\mathrm{THC}=$ tetrahydrocannabinol; WAE $=$ withdrawal due to adverse event . 
Table G-4. KQ1 and 2: Cannabinoids to treat chronic pain - high-THC to CBD ratio, combined synthetic and whole-plant extracted studies

\begin{tabular}{|c|c|c|c|c|c|c|c|c|c|}
\hline Comparison & Outcome & $\begin{array}{l}\text { Number of } \\
\text { Studies and } \\
\text { Total } \\
\text { Participants (N) }\end{array}$ & $\begin{array}{l}\text { Study } \\
\text { Limitations }\end{array}$ & Directness & Consistency & Precision & $\begin{array}{l}\text { Publication } \\
\text { Bias }\end{array}$ & $\begin{array}{l}\text { Main Findings } \\
\text { Effect Size }(95 \% \\
\text { Cl) }\end{array}$ & $\begin{array}{l}\text { Strength of } \\
\text { Evidence } \\
\text { Grade }\end{array}$ \\
\hline $\begin{array}{l}\text { Combined } \\
\text { High THC } \\
\text { Ratio Studies } \\
\text { (Synthetic and } \\
\text { Whole-plant } \\
\text { extracted) }\end{array}$ & $\begin{array}{l}\text { Pain severity } \\
\text { improvement }\end{array}$ & $\begin{array}{l}7 \text { RCTs }(N=658)^{8-} \\
12,14,15\end{array}$ & Moderate & Direct & Consistent & Precise & Unknown & $\begin{array}{l}\text { Moderate effect } \\
\text { MD }-1.26(-2.17 \text { to } \\
\left.-0.65 ; I^{2}=59 \%\right)\end{array}$ & Moderate \\
\hline
\end{tabular}

Abbreviations: $\mathrm{CBD}=$ cannabidiol; $\mathrm{CI}=$ confidence interval; $\mathrm{KQ}=$ Key Question; $\mathrm{MD}=$ mean difference; $\mathrm{RCT}=$ randomized controlled trial; $\mathrm{SOE}=$ strength of evidence; $\mathrm{THC}=$

tetrahydrocannabinol. 
Table G-5. KQ1 and 2: Cannabinoids to treat chronic pain - whole plant cannabis

\begin{tabular}{|c|c|c|c|c|c|c|c|c|c|}
\hline Comparison & Outcome & $\begin{array}{l}\text { Number of } \\
\text { Studies and Total } \\
\text { Participants (N) }\end{array}$ & $\begin{array}{l}\text { Study } \\
\text { Limitations }\end{array}$ & Directness & Consistency & Precision & $\begin{array}{l}\text { Publication } \\
\text { Bias }\end{array}$ & $\begin{array}{l}\text { Main Findings } \\
\text { Effect Size }(95 \% \mathrm{CI})\end{array}$ & $\begin{array}{l}\text { Strength } \\
\text { of } \\
\text { Evidence } \\
\text { Grade } \\
\end{array}$ \\
\hline \multirow[t]{7}{*}{$\begin{array}{l}\text { Whole-plant } \\
\text { Cannabis } \\
\text { (Standardized } \\
\text { to } 12 \% \text { THC) } \\
\text { vs. Placebo }\end{array}$} & $\begin{array}{l}\text { Pain Severity } \\
\text { change }\end{array}$ & $\begin{array}{l}1(\mathrm{~N}=431,302 \\
\text { contribute to pain } \\
\text { outcome })^{16}\end{array}$ & High & Direct & Unknown & Imprecise & Unknown & $\begin{array}{l}\text { Moderate effect } \\
0 \text { to } 10 \text { scale, } \\
\text { Adjusted MD at } 12 \\
\text { months: }-1.10(-1.56 \\
\text { to }-0.72)\end{array}$ & Insufficient \\
\hline & WAE & $1(\mathrm{~N}=431)^{16}$ & High & Direct & Unknown & Imprecise & Unknown & $\begin{array}{l}\text { Large effect with } \\
\text { cannabis } \\
4.7 \% \text { vs. } 0 \%, \mathrm{RR} \\
21.10(1.24 \text { to } \\
357.80)\end{array}$ & Insufficient \\
\hline & SAE & $1(\mathrm{~N}=431)^{16}$ & High & Direct & Unknown & Imprecise & Unknown & $\begin{array}{l}\text { No effect } \\
13 \% \text { vs. } 19 \%, \text { OR } \\
0.64(0.38 \text { to } 1.04)\end{array}$ & Insufficient \\
\hline & Dizziness & $1(\mathrm{~N}=431)^{16}$ & High & Direct & Unknown & Imprecise & Unknown & $\begin{array}{l}\text { Failed to demonstrate } \\
\text { or exclude a } \\
\text { detrimental effect } \\
12.6 \% \text { vs. } 9.7 \%, \text { RR } \\
1.29(0.75 \text { to } 2.21)\end{array}$ & Insufficient \\
\hline & Nausea & $1(\mathrm{~N}=431)^{16}$ & High & Direct & Unknown & Imprecise & Unknown & $\begin{array}{l}\text { Moderate effect } \\
16.7 \% \text { vs. } 9.7 \%, \text { RR } \\
1.72(1.04 \text { to } 2.85)\end{array}$ & Insufficient \\
\hline & Sedation & $1(\mathrm{~N}=431)^{16}$ & High & Direct & Unknown & Imprecise & Unknown & $\begin{array}{l}\text { Large effect } 13.5 \% \\
\text { vs. } 4.63 \%, \mathrm{RR} 2.91 \\
(1.46 \text { to } 5.83)\end{array}$ & Insufficient \\
\hline & \begin{tabular}{|l} 
Cognitive \\
Disorder
\end{tabular} & $1(\mathrm{~N}=431)^{16}$ & High & Direct & Unknown & Imprecise & Unknown & $\begin{array}{l}\text { Large effect } \\
13.9 \% \text { vs. } 5.7 \%, \mathrm{RR} \\
3.12(1.54 \text { to } 6.33)\end{array}$ & Insufficient \\
\hline
\end{tabular}

Abbreviations: $\mathrm{CI}=$ confidence interval; $\mathrm{KQ}=$ Key Question; $\mathrm{MD}=$ mean difference; $\mathrm{OR}=$ odds ratio; $\mathrm{RCT}=$ randomized controlled trial; $\mathrm{RR}=$ relative risk; $\mathrm{SAE}=$ serious adverse event; $\mathrm{SOE}=$ strength of evidence; $\mathrm{THC}=$ tetrahydrocannabinol; $\mathrm{WAE}=$ withdrawal due to adverse event. 
Table G-6. KQ1: Cannabinoids to treat chronic pain - low-THC to CBD ratio

\begin{tabular}{|c|c|c|c|c|c|c|c|c|c|}
\hline Comparison & Outcome & \begin{tabular}{|l|} 
Number of \\
Studies \\
(N) and Total \\
Participants \\
\end{tabular} & \begin{tabular}{|l} 
Study \\
Limitations
\end{tabular} & Directness & Consistency & Precision & $\begin{array}{l}\text { Publication } \\
\text { Bias }\end{array}$ & \begin{tabular}{|l} 
Main Findings \\
Effect Size $(95 \% \mathrm{Cl})$ \\
\end{tabular} & $\begin{array}{l}\text { Strength } \\
\text { of } \\
\text { Evidence } \\
\text { Grade } \\
\end{array}$ \\
\hline $\begin{array}{l}\text { Topical CBD } \\
\text { vs. Placebo }\end{array}$ & $\begin{array}{l}\text { Pain severity } \\
\text { (change) }\end{array}$ & $1 \mathrm{RCT}(\mathrm{N}=29)^{17}$ & High & Direct & Unknown & Imprecise & Unknown & $\begin{array}{l}\text { Small effect with CBD } \\
\text { cream } \\
\text { MD }-0.75, P=0.009 \\
\text { by ANCOVA ( } 0 \text { to } 10 \\
\text { scale) }\end{array}$ & Insufficient \\
\hline
\end{tabular}

$\mathrm{SOE}=$ strength of evidence; $\mathrm{THC}=$ tetrahydrocannabinol. 
Table G-7. KQ1 and 2: Cannabinoids to treat chronic pain - low-THC to CBD ratio

\begin{tabular}{|c|c|c|c|c|c|c|c|c|c|}
\hline Comparison & Outcome & $\begin{array}{l}\text { Number of } \\
\text { Studies } \\
\text { (N) and Total } \\
\text { Participants } \\
\end{array}$ & $\begin{array}{l}\text { Study } \\
\text { Limitations }\end{array}$ & Directness & Consistency & Precision & $\begin{array}{l}\text { Publication } \\
\text { Bias }\end{array}$ & $\begin{array}{l}\text { Main Findings } \\
\text { Effect Size }(95 \% \mathrm{Cl})\end{array}$ & $\begin{array}{l}\text { Strength } \\
\text { of } \\
\text { Evidence } \\
\text { Grade } \\
\end{array}$ \\
\hline $\begin{array}{l}\text { CBDV vs. } \\
\text { Placebo }\end{array}$ & $\begin{array}{l}\text { Pain Response } \\
(\geq 30 \% \\
\text { improvement } \\
\text { from baseline })\end{array}$ & $1 \mathrm{RCT}(\mathrm{N}=31)^{18}$ & Moderate & Direct & Unknown & Imprecise & Unknown & $\begin{array}{l}\text { Large effect, favors } \\
\text { placebo } \\
38 \% \text { vs. } 81 \%, \\
\text { RR } 0.46(95 \% \mathrm{Cl} \\
0.24 \text { to } 0.91)\end{array}$ & Insufficient \\
\hline $\begin{array}{l}\text { CBDV vs. } \\
\text { Placebo }\end{array}$ & $\begin{array}{l}\text { Pain severity } \\
\text { (change) }\end{array}$ & $1 \mathrm{RCT}(\mathrm{N}=31)^{18}$ & Moderate & Direct & Unknown & Imprecise & Unknown & \begin{tabular}{|l|} 
Failed to demonstrate \\
or exclude a \\
detrimental effect \\
MD $0.62(-0.05$ to \\
$1.32)$
\end{tabular} & Insufficient \\
\hline
\end{tabular}

Abbreviations: $\mathrm{CBDV}=$ cannabidivarin; $\mathrm{CI}=$ confidence interval; $\mathrm{KQ}=$ Key Question; $\mathrm{MD}=$ mean difference; $\mathrm{RCT}=$ randomized controlled trial; $\mathrm{RR}=$ relative risk; $\mathrm{SOE}=$ strength of evidence. 


\section{Appendix G References}

1. Langford RM, Mares J, Novotna A, et al. A double-blind, randomized, placebocontrolled, parallel-group study of THC/CBD oromucosal spray in combination with the existing treatment regimen, in the relief of central neuropathic pain in patients with multiple sclerosis. J Neurol. 2013 Apr;260(4):984-97. doi: https://dx.doi.org/10.1007/s00415-0126739-4. PMID: 23180178.

2. Nurmikko TJ, Serpell MG, Hoggart B, et al. Sativex successfully treats neuropathic pain characterised by allodynia: a randomised, double-blind, placebo-controlled clinical trial. Pain. 2007 Dec 15;133(1-3):210-20. PMID: 17997224.

3. Selvarajah D, Gandhi R, Emery CJ, et al. Randomized placebo-controlled doubleblind clinical trial of cannabis-based medicinal product (Sativex) in painful diabetic neuropathy: depression is a major confounding factor. Diabetes Care. 2010 Jan;33(1):128-30. doi: 10.2337/dc09-1029. PMID: 19808912.

4. Serpell M, Ratcliffe S, Hovorka J, et al. A double-blind, randomized, placebocontrolled, parallel group study of THC/CBD spray in peripheral neuropathic pain treatment. Eur J Pain. 2014 Aug;18(7):999-1012. doi: 10.1002/j.15322149.2013.00445.x. PMID: 24420962.

5. Blake DR, Robson P, Ho M, et al. Preliminary assessment of the efficacy, tolerability and safety of a cannabis-based medicine (Sativex) in the treatment of pain caused by rheumatoid arthritis. Rheumatology (Oxford). 2006 Jan;45(1):502. PMID: 16282192.

6. Lynch ME, Cesar-Rittenberg P, Hohmann AG. A double-blind, placebo-controlled, crossover pilot trial with extension using an oral mucosal cannabinoid extract for treatment of chemotherapy-induced neuropathic pain. J Pain Symptom Manage. 2014 Jan;47(1):166-73. doi: https://dx.doi.org/10.1016/j.jpainsymman.20 13.02.018. PMID: 23742737.
7. Rog DJ, Nurmikko TJ, Friede T, et al. Randomized, controlled trial of cannabisbased medicine in central pain in multiple sclerosis. Neurology. 2005 Sep 27;65(6):812-9. PMID: 16186518.

8. Toth C, Mawani S, Brady S, et al. An enriched-enrolment, randomized withdrawal, flexible-dose, double-blind, placebo-controlled, parallel assignment efficacy study of nabilone as adjuvant in the treatment of diabetic peripheral neuropathic pain. Pain. 2012 Oct;153(10):2073-82. doi: https://dx.doi.org/10.1016/j.pain.2012.06.02 4. PMID: 22921260.9. de Vries M, van Rijckevorsel DCM, Vissers KCP, et al. Tetrahydrocannabinol Does Not Reduce Pain in Patients With Chronic Abdominal Pain in a Phase 2 Placebo-controlled Study. Clin Gastroenterol Hepatol. 2017

Jul;15(7):1079-86.e4. doi: https://dx.doi.org/10.1016/j.cgh.2016.09.147 . PMID: 27720917.

10. Schimrigk S, Marziniak M, Neubauer C, et al. Dronabinol Is a Safe Long-Term Treatment Option for Neuropathic Pain Patients. Eur Neurol. 2017;78(5-6):320-9. doi: 10.1159/000481089. PMID: 29073592.

11. Skrabek RQ, Galimova L, Ethans K, et al. Nabilone for the treatment of pain in fibromyalgia. J Pain. 2008 Feb;9(2):164-73. PMID: 17974490.

12. Turcotte D, Doupe M, Torabi M, et al. Nabilone as an adjunctive to gabapentin for multiple sclerosis-induced neuropathic pain: a randomized controlled trial. Pain Med. 2015 Jan;16(1):149-59. doi: https://dx.doi.org/10.1111/pme.12569. PMID: 25288189.

13. Wissel J, Haydn T, Muller J, et al. Low dose treatment with the synthetic cannabinoid Nabilone significantly reduces spasticityrelated pain : a double-blind placebocontrolled cross-over trial. J Neurol. 2006 Oct;253(10):1337-41. PMID: 16988792. 
14. Zajicek JP, Hobart JC, Slade A, et al.

Multiple sclerosis and extract of cannabis:

results of the MUSEC trial. J Neurol

Neurosurg Psychiatry. 2012

Nov;83(11):1125-32. doi:

https://dx.doi.org/10.1136/jnnp-2012-

302468. PMID: 22791906.

15. Chaves C, Bittencourt PCT, Pelegrini A. Ingestion of a THC-Rich Cannabis Oil in People with Fibromyalgia: A Randomized, Double-Blind, Placebo-Controlled Clinical Trial. Pain Med. 2020;21(10):2212-8. doi: https://dx.doi.org/10.1093/pm/pnaa303.

PMID: 33118602.

16. Ware MA, Wang T, Shapiro S, et al.

Cannabis for the Management of Pain:

Assessment of Safety Study (COMPASS). J

Pain. 2015 Dec;16(12):1233-42. doi:

https://dx.doi.org/10.1016/j.jpain.2015.07.01

4. PMID: 26385201.

17. Xu DH, Cullen BD, Tang M, et al. The Effectiveness of Topical Cannabidiol Oil in Symptomatic Relief of Peripheral

Neuropathy of the Lower Extremities. Curr Pharm Biotechnol. 2020;21(5):390-402. doi: https://dx.doi.org/10.2174/13892010206661 91202111534. PMID: 31793418.

18. Eibach L, Scheffel S, Cardebring M, et al. Cannabidivarin for HIV-Associated Neuropathic Pain: A Randomized, Blinded, Controlled Clinical Trial. Clin Pharmacol Ther. 2020 Aug 08;08:08. doi: https://dx.doi.org/10.1002/cpt.2016. PMID: 32770831 . 


\section{Appendix H. Excluded Studies List}

1. Abo Ziad R, Grynbaum MB, Peleg R, et al. The Attitudes and Beliefs of Family Physicians Regarding the Use of Medical Cannabis, Knowledge of Side Effects, and Barriers to Use: A Comparison Between Residents and Specialists. Am J Ther. 2020;Publish Ahead of Print. doi: https://dx.doi.org/10.1097/MJT.0000000000 001236. PMID: 33416237. Exclusion reason: Ineligible study design

2. Aboud T, Schuster NM. Pain Management in Multiple Sclerosis: a Review of Available Treatment Options. Curr Treat Options Neurol. 2019 Nov 27;21(12):62. doi: https://dx.doi.org/10.1007/s11940-0190601-2. PMID: 31773455. Exclusion reason: Systematic review used as source document

3. Abrams DI, Couey P, Dixit N, et al. Effect of Inhaled Cannabis for Pain in Adults With Sickle Cell Disease: A Randomized Clinical Trial. JAMA Netw. 2020 Jul 01;3(7):e2010874. doi: https://dx.doi.org/10.1001/jamanetworkopen .2020.10874. PMID: 32678452. Exclusion reason: Inadequate duration

4. Abrams DI, Jay CA, Shade SB, et al. Cannabis in painful HIV-associated sensory neuropathy: a randomized placebocontrolled trial. Neurology. 2007 Feb 13;68(7):515-21. PMID: 17296917. Exclusion reason: Inadequate duration

5. Abuhasira R, Ron A, Sikorin I, et al. Medical Cannabis for Older PatientsTreatment Protocol and Initial Results. J Clin Med. 2019 Nov 01;8(11):01. doi: https://dx.doi.org/10.3390/jcm8111819. PMID: 31683817 . Exclusion reason: Ineligible population

6. Abuhasira R, Ron A, Sikorin I, et al. Medical cannabis for older patientstreatment protocol and initial results. J Clin Med. 2019;8(11)doi: 10.3390/jcm8111819. PMID: 31683817 . Exclusion reason: Ineligible population

7. Akgün K, Essner U, Seydel C, et al. Daily Practice Managing Resistant Multiple Sclerosis Spasticity With Delta-9Tetrahydrocannabinol: Cannabidiol
Oromucosal Spray: A Systematic Review of Observational Studies. J Cent Nerv Syst Dis. 2019;11doi: 10.1177/1179573519831997. PMID: 30886530. Exclusion reason: Systematic review used as source document

8. Allan GM, Finley CR, Ton J, et al. Systematic review of systematic reviews for medical cannabinoids: Pain, nausea and vomiting, spasticity, and harms. Can Fam Physician. 2018 02;64(2):e78-e94. PMID: 29449262. Exclusion reason: Ineligible publication type

9. Almog S, Aharon-Peretz J, Vulfsons S, et al. The pharmacokinetics, efficacy, and safety of a novel selective-dose cannabis inhaler in patients with chronic pain: A randomized, double-blinded, placebo-controlled trial. Eur J Pain. 2020 May 23;23:23. doi: https://dx.doi.org/10.1002/ejp.1605. PMID: 32445190. Exclusion reason: Inadequate duration

10. Aly E, Masocha W. Targeting the endocannabinoid system for management of HIV-associated neuropathic pain: A systematic review. IBRO Neurosci Rep. 2021 Jun; 10:109-18. doi: https://dx.doi.org/10.1016/j.ibneur.2021.01. 004. PMID: 34179865. Exclusion reason: Systematic review used as source document

11. Amato L, Minozzi S, Mitrova Z, et al. Systematic review of safeness and therapeutic efficacy of cannabis in patients with multiple sclerosis, neuropathic pain, and in oncological patients treated with chemotherapy. Epidemiol Prev. 2017;41(56)doi: 10.19191/EP17.5-6.AD01.069. PMID: 29119763. Exclusion reason: Ineligible publication type

12. Andreae MH, Carter GM, Shaparin N, et al. Inhaled Cannabis for Chronic Neuropathic Pain: A Meta-analysis of Individual Patient Data. J Pain. 2015 Dec;16(12):1221-32. doi: https://dx.doi.org/10.1016/j.jpain.2015.07.00 9. PMID: 26362106. Exclusion reason: Inadequate duration

13. Aviram J, Lewitus GM, Pud D, et al. Specific phytocannabinoid compositions are associated with analgesic response and adverse effects in chronic pain patients 
treated with medical cannabis. Pharmacol

Res. 2021 Jul;169:105651. doi:

https://dx.doi.org/10.1016/j.phrs.2021.10565

1. PMID: 34000362. Exclusion reason:

Ineligible comparator

14. Aviram J, Pud D, Gershoni T, et al. Medical Cannabis Treatment for Chronic Pain:

Outcomes and Prediction of Response. Eur J Pain. 2020 Oct 16;16:16. doi:

https://dx.doi.org/10.1002/ejp.1675. PMID:

33065768. Exclusion reason: Ineligible

comparator

15. Aviram J, Samuelly-Leichtag G. Efficacy of

Cannabis-Based Medicines for Pain

Management: A Systematic Review and

Meta-Analysis of Randomized Controlled

Trials. Pain Physician. 2017 09;20(6):E755-

E96. PMID: 28934780. Exclusion reason:

Systematic review used as source document

16. Ball S, Vickery J, Hobart J, et al. The

Cannabinoid Use in Progressive

Inflammatory brain Disease (CUPID) trial: a

randomised double-blind placebo-controlled

parallel-group multicentre trial and

economic evaluation of cannabinoids to

slow progression in multiple sclerosis.

Health Technol Assess. 2015;19(12):1-187.

PMID: 25676540. Exclusion reason:

Ineligible outcome

17. Barnes MP. Sativex: clinical efficacy and tolerability in the treatment of symptoms of multiple sclerosis and neuropathic pain. Expert Opin Pharmacother. 2006

Apr;7(5):607-15. PMID: 16553576.

Exclusion reason: Ineligible publication type

18. Becker WC, Li Y, Caniglia EC, et al. Cannabis use, pain interference, and prescription opioid receipt among persons with HIV: a target trial emulation study. AIDS Care. 2021 Jun 28:1-9. doi: https://dx.doi.org/10.1080/09540121.2021.1 944597. PMID: 34180721. Exclusion

reason: Ineligible population

19. Bellnier T, Brown GW, Ortega TR. Preliminary evaluation of the efficacy, safety, and costs associated with the treatment of chronic pain with medical cannabis. Ment Health Clin. 2018 May;8(3):110-5. doi: https://dx.doi.org/10.9740/mhc.2018.05.110. PMID: 29955555. Exclusion reason: Ineligible comparator
20. Berger AA, Keefe J, Winnick A, et al. Cannabis and cannabidiol (CBD) for the treatment of fibromyalgia. Best Pract Res Clin Anaesthesiol. 2020. doi: 10.1016/j.bpa.2020.08.010. PMID: 33004171. Exclusion reason: Ineligible publication type

21. Berman JS, Symonds C, Birch R. Efficacy of two cannabis based medicinal extracts for relief of central neuropathic pain from brachial plexus avulsion: results of a randomised controlled trial. Pain. 2004 Dec;112(3):299-306. PMID: 15561385. Exclusion reason: Inadequate duration

22. Blake A, Wan BA, Malek L, et al. A selective review of medical cannabis in cancer pain management. Ann Palliat Med. 2017 Dec;6(Suppl 2):S215-S22. doi: https://dx.doi.org/10.21037/apm.2017.08.05. PMID: 28866904. Exclusion reason: Ineligible population

23. Boehnke KF, Gagnier JJ, Matallana L, et al. Cannabidiol Use for Fibromyalgia: Prevalence of Use and Perceptions of Effectiveness in a Large Online Survey. J Pain. 2021doi:

https://dx.doi.org/10.1016/j.jpain.2020.12.00 1. PMID: 33400996. Exclusion reason: Ineligible study design

24. Boehnke KF, Gagnier JJ, Matallana L, et al. Substituting Cannabidiol for Opioids and Pain Medications Among Individuals With Fibromyalgia: A Large Online Survey. J Pain. 2021doi: 10.1016/j.jpain.2021.04.011. PMID: 33992787. Exclusion reason: Background only

25. Boehnke KF, Scott JR, Litinas E, et al. High-Frequency Medical Cannabis Use Is Associated With Worse Pain Among Individuals With Chronic Pain. J Pain. 2020 May - Jun;21(5-6):570-81. doi: https://dx.doi.org/10.1016/j.jpain.2019.09.00 6. PMID: 31560957. Exclusion reason: Ineligible comparator

26. Boychuk DG, Goddard G, Mauro G, et al. The effectiveness of cannabinoids in the management of chronic nonmalignant neuropathic pain: a systematic review. J Oral Facial Pain Headache. 2015;29(1):7-14. doi: https://dx.doi.org/10.11607/ofph.1274. PMID: 25635955. Exclusion reason: Ineligible publication type 
27. Busse JW, Wang L, Kamaleldin M, et al. Opioids for Chronic Noncancer Pain: A Systematic Review and Meta-analysis. JAMA. 201812 18;320(23):2448-60. doi: https://dx.doi.org/10.1001/jama.2018.18472. PMID: 30561481. Exclusion reason: Systematic review used as source document

28. Chan CJ. Efficacy of plant based cannabis in reducing pain in patients with chronic pain: A meta analysis. Dissertation Abstracts International: Section B: The Sciences and Engineering. 2020;81(10-B):No Pagination Specified. Exclusion reason: Ineligible publication type

29. Christ MM. Pain medicine: Cannabis is effective in neuropathic pain.

Arzneimitteltherapie. 2019;37(6):242-3.

Exclusion reason: Not in English

30. Clermont-Gnamien S, Atlani S, Attal N, et al. The therapeutic use of $\Delta 9$ tetrahydrocannabinol (dronabinol) in refractory neuropathic pain. Presse Medicale. 2002;31(39 I):1840-5. PMID: 12496714. Exclusion reason: Not in English

31. Cooper ZD, Abrams DI. Considering abuse liability and neurocognitive effects of cannabis and cannabis-derived products when assessing analgesic efficacy: a comprehensive review of randomizedcontrolled studies. Am J Drug Alcohol Abuse. 2019;45(6):580-95. doi: https://dx.doi.org/10.1080/00952990.2019.1 669628. PMID: 31687845. Exclusion reason: Systematic review used as source document

32. Corey-Bloom J, Wolfson T, Gamst A, et al. Smoked cannabis for spasticity in multiple sclerosis: a randomized, placebo-controlled trial. CMAJ. 2012 Jul 10;184(10):1143-50. doi: https://dx.doi.org/10.1503/cmaj.110837. PMID: 22586334. Exclusion reason: Inadequate duration

33. Costales B, van Boemmel-Wegmann $\mathrm{S}$, Winterstein A, et al. Clinical Conditions and Prescription Drug Utilization among Early Medical Marijuana Registrants in Florida. J Psychoactive Drugs. 2021:1-10. doi: https://dx.doi.org/10.1080/02791072.2020.1 864069. PMID: 33393877. Exclusion reason: Ineligible study design
34. Coughlin LN, Ilgen MA, Jannausch M, et al. Progression of cannabis withdrawal symptoms in people using medical cannabis for chronic pain. Addiction. 2021doi: https://dx.doi.org/10.1111/add.15370. PMID: 33400332. Exclusion reason: Ineligible study design

35. Crestani F. Medical Cannabis for the Treatment of Fibromyalgia. J Clin Rheumatol. 2018 Aug;24(5):281. doi: https://dx.doi.org/10.1097/RHU.000000000 0000823. PMID: 29757806. Exclusion reason: Ineligible study design

36. Cumenal M, Selvy M, Kerckhove N, et al. The safety of medications used to treat peripheral neuropathic pain, part 2 (opioids, cannabinoids and other drugs): review of double-blind, placebo-controlled, randomized clinical trials. Expert Opin Drug Saf. 2020doi:

https://dx.doi.org/10.1080/14740338.2021.1 842871. PMID: 33103931. Exclusion

reason: Systematic review used as source document

37. Cunetti L, Manzo L, Peyraube R, et al. Chronic Pain Treatment With Cannabidiol in Kidney Transplant Patients in Uruguay. Transplant Proc. 2018 Mar;50(2):461-4. doi: https://dx.doi.org/10.1016/j.transproceed.20 17.12.042. PMID: 29579828. Exclusion reason: Ineligible comparator

38. Cunningham CO, Starrels JL, Zhang C, et al. Medical Marijuana and Opioids (MEMO) Study: protocol of a longitudinal cohort study to examine if medical cannabis reduces opioid use among adults with chronic pain. BMJ Open. 2020;10(12):e043400. doi: https://dx.doi.org/10.1136/bmjopen-2020043400. PMID: 33376181. Exclusion reason: Ineligible study design

39. Curtis SA, Brandow AM, Deveaux M, et al. Daily Cannabis Users with Sickle Cell

Disease Show Fewer Admissions than Others with Similar Pain Complaints. Cannabis Cannabinoid Res. 2020;5(3):25562. doi: 10.1089/can.2019.0036. PMID: 32923662. Exclusion reason: Ineligible study design

40. Darnall BD, Humphreys KN. An experimental method for assessing whether marijuana use reduces opioid use in patients with chronic pain. Addiction. 2018 
08;113(8):1552-3. doi:

https://dx.doi.org/10.1111/add.14239.

PMID: 29882256. Exclusion reason:

Ineligible study design

41. Degenhardt L, Lintzeris N, Campbell G, et al. Experience of adjunctive cannabis use for chronic non-cancer pain: findings from the Pain and Opioids IN Treatment (POINT) study. Drug Alcohol Depend. 2015 Feb 01;147:144-50. doi: https://dx.doi.org/10.1016/j.drugalcdep.2014 .11.031. PMID: 25533893. Exclusion reason: Ineligible study design

42. Denduluri SK, Woolson ST, Indelli PF, et al. Cannabinoid and Opioid Use Among Total Joint Arthroplasty Patients: A 6-Year, Single-Institution Study. Orthopedics. 2020 Oct 01:1-6. doi: https://dx.doi.org/10.3928/0147744720200928-02. PMID: 33002174. Exclusion reason: Ineligible outcome

43. Deshpande A, Mailis-Gagnon A, Zoheiry N, et al. Efficacy and adverse effects of medical marijuana for chronic noncancer pain:

Systematic review of randomized controlled trials. Can Fam Physician. 2015

Aug;61(8):e372-81. PMID: 26505059.

Exclusion reason: Ineligible publication type

44. Durán M, Capellà D. Cannabis and cannabinoids in the treatment of neuropathic pain. DOLOR. 2005;20(4):213-6. Exclusion reason: Not in English

45. Dykukha I, Malessa R, Essner U, et al. Nabiximols in Chronic Neuropathic Pain: A Meta-Analysis of Randomized PlaceboControlled Trials. Pain Med. 202104 20;22(4):861-74. doi: https://dx.doi.org/10.1093/pm/pnab050. PMID: 33561282. Exclusion reason: Systematic review used as source document

46. Eadie L, Lo LA, Christiansen A, et al. Duration of Neurocognitive Impairment With Medical Cannabis Use: A Scoping Review. Front Psychiatry. 2021;12doi: 10.3389/fpsyt.2021.638962. PMID: 33790818. Exclusion reason: Systematic review used as source document

47. Ellis RJ, Toperoff W, Vaida F, et al. Smoked medicinal cannabis for neuropathic pain in HIV: a randomized, crossover clinical trial. Neuropsychopharmacology.
2009 Feb;34(3):672-80. doi: https://dx.doi.org/10.1038/npp.2008.120. PMID: 18688212. Exclusion reason: Inadequate duration

48. Fallon MT, Albert Lux E, McQuade R, et al. Sativex oromucosal spray as adjunctive therapy in advanced cancer patients with chronic pain unalleviated by optimized opioid therapy: two double-blind, randomized, placebo-controlled phase 3 studies. Br J Pain. 2017 Aug;11(3):119-33. doi:

https://dx.doi.org/10.1177/20494637177100 42. PMID: 28785408. Exclusion reason: Ineligible population

49. Feingold D, Brill S, Goor-Aryeh I, et al. Depression and anxiety among chronic pain patients receiving prescription opioids and medical marijuana. J Affect Disord. 201708 15;218:1-7. doi:

https://dx.doi.org/10.1016/j.jad.2017.04.026. PMID: 28453948. Exclusion reason: Ineligible study design

50. Fiani B, Sarhadi KJ, Soula M, et al. Current application of cannabidiol (CBD) in the management and treatment of neurological disorders. Neurol Sci. 2020 Jun 16;16:16. doi: https://dx.doi.org/10.1007/s10072-02004514-2. PMID: 32556748. Exclusion reason: Background only

51. First L, Douglas W, Habibi B, et al. Cannabis Use and Low-Back Pain: A Systematic Review. Cannabis Cannabinoid Res. 2020;5(4):283-9. doi:

10.1089/can.2019.0077. PMID: 33381642.

Exclusion reason: Systematic review used as source document

52. Fishbain DA, Cutler RB, Rosomoff HL, et al. Validity of self-reported drug use in chronic pain patients. Clin J Pain. 1999 Sep;15(3):184-91. PMID: 10524471. Exclusion reason: Background only

53. Fisher E, Moore RA, Fogarty AE, et al. Cannabinoids, cannabis, and cannabis-based medicine for pain management: a systematic review of randomised controlled trials. Pain. 2021 Jul 1;162(Suppl 1):S45-s66. doi: 10.1097/j.pain.0000000000001929. PMID: 32804836. Exclusion reason: Systematic review used as source document

54. Fitzcharles M-A, Rampakakis E, Sampalis J, et al. Use of medical cannabis by patients 
with fibromyalgia in Canada after cannabis legalisation: a cross-sectional study. Clin Exp Rheumatol. 2021. PMID: 33938797.

Exclusion reason: Ineligible study design

55. Fitzcharles MA, Baerwald C, Ablin J, et al. Efficacy, tolerability and safety of cannabinoids in chronic pain associated with rheumatic diseases (fibromyalgia syndrome, back pain, osteoarthritis, rheumatoid arthritis): A systematic review of randomized controlled trials. Schmerz. 2016 Feb;30(1):47-61. doi: https://dx.doi.org/10.1007/s00482-0150084-3. PMID: 26767993. Exclusion reason: Ineligible publication type

56. Fitzcharles MA, Ste-Marie PA, Hauser W, et al. Efficacy, Tolerability, and Safety of Cannabinoid Treatments in the Rheumatic Diseases: A Systematic Review of Randomized Controlled Trials. Arthritis Care Res. 2016 05;68(5):681-8. doi: https://dx.doi.org/10.1002/acr.22727. PMID: 26548380. Exclusion reason: Ineligible publication type

57. Flachenecker P, Henze T, Zettl UK. Nabiximols (THC/CBD oromucosal spray, Sativex ${ }^{\circledR)}$ in clinical practice--results of a multicenter, non-interventional study (MOVE 2) in patients with multiple sclerosis spasticity. Eur Neurol. 2014;71(56):271-9. doi: 10.1159/000357427. PMID: 24525548. Exclusion reason: Ineligible comparator

58. Flachenecker P, Henze T, Zettl UK. Longterm effectiveness and safety of nabiximols (tetrahydrocannabinol/cannabidiol oromucosal spray) in clinical practice. Eur Neurol. 2014;72(1-2):95-102. doi: 10.1159/000360285. PMID: 24943098.

Exclusion reason: Ineligible comparator

59. Gado F, Mohamed KA, Meini S, et al. Variously substituted 2-oxopyridine derivatives: Extending the structure-activity relationships for allosteric modulation of the cannabinoid CB2 receptor. Eur J Med Chem. 2020;211:113116. doi: https://dx.doi.org/10.1016/j.ejmech.2020.11 3116. PMID: 33360803. Exclusion reason: Ineligible study design

60. Gambino A, Cabras M, Panagiotakos E, et al. Evaluating the Suitability and Potential Efficiency of Cannabis sativa Oil for Patients with Primary Burning Mouth
Syndrome: A Prospective, Open-Label, Single-Arm Pilot Study. Pain Med. 2020doi: https://dx.doi.org/10.1093/pm/pnaa318. PMID: 33123730. Exclusion reason: Ineligible comparator

61. Grotenhermen F. Treatment of severe chronic pain with cannabis preparations. Arztliche Praxis Neurologie Psychiatrie. 2002(5):28-30. Exclusion reason: Not in English

62. Guillouard M, Authier N, Pereira B, et al. Cannabis use assessment and its impact on pain in rheumatologic diseases: a systematic review and meta-analysis. Rheumatology (Oxford, England). 2020doi: https://dx.doi.org/10.1093/rheumatology/kea a534. PMID: 33159797. Exclusion reason: Systematic review used as source document

63. Gutierrez T, Hohmann AG. Cannabinoids for the treatment of neuropathic pain: Are they safe and effective? Future Neurol. 2011;6(2):129-33. doi: 10.2217/fnl.11.6. Exclusion reason: Ineligible publication type

64. Haleem R, Wright R. A Scoping Review on Clinical Trials of Pain Reduction With Cannabis Administration in Adults. J Clin Med Res. 2020 Jun;12(6):344-51. doi: https://dx.doi.org/10.14740/jocmr4210. PMID: 32587650. Exclusion reason: Ineligible population

65. Haroutounian S, Arendt-Nielsen L, Belton J, et al. International Association for the Study of Pain Presidential Task Force on Cannabis and Cannabinoid Analgesia: research agenda on the use of cannabinoids, cannabis, and cannabis-based medicines for pain management. Pain. 2021 Jul 01;162(Suppl 1):S117-S24. doi: https://dx.doi.org/10.1097/j.pain.000000000 0002266. PMID: 34138827. Exclusion reason: Background only

66. Hassan S, Zheng Q, Rizzolo E, et al. Does Integrative Medicine Reduce Prescribed Opioid Use for Chronic Pain? A Systematic Literature Review. Pain Med. 202004 01;21(4):836-59. doi: https://dx.doi.org/10.1093/pm/pnz291. PMID: 31755962. Exclusion reason: Ineligible intervention

67. Haungs A, Elizondo J. Does smoking cannabis help with chronic neuropathic 
pain? Evidence-Based Practice. 2018;21(2):E7-E8. Exclusion reason: Ineligible publication type

68. Hauser W, Fitzcharles M-A, Radbruch L, et al. Cannabinoids in pain management and palliative medicine: an overview of systematic reviews and prospective observational studies. Dtsch. 2017 Sep;114(38):627-34. PMID: 29017688. Exclusion reason: Systematic review used as source document

69. Hauser W, Fitzcharles MA, Radbruch L, et al. Cannabinoids in Pain Management and Palliative Medicine. Dtsch. 2017 Sep 22;114(38):627-34. doi: https://dx.doi.org/10.3238/arztebl.2017.0627 . PMID: 29017688. Exclusion reason: Ineligible population

70. Hayes C, Martin JH. Lack of efficacy of cannabidiol for relieving back pain: time to re-set expectations? Med J Aust. 2021doi: 10.5694/mja2.51025. PMID: 33846981.

Exclusion reason: Ineligible publication type

71. Hendricks O, Andersen TE, Christiansen AA, et al. Efficacy and safety of cannabidiol followed by an open label add-on of tetrahydrocannabinol for the treatment of chronic pain in patients with rheumatoid arthritis or ankylosing spondylitis: protocol for a multicentre, randomised, placebocontrolled study. BMJ Open. 201906 04;9(6):e028197. doi: https://dx.doi.org/10.1136/bmjopen-2018028197. PMID: 31167870. Exclusion reason: Ineligible study design

72. Hesselink JM, Kopsky DJ. Enhancing acupuncture by low dose naltrexone. Acupunct Med. 2011 Jun;29(2):127-30. doi: https://dx.doi.org/10.1136/aim.2010.003566. PMID: 21415049. Exclusion reason: Ineligible publication type

73. Hill KP, Hurley-Welljams-Dorof WM. Low to moderate quality evidence demonstrates the potential benefits and adverse events of cannabinoids for certain medical indications. Evid Based Med. 2016 Feb;21(1):17. doi: https://dx.doi.org/10.1136/ebmed-2015110264. PMID: 26490847. Exclusion reason: Ineligible publication type

74. Hill KP, Palastro MD, Johnson B, et al. Cannabis and Pain: A Clinical Review.
Cannabis Cannabinoid Res. 2017;2(1):96104. doi: 10.1089/can.2017.0017. PMID: 28861509. Exclusion reason: Systematic review used as source document

75. Hoggart B, Ratcliffe S, Ehler E, et al. A multicentre, open-label, follow-on study to assess the long-term maintenance of effect, tolerance and safety of THC/CBD oromucosal spray in the management of neuropathic pain. J Neurol. 2015 Jan;262(1):27-40. doi: https://dx.doi.org/10.1007/s00415-0147502-9. PMID: 25270679. Exclusion reason: Ineligible study design

76. Hojsted J, Ekholm O, Kurita GP, et al. Addictive behaviors related to opioid use for chronic pain: a population-based study. Pain. 2013;154(12):2677-83. PMID: 23906554. Exclusion reason: Ineligible intervention

77. Holdcroft A, Smith M, Jacklin A, et al. Pain relief with oral cannabinoids in familial Mediterranean fever. Anaesthesia. 1997 May;52(5):483-6. PMID: 9165969.

Exclusion reason: Ineligible study design

78. Huang IC, Alberts NM, Buckley MG, et al. Change in Pain Status and Subsequent Opioid and Marijuana Use Among LongTerm Adult Survivors of Childhood Cancer. JNCI Cancer Spectr. 2020;4(6):pkaa070.

doi:

https://dx.doi.org/10.1093/jncics/pkaa070. PMID: 33409451. Exclusion reason: Ineligible study design

79. Hwang JK, Clarke H. Cannabis and pain: A review. J Pain Manag. 2016;9(4):395-413. Exclusion reason: Ineligible publication type

80. Iskedjian M, Bereza B, Gordon A, et al. Meta-analysis of cannabis based treatments for neuropathic and multiple sclerosisrelated pain. Curr Med Res Opin. 2007 Jan;23(1):17-24. PMID: 17257464. Exclusion reason: Ineligible publication type

81. Jawahar R, Oh U, Yang S, et al. A systematic review of pharmacological pain management in multiple sclerosis. Drugs. 2013 Oct;73(15):1711-22. doi: https://dx.doi.org/10.1007/s40265-0130125-0. PMID: 24085618. Exclusion 
reason: Systematic review used as source document

82. Jensen TS, Madsen CS, Finnerup NB. Pharmacology and treatment of neuropathic pains. Curr Opin Neurol. 2009

Oct;22(5):467-74. doi:

https://dx.doi.org/10.1097/WCO.0b013e328

3311e13. PMID: 19741531. Exclusion

reason: Ineligible publication type

83. Johal H, Devji T, Chang Y, et al. Cannabinoids in Chronic Non-Cancer Pain: A Systematic Review and Meta-Analysis. Clin Med Insights Arthritis Musculoskelet Disord. 2020;13:1179544120906461. doi: https://dx.doi.org/10.1177/11795441209064 61. PMID: 32127750. Exclusion reason: Systematic review used as source document

84. Julia SG, Marta VR, Lourdes GR, et al. Offlabel use of cannabinoids efficacy and safety. European Journal of Clinical Pharmacy. 2017;19(3):158-63. Exclusion reason: Ineligible study design

85. Kafil TS, Nguyen TM, MacDonald JK, et al. Cannabis for the treatment of ulcerative colitis. Cochrane Database Syst Rev. 2018 Nov 08;11:CD012954. doi: https://dx.doi.org/10.1002/14651858.CD012 954.pub2. PMID: 30406638. Exclusion reason: Ineligible population

86. Karst M, Salim K, Burstein S, et al. Analgesic effect of the synthetic cannabinoid CT-3 on chronic neuropathic pain: a randomized controlled trial. JAMA. 2003 Oct 01;290(13):1757-62. PMID: 14519710. Exclusion reason: Inadequate duration

87. Kaskie B, Kang H, Bhagianadh D, et al. Cannabis Use among Older Persons with Arthritis, Cancer and Multiple Sclerosis: Are We Comparing Apples and Oranges? Brain Sci. 2021;11(5)doi:

https://dx.doi.org/10.3390/brainsci1 1050532 . PMID: 33922425. Exclusion reason: Ineligible study design

88. Kocot-Kepska M, Zajaczkowska R, Mika J, et al. Topical Treatments and Their Molecular/Cellular Mechanisms in Patients with Peripheral Neuropathic Pain-Narrative Review. Pharmaceutics. 2021;13(4)doi: https://dx.doi.org/10.3390/pharmaceutics 130 40450. PMID: 33810493. Exclusion

reason: Ineligible publication type
89. Kurlyandchik I, Tiralongo E, Schloss J. Safety and Efficacy of Medicinal Cannabis in the Treatment of Fibromyalgia: A Systematic Review. J Altern Complement Med (New York, N.Y.). 2020doi: https://dx.doi.org/10.1089/acm.2020.0331. PMID: 33337931. Exclusion reason: Systematic review used as source document

90. Lake S, Walsh Z, Kerr T, et al. Frequency of cannabis and illicit opioid use among people who use drugs and report chronic pain: A longitudinal analysis. PLoS Med. 2019 11;16(11):e1002967. doi: https://dx.doi.org/10.1371/journal.pmed.100 2967. PMID: 31743343. Exclusion reason: Ineligible study design

91. Lee G, Grovey B, Furnish T, et al. Medical Cannabis for Neuropathic Pain. Curr Pain Headache Rep. 2018 Feb 01;22(1):8. doi: https://dx.doi.org/10.1007/s11916-0180658-8. PMID: 29388063. Exclusion reason: Systematic review used as source document

92. Lichtman AH, Lux EA, McQuade R, et al. Results of a Double-Blind, Randomized, Placebo-Controlled Study of Nabiximols Oromucosal Spray as a Adjunctive Therapy in Advanced Cancer Patients with Chronic Uncontrolled Pain. J Pain Symptom Manage. 2017(pagination) PMID: 28923526. Exclusion reason: Ineligible population

93. Lichtman AH, Lux EA, McQuade R, et al. Results of a Double-Blind, Randomized, Placebo-Controlled Study of Nabiximols Oromucosal Spray as an Adjunctive Therapy in Advanced Cancer Patients with Chronic Uncontrolled Pain. J Pain Symptom Manage. 2018 02;55(2):179-88.e1. doi: https://dx.doi.org/10.1016/j.jpainsymman.20 17.09.001. PMID: 28923526. Exclusion reason: Ineligible population

94. Longo R, Oudshoorn A, Befus D. Cannabis for Chronic Pain: A Rapid Systematic Review of Randomized Control Trials. Pain Manag Nurs. 2020doi: 10.1016/j.pmn.2020.11.006. PMID: 33353819. Exclusion reason: Systematic review used as source document

95. Lopez-Sendon Moreno JL, Garcia Caldentey J, Trigo Cubillo P, et al. A double-blind, randomized, cross-over, placebo-controlled, pilot trial with Sativex in Huntington's 
disease. J Neurol. 2016;263(7):1390-400. PMID: 27159993. Exclusion reason: Ineligible population

96. Lucas P, Boyd S, Milloy MJ, et al. Cannabis Significantly Reduces the Use of Prescription Opioids and Improves Quality of Life in Authorized Patients: Results of a Large Prospective Study. Pain Med. 2020doi: https://dx.doi.org/10.1093/pm/pnaa396. PMID: 33367882. Exclusion reason: Ineligible population

97. Luchetti M, Zanarella C, Moretti C, et al. Cannabinoids for the treatment of neuropathic pain. Acta Anaesthesiologica Italica/Anaesthesia and Intensive Care in Italy. 2008;59(2):187-95. Exclusion reason: Not in English

98. Lynch ME, Campbell F. Cannabinoids for treatment of chronic non-cancer pain; a systematic review of randomized trials. Br J Clin Pharmacol. 2011 Nov;72(5):735-44. doi: https://dx.doi.org/10.1111/j.13652125.2011.03970.x. PMID: 21426373. Exclusion reason: Ineligible publication type

99. Lynch ME, Ware MA. Cannabinoids for the Treatment of Chronic Non-Cancer Pain: An Updated Systematic Review of Randomized Controlled Trials. J Neuroimmune Pharmacol. 2015 Jun;10(2):293-301. doi: https://dx.doi.org/10.1007/s11481-0159600-6. PMID: 25796592. Exclusion reason: Ineligible publication type

100. Maayah ZH, Takahara S, Ferdaoussi M, et al. The anti-inflammatory and analgesic effects of formulated full-spectrum cannabis extract in the treatment of neuropathic pain associated with multiple sclerosis. Inflamm Res. 2020 Jun;69(6):549-58. doi: https://dx.doi.org/10.1007/s00011-02001341-1. PMID: 32239248. Exclusion reason: Ineligible publication type

101. MacCallum CA, Eadie L, Barr AM, et al. Practical Strategies Using Medical Cannabis to Reduce Harms Associated With Long Term Opioid Use in Chronic Pain. Front Pharmacol. 2021;12doi: 10.3389/fphar.2021.633168. PMID: 33995035. Exclusion reason: Ineligible publication type
102. Maida V, Ennis M, Irani S, et al. Adjunctive nabilone in cancer pain and symptom management: a prospective observational study using propensity scoring. J Support Oncol. 2008 Mar;6(3):119-24. PMID: 18402303. Exclusion reason: Ineligible population

103. Martin-Sanchez E, Furukawa TA, Taylor J, et al. Systematic review and meta-analysis of cannabis treatment for chronic pain. Pain Med. 2009 Nov;10(8):1353-68. doi: https://dx.doi.org/10.1111/j.15264637.2009.00703.x. PMID: 19732371. Exclusion reason: Ineligible publication type

104. Matarazzo AP, Elisei LMS, Carvalho FC, et al. Mucoadhesive nanostructured lipid carriers as a cannabidiol nasal delivery system for the treatment of neuropathic pain. Eur J Pharm Sci. 2021:105698. doi: https://dx.doi.org/10.1016/j.ejps.2020.10569 8. PMID: 33406408 . Exclusion reason: Ineligible study design

105. Maurer M, Henn V, Dittrich A, et al. Delta9-tetrahydrocannabinol shows antispastic and analgesic effects in a single case doubleblind trial. Eur Arch Psychiatry Clin Neurosci. 1990;240(1):1-4. doi: 10.1007/bf02190083. PMID: 2175265.

Exclusion reason: Inadequate duration

106. Mazza M. Medical cannabis for the treatment of fibromyalgia syndrome: a retrospective, open-label case series. J Cannabis Res. 2021;3(1):4. doi: https://dx.doi.org/10.1186/s42238-02100060-6. PMID: 33597032. Exclusion reason: Ineligible comparator

107. McDonagh MS, Selph SS, Buckley DI, et al. Nonopioid Pharmacologic Treatments for Chronic Pain. Agency for Healthcare Research and Quality (US). 2020 04:04. PMID: 32338847. Exclusion reason: Systematic review used as source document

108. McGinty EE, Tormohlen KN, Barry CL, et al. Protocol: mixed-methods study of how implementation of US state medical cannabis laws affects treatment of chronic non-cancer pain and adverse opioid outcomes. Implement Sci. 2021;16(1):2. doi: https://dx.doi.org/10.1186/s13012-02001071-2. PMID: 33413454. Exclusion reason: Ineligible publication type 
109. Meng H, Johnston B, Englesakis M, et al. Selective Cannabinoids for Chronic Neuropathic Pain: A Systematic Review and Meta-analysis. Anesth Analg. 2017 11;125(5):1638-52. doi: https://dx.doi.org/10.1213/ANE.0000000000 002110. PMID: 28537982. Exclusion reason: Ineligible publication type

110. Meng H, Page MG, Ajrawat P, et al. Patientreported outcomes in those consuming medical cannabis: a prospective longitudinal observational study in chronic pain patients. Resultats rapportes par les patients consommant du cannabis medical : une etude observationnelle longitudinale prospective chez des patients souffrant de douleur chronique. 2021 doi: https://dx.doi.org/10.1007/s12630-02001903-1. PMID: 33469735. Exclusion reason: Ineligible population

111. Mohiuddin M, Blyth FM, Degenhardt L, et al. General risks of harm with cannabinoids, cannabis, and cannabis-based medicine possibly relevant to patients receiving these for pain management: an overview of systematic reviews. Pain. 2021 Jul 01;162(Suppl 1):S80-S96. doi: https://dx.doi.org/10.1097/j.pain.000000000 0002000. PMID: 32941319. Exclusion reason: Background only

112. Montero-Oleas N, Arevalo-Rodriguez I, Nunez-Gonzalez S, et al. Therapeutic use of cannabis and cannabinoids: an evidence mapping and appraisal of systematic reviews. BMC Complement Med Ther. 2020 Jan 15;20(1):12. doi: https://dx.doi.org/10.1186/s12906-0192803-2. PMID: 32020875. Exclusion reason: Systematic review used as source document

113. Moore RA, Fisher E, Finn DP, et al. Cannabinoids, cannabis, and cannabis-based medicines for pain management: an overview of systematic reviews. Pain. 2021 Jul 1;162(Suppl 1):S67-s79. doi: 10.1097/j.pain.0000000000001941. PMID: 32804833. Exclusion reason: Systematic review used as source document

114. Moreno Torres I, Sanchez AJ, GarciaMerino A. Evaluation of the tolerability and efficacy of Sativex in multiple sclerosis. Expert Rev. 2014 Nov;14(11):1243-50. doi: https://dx.doi.org/10.1586/14737175.2014.9
71758. PMID: 25331416. Exclusion reason: Ineligible publication type

115. Mucke M, Phillips T, Radbruch L, et al. Cannabis-based medicines for chronic neuropathic pain in adults. Cochrane Database Syst Rev. 201803 07;3:CD012182. doi: https://dx.doi.org/10.1002/14651858.CD012 182.pub2. PMID: 29513392. Exclusion reason: Systematic review used as source document

116. Muller C, Reggio PH. An Analysis of the Putative CBD Binding Site in the Ionotropic Cannabinoid Receptors. Front Cell Neurosci. 2020;14:615811. doi: https://dx.doi.org/10.3389/fncel.2020.61581 1. PMID: 33362478. Exclusion reason: Ineligible study design

117. Murff HJ. Review: Weak evidence of benefits of cannabis for chronic neuropathic pain; moderate to weak evidence of adverse effects. Ann Intern Med. 201712 19;167(12):JC62. doi: https://dx.doi.org/10.7326/ACPJC-2017167-12-062. PMID: 29255852. Exclusion reason: Ineligible publication type

118. Narang S, Gibson D, Wasan AD, et al. Efficacy of dronabinol as an adjuvant treatment for chronic pain patients on opioid therapy. J Pain. 2008 Mar;9(3):254-64. PMID: 18088560. Exclusion reason: Ineligible study design

119. Neilson LM, Swift C, Swart ECS, et al. Impact of Marijuana Legalization on Opioid Utilization in Patients Diagnosed with Pain. J Gen Intern Med. 2021doi: https://dx.doi.org/10.1007/s11606-02006530-6. PMID: 33575906. Exclusion reason: Background only

120. Novotna A, Mares J, Ratcliffe S, et al. A randomized, double-blind, placebocontrolled, parallel-group, enriched-design study of nabiximols* (Sativex), as add-on therapy, in subjects with refractory spasticity caused by multiple sclerosis. Eur J Neurol. 2011;18(9):1122-31. PMID: 21362108.

Exclusion reason: Ineligible outcome

121. Nugent SM, Kansagara D. The Effects of Cannabis Among Adults With Chronic Pain. Ann Intern Med. 201804 03;168(7):525. doi: https://dx.doi.org/10.7326/L17-0732. 
PMID: 29610910. Exclusion reason:

Ineligible publication type

122. Nugent SM, Morasco BJ, O'Neil ME, et al. The Effects of Cannabis Among Adults With Chronic Pain and an Overview of General Harms: A Systematic Review. Ann Intern Med. 2017 Sep 05;167(5):319-31. doi: https://dx.doi.org/10.7326/M17-0155. PMID: 28806817. Exclusion reason: Systematic review used as source document

123. Nurmikko TJ, Serpell MG, Hoggart B, et al. A multi-centre, double-blind, randomized, controlled trial of oro-mucosal cannabis based medicine in the treatment of neuropathic pain characterized by allodynia. Neurology. no: PO6;64(Suppl 1):A374.

Exclusion reason: Ineligible publication type

124. Nutt DJ, Phillips LD, Barnes MP, et al. A Multicriteria Decision Analysis Comparing Pharmacotherapy for Chronic Neuropathic Pain, Including Cannabinoids and CannabisBased Medical Products. Cannabis Cannabinoid Res. 2021 Mar 17;17:17. doi: https://dx.doi.org/10.1089/can.2020.0129. PMID: 33998895. Exclusion reason: Ineligible study design

125. O'Connell M, Sandgren M, Frantzen L, et al. Medical Cannabis: Effects on Opioid and Benzodiazepine Requirements for Pain Control. Ann Pharmacother. 2019 11;53(11):1081-6. doi: https://dx.doi.org/10.1177/10600280198542 21. PMID: 31129977 . Exclusion reason: Ineligible comparator

126. Okusanya BO, Asaolu IO, Ehiri JE, et al. Medical cannabis for the reduction of opioid dosage in the treatment of non-cancer chronic pain: a systematic review. Syst Rev. 2020 Jul 28;9(1):167. doi: https://dx.doi.org/10.1186/s13643-02001425-3. PMID: 32723354. Exclusion reason: Systematic review used as source document

127. Pellesi L, Licata M, Verri P, et al. Pharmacokinetics and tolerability of oral cannabis preparations in patients with medication overuse headache $(\mathrm{MOH})-\mathrm{a}$ pilot study. Eur J Clin Pharmacol. 2018;74(11):1427-36. doi: 10.1007/s00228018-2516-3. PMID: 29980818. Exclusion reason: Ineligible study design
128. Perras C. Sativex for the management of multiple sclerosis symptoms. Issues Emerg Health Technol. 2005 Sep(72):1-4. PMID: 16317825. Exclusion reason: Ineligible publication type

129. Pichini S, Pacifici R, Busardo FP, et al. The challenge of clinical application of FM2 cannabis oil produced in Italy for the treatment of neuropathic pain. Eur Rev Med Pharmacol Sci. 2018 02;22(4):863-5. doi: https://dx.doi.org/10.26355/eurrev_201802_ 14363. PMID: 29509231. Exclusion reason: Ineligible publication type

130. Pinsger M, Schimetta W, Volc D, et al. Benefits of an add-on treatment with the synthetic cannabinomimetic nabilone on patients with chronic pain--a randomized controlled trial. Wiener klinische wochenschrift. 2006;118(11-12):327-35. PMID: 16855921. Exclusion reason: Not in English

131. Pinsger M, Schimetta W, Volc D, et al. Benefits of an add-on treatment with the synthetic cannabinomimetic nabilone on patients with chronic pain - A randomized controlled trial. Wiener Klinische Wochenschrift. 2006;118(11-12):327-35. doi: 10.1007/s00508-006-0611-4. Exclusion reason: Not in English

132. Podda G, Constantinescu CS. Nabiximols in the treatment of spasticity, pain and urinary symptoms due to multiple sclerosis. Expert Opin Biol Ther. 2012 Nov;12(11):1517-31. doi:

https://dx.doi.org/10.1517/14712598.2012.7 21765. PMID: 22954177. Exclusion

reason: Ineligible publication type

133. Portenoy RK, Ganae-Motan ED, Allende S, et al. Nabiximols for opioid-treated cancer patients with poorly-controlled chronic pain: a randomized, placebo-controlled, gradeddose trial. J Pain. 2012 May;13(5):438-49. doi:

https://dx.doi.org/10.1016/j.jpain.2012.01.00 3. PMID: 22483680. Exclusion reason: Ineligible population

134. Prevete E, Hupli A, Marrinan S, et al. Exploring the use of Kratom (Mitragyna speciosa) via the YouTube data tool: A novel netnographic analysis. Emerg Trends Drugs Addict Health. 2021 2021/01/01/;1:100007. doi: 
https://doi.org/10.1016/j.etdah.2021.100007. Exclusion reason: Background only

135. Prieto Gonzalez JM, Vila Silvan C. Safety and tolerability of nabiximols oromucosal spray: a review of real-world experience in observational studies, registries and case reports. Expert Rev. 2021doi: https://dx.doi.org/10.1080/14737175.2021.1 904896. PMID: 33749480. Exclusion reason: Systematic review used as source document

136. Prieto Gonzalez JM, Vila Silvan C. Safety and tolerability of nabiximols oromucosal spray: a review of more than 15 years' accumulated evidence from clinical trials. Expert Rev. 2021 Jun 07;07:07. doi: https://dx.doi.org/10.1080/14737175.2021.1 935879. PMID: 34092180. Exclusion reason: Systematic review used as source document

137. Rabgay K, Waranuch N, Chaiyakunapruk N, et al. The effects of cannabis, cannabinoids, and their administration routes on pain control efficacy and safety: A systematic review and network meta-analysis. J Am Pharm Assoc (2003). 2020 Jan Feb;60(1):225-34.e6. doi: https://dx.doi.org/10.1016/j.japh.2019.07.01 5. PMID: 31495691. Exclusion reason: Systematic review used as source document

138. Reisdorf S. Analgesia: Cannabis for neuropathic pain. MMW-Fortschritte der Medizin. 2020;162(7):58. doi: 10.1007/s15006-020-0397-8. Exclusion reason: Not in English

139. Richards BL, Whittle SL, Buchbinder R. Neuromodulators for pain management in rheumatoid arthritis. Cochrane Database Syst Rev. 2012 Jan 18;1:CD008921. doi: https://dx.doi.org/10.1002/14651858.CD008 921.pub2. PMID: 22258992. Exclusion reason: Ineligible publication type

140. Rogers AH, Bakhshaie J, Buckner JD, et al. Opioid and Cannabis Co-Use among Adults With Chronic Pain: Relations to Substance Misuse, Mental Health, and Pain Experience. J Addict Med. 2019 Jul/Aug;13(4):287-94. doi: https://dx.doi.org/10.1097/ADM.000000000 0000493. PMID: 30557213. Exclusion reason: Ineligible study design
141. Rouhollahi E, Macleod BA, Barr AM, et al. Cannabis extract CT-921 has a high efficacy-adverse effect profile in a neuropathic pain model. Drug Des Devel Ther. 2020;14:3351-61. doi: 10.2147/DDDT.S247584. PMID: 32884239. Exclusion reason: Ineligible population

142. Russo E. Cannabis and Cannabis based medicine extracts: Additional results. Journal of Cannabis Therapeutics. 2004;3(4):153-61. doi: 10.1300/J175v03n04_03. Exclusion reason: Ineligible study design

143. Russo M, Naro A, Leo A, et al. Evaluating Sativex R in Neuropathic Pain Management: A Clinical and Neurophysiological Assessment in Multiple Sclerosis. Pain Med. 2016 06;17(6):1145-54. doi: https://dx.doi.org/10.1093/pm/pnv080. PMID: 26764336. Exclusion reason: Ineligible population

144. S G, Hb S, K L, et al. Safety and efficacy of low-dose medical cannabis oils in multiple sclerosis. Mult Scler Relat Disord.

2020;48:102708. doi: https://dx.doi.org/10.1016/j.msard.2020.102 708. PMID: 33387864 . Exclusion reason: Ineligible outcome

145. Safakish R, Ko G, Salimpour V, et al. Medical Cannabis for the Management of Pain and Quality of Life in Chronic Pain Patients: A Prospective Observational Study. Pain Med. 2020 Jun 18;21(11):307386. doi: https://dx.doi.org/10.1093/pm/pnaa163. PMID: 32556203. Exclusion reason: Ineligible study design

146. Sagy I, Bar-Lev Schleider L, Abu-Shakra M, et al. Safety and Efficacy of Medical Cannabis in Fibromyalgia. J Clin Med. 2019 Jun 05;8(6):05. doi: https://dx.doi.org/10.3390/jcm8060807. PMID: 31195754. Exclusion reason: Ineligible comparator

147. Santos SA, Kontorinis N, Dieterich DT. Management of chronic hepatitis $\mathrm{C}$ virus in patients with HIV. Curr Treat Options Gastroenterol. 2005;8(6):433-41. PMID: 16313860. Exclusion reason: Ineligible population

148. Schenk M. Chronic neuropathic pain: Minimal side effects of therapy with 
cannabis. MMW-Fortschritte der Medizin. 2020;162(3):72. doi: 10.1007/s15006-0200171-y. Exclusion reason: Not in English

149. Schulze-Schiappacasse C, Duran J, BravoJeria R, et al. Are Cannabis, CannabisDerived Products, and Synthetic Cannabinoids a Therapeutic Tool for Rheumatoid Arthritis? A Friendly Summary of the Body of Evidence. J Clin Rheumatol. 2021doi: https://dx.doi.org/10.1097/RHU.000000000 0001745. PMID: 33859125. Exclusion reason: Background only

150. Shebaby W, Saliba J, Faour WH, et al. In vivo and in vitro anti-inflammatory activity evaluation of Lebanese Cannabis sativa L. ssp. indica (Lam.). J Ethnopharmacol. 2020:113743. doi: https://dx.doi.org/10.1016/j.jep.2020.113743 . PMID: 33359187. Exclusion reason: Ineligible study design

151. Smaga S, Gharib A. In adults with chronic low back pain, does the use of inhaled cannabis reduce overall opioid use? Evidence-Based Practice. 2017;20(1):E10E1. Exclusion reason: Ineligible publication type

152. Socias ME, Choi J, Lake S, et al. Cannabis use is associated with reduced risk of exposure to fentanyl among people on opioid agonist therapy during a communitywide overdose crisis. Drug Alcohol Depend. 2020;219:108420. doi:

https://dx.doi.org/10.1016/j.drugalcdep.2020 .108420. PMID: 33342591. Exclusion

reason: Ineligible population

153. Stockings E, Campbell G, Hall WD, et al. Cannabis and cannabinoids for the treatment of people with chronic noncancer pain conditions: a systematic review and metaanalysis of controlled and observational studies. Pain. 2018 Oct;159(10):1932-54. doi:

https://dx.doi.org/10.1097/j.pain.000000000 0001293. PMID: 29847469. Exclusion reason: Systematic review used as source document

154. Sturgeon JA, Khan J, Hah JM, et al. Clinical Profiles of Concurrent Cannabis Use in Chronic Pain: A CHOIR Study. Pain Med. 2020 Mar 31;31:31. doi: https://dx.doi.org/10.1093/pm/pnaa060.
PMID: 32232476. Exclusion reason: Ineligible population

155. Svendsen KB, Jensen TS, Bach FW. Does the cannabinoid dronabinol reduce central pain in multiple sclerosis? Randomised double blind placebo controlled crossover trial. BMJ. 2004 Jul 31;329(7460):253. PMID: 15258006. Exclusion reason: Inadequate duration

156. Swogger MT, Walsh Z. Kratom use and mental health: A systematic review. Drug Alcohol Depend. 2018 Feb 1;183:134-40. doi: 10.1016/j.drugalcdep.2017.10.012. PMID: 29248691. Exclusion reason: Systematic review used as source document

157. Sznitman SR, Vulfsons S, Meiri D, et al. Medical cannabis and cognitive performance in middle to old adults treated for chronic pain. Drug Alcohol Rev. 2020 Sep 22;22:22. doi: https://dx.doi.org/10.1111/dar.13171. PMID: 32964502. Exclusion reason: Ineligible study design

158. Takakuwa KM, Sulak D. A Survey on the Effect That Medical Cannabis Has on Prescription Opioid Medication Usage for the Treatment of Chronic Pain at Three Medical Cannabis Practice Sites. Cureus. 2020;12(12):e11848. doi: https://dx.doi.org/10.7759/cureus.11848. PMID: 33409086 . Exclusion reason: Ineligible study design

159. Terrie YC. Medical cannabis for chronic pain. U.S. Pharmacist. 2020;45(3):24-8. Exclusion reason: Ineligible publication type

160. Thomas J. Inhaled cannabis relieves neuropathic pain. Australas J Pharm. 2011;92(1091):88. Exclusion reason: Ineligible publication type

161. Thomas PA, Carter GT, Bombardier CH. A scoping review on the effect of cannabis on pain intensity in people with spinal cord injury. J Spinal Cord Med. 2021:1-12. doi: https://dx.doi.org/10.1080/10790268.2020.1 865709. PMID: 33465022. Exclusion reason: Systematic review used as source document

162. Turcotte DA, Namaka MP, Gomori AJ, et al. A randomized, double-blinded, placebocontrolled study evaluating the efficacy and safety of nabilone as an adjunctive to gabapentin in managing multiple sclerosis- 
induced neuropathic pain: an interim analysis. Pain Res Manag. 2011;15(2):99.

Exclusion reason: Ineligible publication type

163. Uberall MA. A Review of Scientific Evidence for THC:CBD Oromucosal Spray (Nabiximols) in the Management of Chronic Pain. J Pain Res. 2020;13:399-410. doi: https://dx.doi.org/10.2147/JPR.S240011. PMID: 32104061. Exclusion reason: Systematic review used as source document

164. Ueberall MA, Essner U, Mueller-Schwefe GH. Effectiveness and tolerability of THC:CBD oromucosal spray as add-on measure in patients with severe chronic pain: analysis of 12-week open-label realworld data provided by the German Pain eRegistry. J Pain Res. 2019;12:1577-604. doi: https://dx.doi.org/10.2147/JPR.S192174. PMID: 31190969. Exclusion reason: Ineligible comparator

165. Urits I, Adamian L, Fiocchi J, et al. Advances in the Understanding and Management of Chronic Pain in Multiple Sclerosis: a Comprehensive Review. Curr Pain Headache Rep. 2019 Jul 25;23(8):59. doi: https://dx.doi.org/10.1007/s11916-0190800-2. PMID: 31342191. Exclusion reason: Systematic review used as source document

166. Urits I, Charipova K, Gress K, et al. Adverse Effects of Recreational and Medical Cannabis. Psychopharmacol Bull. 2021;51(1):94-109. PMID: 33897066.

Exclusion reason: Ineligible study design

167. van Amerongen G, Kanhai K, Baakman AC, et al. Effects on Spasticity and Neuropathic Pain of an Oral Formulation of DELTA9tetrahydrocannabinol in Patients With Progressive Multiple Sclerosis. Clin Ther. 2018 09;40(9):1467-82. doi: https://dx.doi.org/10.1016/j.clinthera.2017.0 1.016. PMID: 28189366. Exclusion reason: Ineligible population

168. Vermersch P, Trojano M.

Tetrahydrocannabinol:Cannabidiol Oromucosal Spray for Multiple SclerosisRelated Resistant Spasticity in Daily Practice. Eur Neurol. 2016;76(5-6):216-26. doi: 10.1159/000449413. PMID: 27732980.

Exclusion reason: Ineligible comparator
169. Vicknasingam B, Chooi WT, Rahim AA, et al. Kratom and pain tolerance: a randomized, placebo-controlled, doubleblind study. Yale J Biol Med. 2020;93(2):229-38. PMID: 32607084. Exclusion reason: Ineligible population

170. Wade DT, Makela P, Robson P, et al. Do cannabis-based medicinal extracts have general or specific effects on symptoms in multiple sclerosis? A double-blind, randomized, placebo-controlled study on 160 patients. Mult Scler. 2004;10(4):434-41. PMID: 15327042. Exclusion reason: Ineligible population

171. Walitt B, Klose P, Fitzcharles MA, et al. Cannabinoids for fibromyalgia. Cochrane Database Syst Rev. 2016 Jul 18;7:CD011694. doi: https://dx.doi.org/10.1002/14651858.CD011 694.pub2. PMID: 27428009. Exclusion reason: Ineligible publication type

172. Wallace MS, Marcotte TD, Umlauf A, et al. Efficacy of Inhaled Cannabis on Painful Diabetic Neuropathy. J Pain. 2015 Jul;16(7):616-27. doi: https://dx.doi.org/10.1016/j.jpain.2015.03.00 8. PMID: 25843054. Exclusion reason: Inadequate duration

173. Wang T, Collet JP, Shapiro S, et al. Adverse effects of medical cannabinoids: a systematic review. CMAJ. 2008;178(13):1669-78. PMID: 18559804. Exclusion reason: Ineligible publication type

174. Ware MA, Fitzcharles MA, Joseph L, et al. The effects of nabilone on sleep in fibromyalgia: results of a randomized controlled trial. Anesth Analg. 2010 Feb 01;110(2):604-10. doi: https://dx.doi.org/10.1213/ANE.0b013e3181 c76f70. PMID: 20007734. Exclusion reason: Inadequate duration

175. Ware MA, Wang T, Shapiro S, et al. Smoked cannabis for chronic neuropathic pain: a randomized controlled trial. CMAJ. 2010 Oct 05;182(14):E694-701. doi: https://dx.doi.org/10.1503/cmaj.091414. PMID: 20805210. Exclusion reason: Inadequate duration

176. White CM. Pharmacologic and clinical assessment of kratom. Am J Health Syst Pharm. 2018 Mar 1;75(5):261-7. doi: 
10.2146/ajhp161035. PMID: 29255059.

Exclusion reason: Background only

177. White CM. Pharmacologic and clinical assessment of kratom: An update. Am J Health-Syst Pharm. 201911

13;76(23):1915-25. doi: https://dx.doi.org/10.1093/ajhp/zxz221. PMID: 31626272. Exclusion reason:

Background only

178. Williams AR, Hill KP. Care of the Patient Using Cannabis. Ann Intern Med. 2020;173(9):ITC65-ITC80. doi: https://dx.doi.org/10.7326/AITC202011030. PMID: 33137270. Exclusion reason: Ineligible publication type

179. Wilsey B, Marcotte T, Deutsch R, et al. Low-dose vaporized cannabis significantly improves neuropathic pain. J Pain. 2013 Feb;14(2):136-48. doi: https://dx.doi.org/10.1016/j.jpain.2012.10.00 9. PMID: 23237736. Exclusion reason: Inadequate duration

180. Wilsey B, Marcotte T, Tsodikov A, et al. A randomized, placebo-controlled, crossover trial of cannabis cigarettes in neuropathic pain. J Pain. 2008 Jun;9(6):506-21. doi: https://dx.doi.org/10.1016/j.jpain.2007.12.01 0. PMID: 18403272. Exclusion reason: Inadequate duration

181. Wong SSC, Chan WS, Cheung CW. Analgesic Effects of Cannabinoids for Chronic Non-cancer Pain: a Systematic Review and Meta-Analysis with MetaRegression. J Neuroimmune Pharmacol. 2020 Mar 14;14:14. doi: https://dx.doi.org/10.1007/s11481-02009905-y. PMID: 32172501. Exclusion reason: Systematic review used as source document

182. Yacyshyn Br. Safety, Pharmacokinetics, and Efficacy of Olorinab, a Peripherally Acting, Highly Selective, Full Agonist of the Cannabinoid Receptor 2, in a Phase 2a Study of Patients with Chronic Abdominal Pain Associated with Crohn's Disease. Crohns Colitis 360. 2021;3(1). Exclusion reason: Ineligible intervention

183. Yanes JA, McKinnell ZE, Reid MA, et al. Effects of cannabinoid administration for pain: A meta-analysis and meta-regression. Exp Clin Psychopharmacol. 2019 Aug;27(4):370-82. doi: https://dx.doi.org/10.1037/pha0000281. PMID: 31120281. Exclusion reason: Ineligible population

184. Yassin M, Oron A, Robinson D. Effect of adding medical cannabis to analgesic treatment in patients with low back pain related to fibromyalgia: an observational cross-over single centre study. Clin Exp Rheumatol. 2019 Jan-Feb;37 Suppl 116(1):13-20. PMID: 30418116. Exclusion reason: Ineligible study design

185. Yimam M, O'Neal A, Horm T, et al. Antinociceptive and Anti-Inflammatory Properties of Cannabidiol Alone and in Combination with Standardized Bioflavonoid Composition. J Med Food. 2021doi: https://dx.doi.org/10.1089/jmf.2020.0178. PMID: 33570460. Exclusion reason: Ineligible population

186. Yu JS, Premkumar A, Liu S, et al. Rates of self-directed perioperative cannabidiol use in patients undergoing total hip or knee arthroplasty. Pain Manag. 2021 Jun 09;09:09. doi:

https://dx.doi.org/10.2217/pmt-2021-0018. PMID: 34102871. Exclusion reason: Ineligible study design

187. Zavori L, Xantus G, Matheson C, et al. Cannabidiol in low back pain: scientific rationale for clinical trials in low back pain. Expert Rev Clin Pharmacol. 2021doi: https://dx.doi.org/10.1080/17512433.2021.1 917379. PMID: 33861675. Exclusion reason: Background only 


\section{Appendix I. Funnel Plot of High-THC Ratio Studies Included in Meta- Analysis for Pain Severity}

Figure I-1. Funnel plot of eight trials of pain severity for high-THC ratio products versus placebo

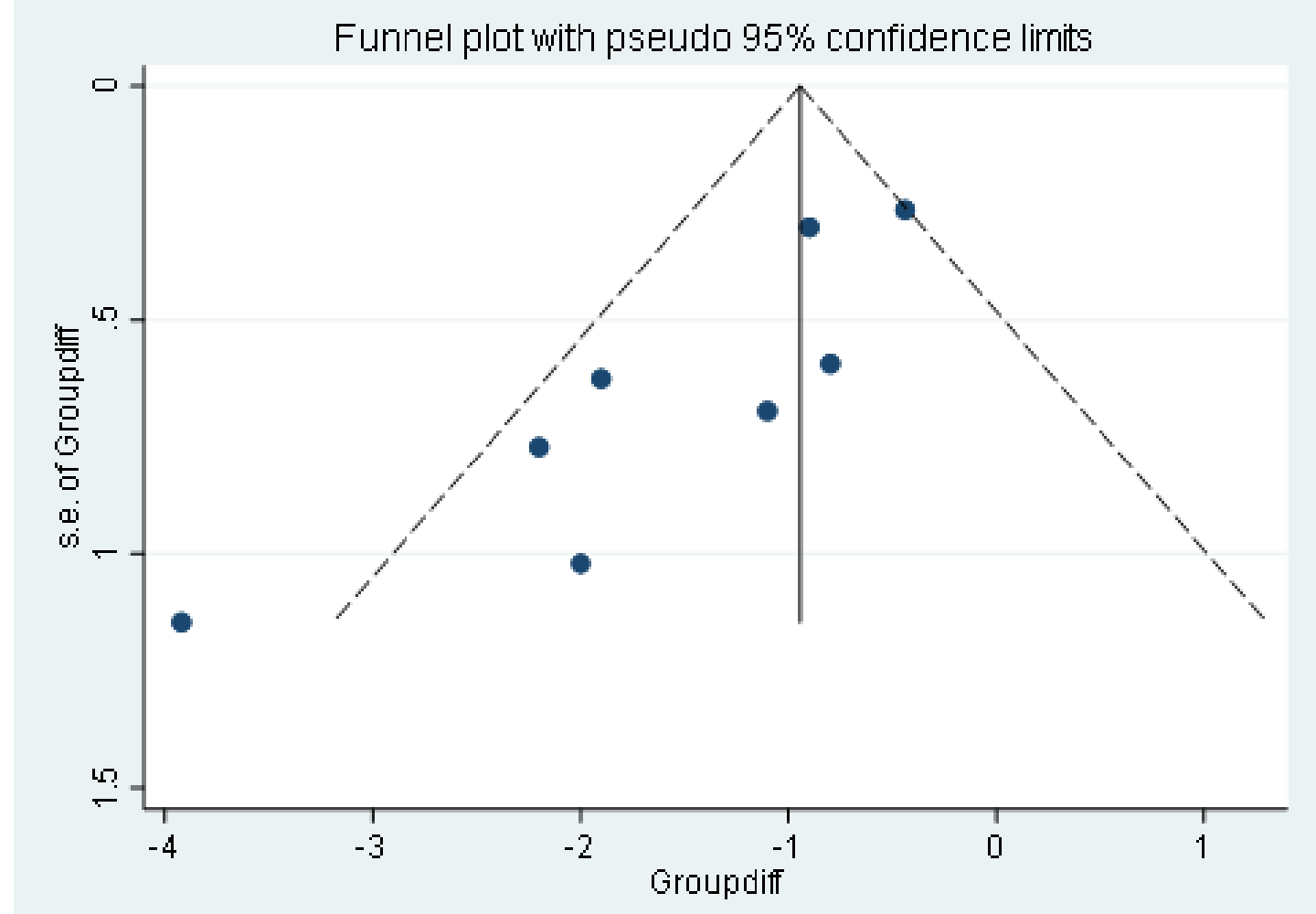

Abbreviations: Groupdiff = group difference; $\mathrm{SE}=$ standard error. 